\author{
Universidade de São Paulo \\ Faculdade de Filosofia, Letras e Ciências Humanas \\ Departamento de Ciência Política
}

\author{
Ricardo Ceneviva
}

\title{
O Nível de Governo Importa para a Qualidade da Política Pública? O Caso da Educação Fundamental no Brasil
}

São Paulo

2011 


\section{Ricardo Ceneviva}

\section{O Nível de Governo Importa para a Qualidade da Política Pública? O Caso da Educação Fundamental no Brasil}

Tese apresentada ao programa de pós-graduação do Departamento de Ciência Política da Universidade de São Paulo, como requisito para a obtenção do título de Doutor em Ciência Política

Orientadora: Profa Dra. Marta Teresa da Silva Arretche

\section{São Paulo}

2011 


\section{Folha de Aprovação}

Ricardo Ceneviva

O Nível de Governo Importa?

Tese apresentada ao programa de pós-graduação do Departamento de Ciência Política da Universidade de São Paulo, como requisito para a obtenção do título de Doutor em Ciência Política

Aprovado em:

Banca Examinadora:

Prof. Dr. Instituição:

Assinatura:

Prof. Dr.

Instituição:

Assinatura:

Prof. Dr.

Instituição:

Assinatura:

Prof. Dr.

Instituição:

Assinatura:

Prof. Dr.

Instituição:

Assinatura: 
À Milena e ao Thomaz,

por ontem, quando estávamos a parte

por hoje, quando estamos reunidos

para sempre, por seu amor 


\section{Agradecimentos}

Esta tese beneficiou-se da colaboração, das sugestões e das críticas de muitas pessoas. Sob o risco de cometer desatenções imperdoáveis, deixando de fora algumas dessas pessoas, agradeço de forma especial aos professores Eduardo Marques e Matthew Taylor, do Departamento de Ciência Política da USP, presentes à banca de qualificação do projeto de pesquisa, pelos comentários e críticas que me permitiram corrigir aspectos importantes do desenho de pesquisa. Agradeço de forma especial, à orientação e a critica amiga e contundente da professora Marta Arretche, sem cuja ajuda esta tese não teria sido possível. Sua leitura, sempre cuidadosa e aguda; seus comentários; críticas e sugestões, sempre construtivos e valiosos, muito contribuiram para a consecução desta tese. Mas, principalmente, pela paciência e pelo bom humor, com que suportou meus atrasos, dúvidas e procrastinação.

Agradeço também a todo corpo docente do Departamento de Ciência Política da USP, onde tive o prazer de compartilhar da companhia intelectualmente estimulante de seus professores e, mais importante, onde me senti acolhido num ambiente guiado pelos valores da meritocracia e da pluralidade. Em especial gostaria de agradecer ao professor Fernando Limongi, sempre disposto a esclarecer minhas dúvidas acerca de assuntos acadêmicos e, ainda, que me permitiu que apresentasse o projeto de pesquisa e o comentou nos seminários de acompanhamento de tese, do qual era coordenador.

Aos professores Elizabeth Balbachevsky, Wagner Pralon Mancuso, Leandro Piquet Carneiro, Adrian Gurza Lavalle, João Paulo Candia Veiga e Amâncio Jorge Silva Nunes de Oliveira que, em momentos diversos, me permitiram a troca franca de idéias, que leram ou comentaram versões anteriores desse trabalho e, principalmente, pela con- 
vivência intelectualmente estimulante que me permitiu apreender bastante. A todo corpo discente do Programa de Pós-graduação do Departamento de Ciência Política, em especial, a Rodolpho Talaisys Bernabel, Umberto Guarnier Mignozzetti, Manoel Galdino, Sandra Gomes, Murilo Junqueira, Daniel Vasquez e a todo grupo de estudos dos orientandos da professora Marta Arretche pelas reflexões sobre textos de interesse comum onde aprendi sempre.

À equipe da secretaria do Departamento de Ciência Política: Rai, Marcia, Ana Maria, Leo, Vasne e Vivian, sem os quais, seria impossível cumprir os prazos e enfrentar os procedimentos ultra burocráticos da Universidade de São Paulo.

Ao professor Jonathan Rodden, da Universidade de Stanford, pela oportunidade que me concedeu, tornando possível minha estada no Departamento de Ciência Política de Stanford como visiting researcher no período entre 2009 e 2010. Mas, principalmente, pelas conversas sempre estimulantes, pela orientação e pelos comentários a versões preliminares dessa tese. Aos professores David Laitin, Simom jackmam, Jonathan Wand, Stephen Haber, Barry Weingast e James Fearon que me acolheram em seus cursos e seminários em Stanford, nos quais muito aprendi. Mas, principalmente, pela receptividade com que receberam minhas questões e dúvidas fora de sala de aula, mostrando-se sempre abertos ao debate de idéias.

A Thomas Brambor, amigo e parceiro, pelos comentários, pela ajuda e pela convivência agradável e intelectualmente estimulante, além do bom humor, sempre! Aos alunos do programa de doutorado do Departamento de Ciência Política da Universidade de Stanford, Ken Opalo, Mike Albertus, Oliver Kaplan, Melina Raquel Platas, Tomer Pery, Melissa Lee, Ariel Mendez, Jennifer Haskell, Kara Downey, Lauren Pratner e 
Mackkenzie Israel-Trummel, pela amizade, pelas conversas, nas quais sempre aprendi e, principalmente, pelo acolhimento fraterno e caloroso.

À professora Elaine Pazzelo, da FEARP, pela ajuda com a obtenção dos dados e pelos comentários valiosos com sua manipulação. Ao professor e amigo, Rodrigo Moita, do Insper, pelos comentários e ajuda com a análise e tratamento dos dados.

Ao professor Reginaldo Ceneviva, meu pai, pelo apoio incondicional, pelo amor e pelo exemplo de uma vida dedicada à ciência, ao ensino e, sobretudo, à assistência de todos aqueles que the estenderam a mão em busca de apoio. A meus irmãos, Rogerio e Renata, pela amizade, pelo companheirismo e pelo apoio, sempre.

À Milena e ao Thomaz pelo amor, pela amizade e, simplesmente, por existirem na minha vida. A Dora e ao Tiburcio pelo amor canino com que tem me suportado e reconfortado.

Finalmente, cabe acrescentar, um tanto obviamente, que os equívocos e imprecisões desta tese são de responsabilidade exclusiva do autor.

P.S. Esta tese beneficiou-se do apoio financeiro do CNPq e da Comissão Fulbright, sem os quais não teria sido possível. 


\section{Resumo}

O objetivo do presente trabalho é investigar se o nível de governo responsável pela prestação da política pública importa para a qualidade dos serviços públicos oferecidos à população. Para tanto, é examinado o caso da municipalização da educação fundamental no Brasil. Secundariamente, tenciona-se também estimar o efeito da municipalização das matrículas e dos gastos em educação no desempenho acadêmico dos alunos, das escolas municipalizadas e das redes escolares. São conduzidas três análises empíricas distintas de estimação do efeito da municipalização nos resultados educacionais. Primeiro, procura-se identificar e mensurar a diferença de desempenho dos estudantes de escolas púbicas estaduais e escolas públicas municipais. Num segundo momento, utilizando dados do SAEB e da Prova Brasil são acompanhados (retrospectivamente) um grupo de escolas em dois pontos no tempo: antes e depois da municipalização. Ou seja, é selecionado um grupo experimental de escolas que estavam sob controle estadual e foram transferidas para o controle municipal, e dois grupos de controle de escolas que estavam sob a gestão estadual ou municipal e assim permaneceram. Dessa forma, é comparado o efeito da municipalização das escolas no desempenho dos estudantes. Alternativamente, é utilizado um painel de dados de 2837 municípios com informações do Censo Escolar entre os anos 1999 e 2005, ao qual são empregadas as usuais técnicas de Mínimos Quadrados Ordinários (MQO) e Efeitos Fixos (EF) para se estimar o efeito da municipalização das matrículas e dos gastos em educação sobre uma série de indicadores educacionais. 


\begin{abstract}
This study investigates the impact of level of government on the quality of the policy. the decentralization in the education system that has taken place in Brazil over the last 15 years. Since re-democratization, the Brazilian federal government has approved several laws that encourage municipalities to invest in primary education. The proficiency tests undertaken by MEC/INPEP (Ministry of Education Research Agency) allows for using two different identification strategies. First, I assemble a panel of municipalities using data from SAEB (a standardized proficiency test), Censo Escolar (the School Census), and expenditure on education to compare the evolution of municipalities and states school systems. Second, I compare the difference in the students performance at school level between two periods of time comparing three groups of schools: those that were already under the municipality control at the time of the SAEB exam (control group 1); those that were under the states control in the SAEB exam and remained in it by the time of Prova Brasil (control group 2) and; those that migrated from the state to the municipality control between the two periods exams (treatment group).
\end{abstract}




\section{Sumário}

1 Introdução 15

1.1 Revisão da Literatura . . . . . . . . . . . . . . . . . . . . . . . . . . 21

2 Definindo e Medindo Resultados Educacionais 39

2.1 Mensuração . . . . . . . . . . . . . . . . . . . . . . . . . . 40

2.1 .1 Mensuração no SAEB . . . . . . . . . . . . . . . . . . . 42

2.2 Avaliação . . . . . . . . . . . . . . . . . . . . . . . . . 44

2.3 Resultados Educacionais . . . . . . . . . . . . . . . . . . . . . 46

3 Definindo e Medindo Descentralização 53

3.0 .1 Os estudos no Brasil . . . . . . . . . . . . . . . . . . . . . . . 58

4 A Descentralização da educação no Brasil 63

4.0 .2 As matrículas . . . . . . . . . . . . . . . . . . . . 63

4.0 .3 As escolas . . . . . . . . . . . . . . . . . . . . . 67

4.0 .4 As turmas . . . . . . . . . . . . . . . . . . . . . . . 68

5 Dados e Métodos $\quad 71$

5.1 O SAEB . . . . . . . . . . . . . . . . . . . . . 71

5.2 O Censo Escolar . . . . . . . . . . . . . . . . . . . . . . . 76

5.3 Variáveis e estatísticas descritivas . . . . . . . . . . . . . . . . 78

5.4 Metodologia . . . . . . . . . . . . . . . . . . . . . . 84

5.4.1 O desempenho escolar dos alunos: o nível de governo importa? 87

5.4 .2 O efeito da municipalização nas escolas . . . . . . . . . . . . . . 91

5.4.3 O efeito da municipalização sobre as redes escolares nos municípios . . . . . . . . . . . . . . . . . . . . . . . . . . . 97

6 Resultados 106

6.1 O Efeito da rede escolar sobre a proficiência dos alunos: o nível de governo importa? . . . . . . . . . . . . . . . . . . . . . 106

6.2 O Efeito da municipalização nas escolas . . . . . . . . . . . . . . . . . 129

6.3 O Efeito da municipalização sobre as redes escolares . . . . . . . . . . . 147

$\begin{array}{llr}7 & \text { Conclusão } & 163\end{array}$ 


\section{Lista de Figuras}

1 Evolução das matrículas em escolas privadas e públicas estaduais e municipais do ensino fundamental (1991-2010) . . . . . . . . . . . . 22

2 Evolução das matrículas em escolas privadas e públicas estaduais e municipais em relação ao total de matrículas do ensino fundamental no Brasil (1991-2010) . . . . . . . . . . . . . . . . . . 65

3 Divisão das matrículas do ensino fundamental em escolas privadas e públicas estaduais e municipais no Brasil (1991-2010) . . . . . . . . . 66

$4 \quad$ Número de estabelecimentos públicos de ensino fundamental segundo a dependência administrativa (1991-2010) . . . . . . . . . . . 67

5 Número de turmas do ensino fundamental público segundo a dependência administrativa (1991-2010) . . . . . . . . . . . 69

6 Proficiências médias em Língua Portuguesa nos exames do SAEB (1995-2005) . . . . . . . . . . . . . . . . . . . . . . 73

7 Proficiências médias em Matemática nos exames do SAEB (1995-2005) . . . . . . . . . . . . . . . . . . . . . 74

8 Proficiências médias em língua portuguesa por grupo de escolas: SAEB (1997-2005) e Prova Brasil (2007) . . . . . . . . . . 130

9 Proficiências médias em matemática por grupo de escolas: SAEB (1997-2005) e Prova Brasil (2007) . . . . . . . . . . 131

10 Distribuição da variância das proficiências médias condicionais em matemática por grupo de escolas : EM x MM . . . . . . . . . . . . . . . 144

11 Distribuição da variância das proficiências médias condicionais em matemática por grupo de escolas: EM x EE . . . . . . . . . . . . . . . 145 


\section{Lista de Tabelas}

1 Níveis de Desempenho em Língua Portuguesa: escala única SAEB . . . 43

2 Tipos de decisão em educação que podem ser alocadas em diferentes esferas ou orgãos de governo . . . . . . . . . . . . . . 57

3 Proficiência SAEB, 4a. série do ensino fundamental Língua Portuguesa . . . . . . . . . . . . . . . . . . . . . . . . . . . . 79

4 Proficiência SAEB, 4a. série do ensino fundamental Matemática . . . . . . . . . . . . . . . . . . . . . . . . . . . . . . . 79

$5 \quad$ Número de alunos e de escolas por ano e por frequência em que aparecem nas avaliações do SAEB (1997-2005) . . . . . . . . . . . . . 80

6 Variáveis dos alunos da 4a. série do ensino fundamental Língua Portuguesa . . . . . . . . . . . . . . . . . . . . . . . . . . . 81

7 Variáveis dos Professores da 4a. série do ensino fundamental . . . . . 82

8 Variáveis dos Diretores . . . . . . . . . . . . . . . . . . . . . 82

9 Variáveis das Turmas . . . . . . . . . . . . . . . . . . . 83

10 Variáveis das Escolas . . . . . . . . . . . . . . . . . . . . . . . . 83

11 Número de escolas por ano no painel (1997-2007) . . . . . . . . . . . 93

12 Base de dados dos municípios: as variáveis e suas fontes . . . . . . . . . 101

13 Insumos escolares segundo a rede escolar . . . . . . . . . . . . . . . . . . . . 102

14 Rendimento do fluxo escolar segundo a rede . . . . . . . . . . . . . 103

15 Características populacionais e socioeconômicas do municípios . . . . 103

16 Resultados da estimação por MQA usando dados de alunos, painel de escolas (1997-2005), Português 4a. série . . . . . . . . . . . . . . 107

17 Resultados da estimação por MQA usando dados de alunos, painel de escolas (1997-2005), Português 4a. série, Continuação da página anterior . . . . . . . . . . . . . . . . . . . . 108

18 Resultados da estimação por EF, painel de escolas (1997-2005) Português, 4a. série . . . . . . . . . . . . . . . . . . . . 113

19 Correlação condicional entre os atributos e a probabilidade de estar matriculado na rede municipal . . . . . . . . . . . . . . 116

20 Correlação condicional entre os atributos e a probabilidade de estar matriculado na rede municipal (continuação da tabela 13, características da escola) . . . . . . . . . . . . . . . . . . . . . . . . . 117 
21 Correlação condicional entre os atributos e a probabilidade de estar matriculado na rede municipal, (contuniação da tabela 13, características do professor) . . . . . . . . . . . . . . . . . . . . . 118

22 Perfil médio dos alunos por grupo de escolas, (1997-2001) . . . . . 132

23 Perfil médio dos alunos por grupo de escolas, (2003-2007) . . . . . 132

24 Distribuição dos grupos tratamento e controle segundo as regiões do Brasil . . . . . . . . . . . . . . . . . . . . 135

25 Resultados do estimador de diferença-em-diferenças com efeito fixo da escola para português, 4a. série . . . . . . . . . . . 138

26 Resultados do estimador de diferença-em-diferenças com efeito fixo da escola para português, 4a. série . . . . . . . . . . . 139

27 Resultados do estimador de diferença-em-diferenças com efeito fixo da escola para matemática, 4a. série . . . . . . . . . . . 141

28 Resultados do estimador de diferença-em-diferenças com efeito fixo da escola para matemática, 4a. série . . . . . . . . . . 143

29 Efeito da taxa de municipalização sobre os insumos escolares . . . . . . 149

30 Efeito da taxa de municipalização sobre a taxa de reprovação . . . . . 154

31 Efeito da taxa de municipalização sobre a taxa de abandono . . . . . . 156

32 Efeito da taxa de municipalização sobre a distorção idade-série . . . . . . 158 
Em primeiro lugar, a administração torna-se mais penosa nas grandes distâncias, assim como um peso se torna mais pesado na ponta de uma alavanca maior. Torna-se também mais onerosa à medida que os escalões se multiplicam; pois cada cidade tem, a princípio, a sua administração, que o povo paga; cada distrito tem a sua, paga ainda pelo povo; em seguida cada província, depois os grandes governos, as satrapias, os vice reinos, que se deve pagar cada vez mais caro, à medida que se sobe, e sempre à custa do desditoso povo; vem, por fim, a administração suprema, que tudo esmaga. Tantas sobrecargas exaurem continuamente os súditos que, longe de serem mais bem governados por essas diferentes ordens, o são menos do que se houvesse apenas uma acima deles. Entretanto, mal restam recursos para os casos extraordinários; e, quando é preciso recorrer a eles, o Estado sempre se encontra à beira da ruína.

Jean-Jaques Rousseau, O Contrato Social.

O que mais admiro na América não são os efeitos administrativos da descentralização, mas os efeitos políticos. Nos Estados Unidos, a pátria está em toda a parte. É um objeto de solicitude desde a cidadezinha até a União inteira. O habitante se apega a cada um dos interesses de seu país como se fossem os seus. (...) Como a autoridade administrativa está situada ao lado dos administrados e, de certa forma, os representa, não suscita nem inveja nem ódio. Como seus meios de ação são limitados, cada qual sente que não pode se apoiar unicamente nela.

Alexis de Tocqueville, A Democracia na America. 


\section{Introdução}

Níveis de governo importam para a efetividade das políticas públicas? A ciência política tem longa tradição de debates e controvérsias a respeito do nível ótimo de governo que deve ser responsável pelas decisões e pela prestação da política pública aos cidadãos. Neste debate, "quem" faz é tão importante quanto "o que" deve ser feito pelo Estado.

Se Tocqueville voltasse ao mundo hoje, provavelmente, se espantaria com a quantidade de nações nas quais o processo de descentralização avançou não apenas sobre o aparato administrativo, mas também fiscal e político. Na América Latina, particularmente, após décadas marcadas pela centralização, assistiu-se nos últimos 20 anos a um acelerado processo de transferência de atribuições, recursos fiscais e autonomia política aos governos subnacionais. Como atestam Willis, Garman e Haggard, um dos mais significativos desenvolvimentos políticos e econômicos da América Latina nas últimas duas décadas foi a crescente descentralização dos governos (Willis, Garman e Haggard, 1999: 7).

Esse movimento, contudo, não se verifica apenas na América Latina. Ao contrário, nos últimos 30 anos a descentralização administrativa e fiscal consolidou-se como uma das mais fortes tendências governamentais. Nas palavras de James Manor "quase todos os países do mundo vêm experimentando algum tipo de descentralização... vista como uma solução para os mais variados problemas". (1999, vii). Dados fiscais compilados pelo Banco Mundial ratificam essa afirmação: em 1980, os governos subnacionais eram responsáveis, em média, por 15 por cento das receitas e 20 por cento dos gastos 
governamentais totais. Em finais dos anos 1990 esses números eram 19 por cento e 25 por cento, respectivamente. No caso dos países latino-americanos, essas cifras quase dobraram no período. A fração média de receitas coletadas pelos governos subnacionais subiu de 14,2 por cento no ano de 1980, para aproximadamente 16 cento em 1990 e 23 cento no ano 2000. Para os gastos subnacionais também se constata um acentuado aumento: o valor médio que era de 15,7 por cento em 1980 , saltou para 19,4 cento em 1990 e para 29 por cento no ano $2000^{1}$

É importante salientar, todavia, que essa descentralização fiscal nem sempre corresponde a um aumento da autonomia para tomar decisões sobre as políticas, ou mesmo a maior autonomia de gastos por parte dos governos subnacionais, não obstante tais conceitos serem frequentemente tratados como equivalentes por parte da literatura (Arretche, 2006; Falleti, 2005).

Para além da esfera fiscal, esse processo de descentralização também se fez sentir nas atribuições dos governos subnacionais, sobretudo no campo social, e na arena política de muitas nações na América Latina. Governos subnacionais desempenham atualmente um papel relevante - quando não são inteiramente responsáveis - na prestação de serviços públicos fundamentais, tais como saúde e educação. Reformas políticas e eleitorais em muitos países da região atribuíram maior autonomia e destaque políticos aos governos e atores subnacionais.

No campo das políticas públicas, a educação foi seguramente um dos setores mais fortemente impactados pelo processo de descentralização na América Latina. Um

\footnotetext{
${ }^{1}$ Dados disponíveis apenas para Argentina, Bolívia, Brasil, Chile, Colômbia, México, Paraguai e Peru; fonte: http://www1.worldbank.org/publicsector/decentralization/ fiscalindicators.htm.
} 
estudo recente, organizado por Robert Kaufman e Joan Nelson (?), demonstra que a descentralização dos sistemas públicos de educação - ou de parte de seus componentes - foi o principal item na agenda de reforma das mais expressivas economias latinoamericanas: Argentina, Colômbia, México e Venezuela.

No Brasil, os governos subnacionais já eram responsáveis por parcela substancial do financiamento e da gestão do sistema de educação básica. Além disto, nos anos 1990, foi aprovada uma série de medidas legais que incentivaram um significativo aumento dos gastos e das responsabilidades dos municípios na prestação dos serviços públicos de educação fundamental.

Assim, a descentralização dos sistemas educacionais pode ser apontada como uma das principais medidas governamentais recentemente implementadas no Brasil. Esta é vista como uma possível solução para tornar o sistema educacional mais responsivo às demandas da sociedade, melhorar a gestão escolar e, principalmente, como um mecanismo capaz de promover a participação de familiares e da comunidade no ensino público. Seu objetivo é não apenas aumentar o numero de vagas disponíveis, mas, sobretudo melhorar a baixa qualidade do sistema educacional público no pais (Souza, 1999).

A descentralização da educação pode variar desde a simples desconcentração física da rede escola, passando pela descentralização da execução dos gastos para os governos subnacionais, que podem ser mais ou menos regulamentados pelo governo central, até a transferência completa para as esferas subnacionais de governo da autoridade política e administrativa sobre os vários componentes das políticas educacionais.

No Brasil, a descentralização da educação está associada à transferência de controle do 
ensino fundamental (1a. a 8a. séries) dos estados para os municípios (de Araújo 2005). No âmbito do presente trabalho, portanto, descentralização refere-se especificamente ao processo de transferência de autoridade e de atribuições das esferas estaduais para as municipais de governo na área de educação fundamental. Os termos municipalização e descentralização são, nesse sentido, usados indistintamente para se referir ao processo de expansão das matrículas nas redes públicas municipais de ensino fundamental vis-avis a redução das matrículas nas redes públicas estaduais no ensino fundamental.

Assim, esta tese pretende explorar este tema tão antigo para a ciência política - qual seja, o da relevância do nível de governo para a qualidade das politicas publicas tomando como objeto empírico de análise os efeitos da descentralizaçao da educação fundamental no Brasil dos últimos 20 anos. A tese Investiga se o nível de governo responsável pela prestação da política pública importa para a qualidade dos serviços públicos oferecidos à população. Nesse sentido, a antiga pergunta - níveis de governo importam? - é aplicada ao contexto contemporâneo. Dadas as características da descentralização no Brasil, a tese examina o efeito da expansão das matrículas e dos gastos municipais em educação na qualidade e na equidade dos serviços de educação oferecidos à população. Para tal, investiga o efeito da municipalização do ensino fundamental no desempenho dos estudantes, das escolas e das redes escolares.

Tais efeitos podem ocorrer em diferentes dimensões: nos insumos escolares bem como nos resultados educacionais. Para examinar estes efeitos, são realizados três exercícios de estimação do efeito da descentralização sobre a educação. Primeiro, é identificada a diferença (e sua magnitude) de desempenho dos estudantes das escolas púbicas estaduais e municipais. Em segundo lugar, é identificado o efeito da municipalização 
sobre as escolas que foram transferidas dos estados para os municípios. E, finalmente, é identificado o efeito da municipalização das matrículas e dos gastos em educação sobre os insumos educacionais e as taxas de rendimento do fluxo escolar nas redes municipais.

Diferentes indicadores de insumos e rendimento dos sistemas de educação foram considerados inicialmente. Optou-se por aqueles mais comumente utilizados pela literatura especializada. Os insumos escolares são auferidos por meio de características observáveis das escolas e de seus professores que podem contribuir para o aprendizado dos alunos. O rendimento das redes escolares foi auferido por meio do fluxo de estudantes; isto é, por meio das taxas de evasão, repetição, e da taxa de defasagem idade-série. O desempenho dos estudantes é auferido por meio dos testes de proficiência em língua portuguesa e matemática conduzidos pelo INEP desde 1990, em particularmente pelo SAEB, mas também pela Prova Brasil. A mensuração da descentralização da educação é feita tanto por meio da proporção de matrículas em escolas municipais no total de matrículas em escolas públicas em cada um dos municípios brasileiros, denominada aqui de taxa de municipalização das matriculas.

O trabalho conclui que: (1) há, de fato, uma diferença significativa de desempenho, tanto em português como em matemática, entre estudantes de escolas públicas municipais e estaduais. Os estudantes da 4a. série do ensino fundamental das escolas estaduais têm aproximadamente um rendimento médio 3 pontos percentuais acima do que seu pares de escolas públicas municipais. (2) Essa diferença torna-se estatisticamente negligenciável quando os resultados das estimações são controlados por meio das variáveis observadas dos alunos (tais como, educação dos pais, idade, cor e 
gênero), e das escolas (como, por exemplo, infraestrutura física da escola, formação e experiência do corpo docente e diretivo). Esse resultado, por sua vez, sugere que possivelmente existe um problema de "efeito composição" entre as redes de ensino publico estaduais ou municipais. (3) O efeio da municipalização sobre as escolas que foram transferidas do estado para os municípios, quando comparadas as escolas que permaneceram sobre o controle dos estados e municípios, tanto em português como em matemática é praticamente nulo. (4) Finalmente, a taxa de municipalização de matrículas do ensino fundamental nos municípios tem um efeito global muito tênue sobre os insumos escolares das redes públicas de ensino. (5) O efeito da taxa de municipalização das matrículas sobre os indicadores de rendimento do fluxo escolar são nulos, para a taxa de reprovação e abandono, ou negativos, para a taxa de defasagem idade-série.

Os capítulos remanescentes desta tese estão organizados da seguinte maneira: O capitulo I traz uma resenha dos trabalhos produzidos nos últimos anos que abordam a relação entre descentralização e educação. O capítulo II procura discutir mais detaIhadamente a conceituação e a mensuração dos resultados dos sistemas educacionais. O capítulo III faz o mesmo para a variável independente, a descentralização da educação. O capítulo IV apresenta do dados utilizados no trabalho, discute a metodologia empregada na análise empírica. O capítulo $\mathrm{V}$ traz os principais resultados da análise empírica da tese. Finalmente, o capítulo VI traz à guisa de conclusão um breve exame dos resultados empíricos à luz dos objetivos expostos acima. 


\subsection{Revisão da Literatura}

Durante os anos 1990, foi aprovada uma série de medidas legais que incentivaram um significativo aumento nos gastos municipais em educação ${ }^{2}$ (Gomes 2008). De fato, a implementação nacional do FUNDEF, em 1998, coincide com um rápido crescimento da municipalização do ensino fundamental no Brasil. Em 1996, apenas 37 por cento dos alunos matriculados no ensino fundamental público no país freqüentavam escolas municipais. O restante, 63 por cento, freqüentava escolas das redes estaduais de ensino. Dez anos depois, em 2006, tal cenário havia se invertido totalmente. Os municípios passaram a atender aproximadamente 60 por cento dos alunos do país. A figura 1 ilustra a evolução da participação de matrículas no ensino fundamental entre escolas privadas, públicas estaduais e públicas municipais no Brasil nos últimos 20 anos.

Apesar desse aumento considerável das responsabilidades e dos investimentos municipais na provisão pública de educação no Brasil, ainda são relativamente escassos os estudos empíricos que procuram examinar em detalhe o impacto da municipalização da educação no desempenho dos estudantes, das escolas e das redes públicas municipais de ensino.

Podem-se identificar três grupos de trabalhos e pesquisas acerca da descentralização na produção recente em ciência política e disciplinas afins: (a) uma vasta quantidade de trabalhos teóricos e estudos de caso voltados para a compreensão de seus efeitos e, portanto, posicionando-se contra ou a favor da descentralização; (b) um número

\footnotetext{
${ }^{2}$ Dentre as iniciativas governamentais que visavam impulsionar os investimentos municipais em educação fundamental, pode-se citar: a Lei de Diretrizes e Bases da Educação Nacional 9394/96; A Emenda Constitucional 14/96, que cria o FUNDEF; lei 9424/96, dispõe sobre as regras de manutenção do FUNDEF e o decreto federal 2264/97, que regulamenta o FUNDEF no âmbito federal, como as mais importantes.
} 
pouco menor de trabalhos que procuram explicar suas causas e; finalmente, (c) um terceiro grupo - ainda pouco expressivo numericamente - de análises empíricas que buscam mensurar diferentes graus, padrões e efeitos de descentralização.

Figura 1: Evolução das matrículas em escolas privadas e públicas estaduais e municipais do ensino fundamental (1991-2010)

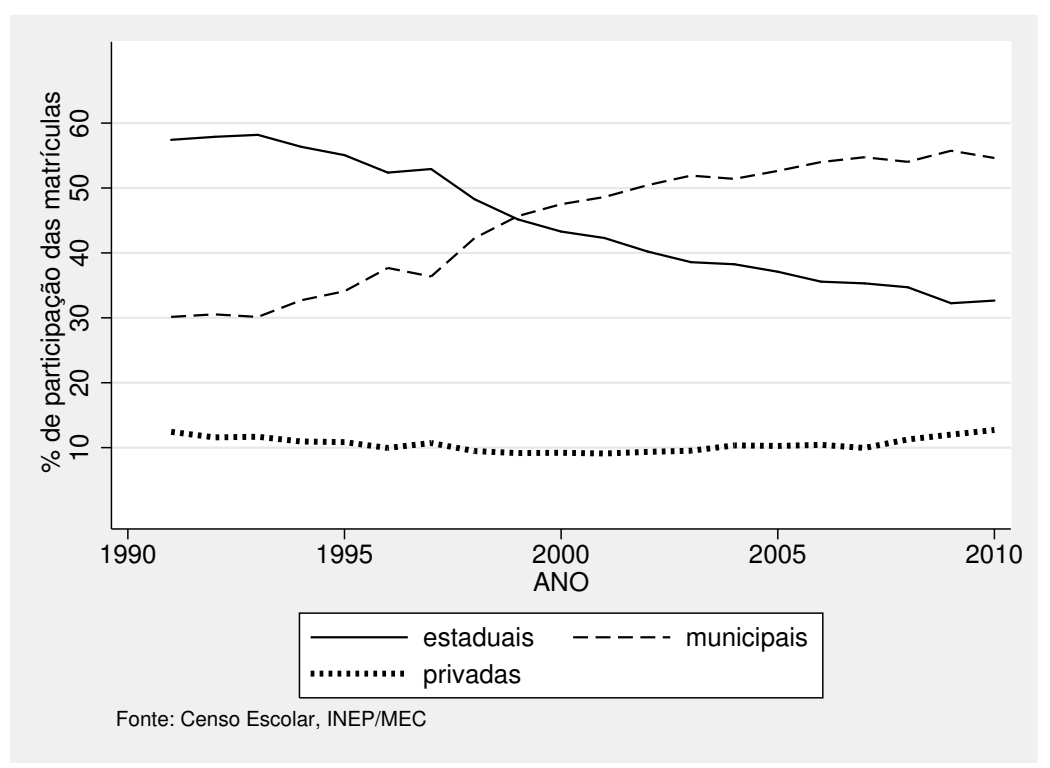

No primeiro grupo de trabalhos, há uma profusão de trabalhos teóricos e estudos de casos. $^{3}$. Essa literatura, embora muito rica em estudos específicos, é bastante limitada no exame sistemático dos efeitos da descentraliazcão. Esses estudos, em geral, posicionam-se contra ou a favor da descentralização.

Os defensores da descentralização argumentam que a transferência de gastos e de poder de decisão para as esferas subnacionais pode tornar os governos mais responsivos

\footnotetext{
${ }^{3} \mathrm{~A}$ esse respeito ver, entre outros, Gil e Arelano (2004); Araújo (2005); Oliveira (1999); Pinto (2000)
} 
às preferências dos cidadãos "adequando o provimento dos serviços públicos a grupos menores e mais homogêneos" (Wallis \& Oates 1998). Essa argumentação, que possui diferentes formulações, ${ }^{4}$ baseia-se nos trabalhos seminais de Charles Tiebout (1956) e Wallace Oates (1972) para quem a descentralização fiscal - e a conseqüente competição entre os governos locais - aparece como uma forma de mimetizar o mercado de bens privados para regular a oferta e a demanda de bens públicos ${ }^{5}$.

Para os críticos da descentralização, por outro lado, esta tende a contribuir para o fortalecimento das elites políticas locais e de suas práticas clientelísticas. Ademais, segundo a versão crítica, os governos locais carecem dos recursos financeiros, técnicos e humanos necessários para um provimento eficiente das demandas locais ${ }^{6}$. Essa crítica, quando direcionada especificamente ao caso da educação brasileira, enfatiza além dos fatores apontados acima - que a ausência de coordenação entre os sistemas educacionais de estados e municípios no Brasil teria gerado uma miríade de propostas pedagógicas e políticas educacionais, não apenas dispares entre si, mas em alguns casos, mesmo contraditórias.

O Segundo grupo de análises, que busca compreender as origens e causas da descentralização, é seguramente a maior, mais diversa e consolidada parcela da literatura em Ciência Política que trata da descentralização. Em geral, essa literatura explica a des-

\footnotetext{
${ }^{4}$ Essas formulações vão desde a "competição predatória" de Paul Peterson (1995) até o "federalismo protetor do mercado" de Bary Weingast (1995) passando pelas análises de James Buchanan (1995) dentro da tradição teórica da public choice.

${ }^{5}$ Entre os principais entusiastas da descentralização que se apóiam nos argumentos de mais eficiência e democracia nas políticas públicas ver, entre outros: Borja (1987), Borja et al (1989), Bennet (1990), Olowu at al. (2004), Putnam (1994), UNDP (1993.) , World Bank (1994). Para uma crítica dessa linha argumentativa ver Arretche (1996).

${ }^{6}$ Para trabalhos com um enfoque mais crítico aos efeitos da descentralização ver: Murillo (1999), Kraemer (1997), Crook e Sverrisson (1999), Prud'homme (1995), Samoff (1990) e Tanzi (1996), entre outros.
} 
centralização como uma função de: (i) incentivos eleitorais ou, (ii) de características do sistema partidário. Riker (1964), por exemplo, argumenta que o grau de descentralização das federações depende, fundamentalmente, da estrutura de seus partidos políticos. Ou seja, segundo Riker, a descentralização dos sistemas federativos está diretamente relacionada ao grau de descentralização do sistema partidário. Assim, se a descentralização dos Estados federativos está associada à estrutura do sistema partidário, os processos de centralização e descentralização poderiam ser explicados em função das variações na estrutura dos sistemas partidários e dos partidos políticos. Mudanças nos partidos e nos sistemas partidários seriam seguidas de alterações no grau de centralização ou descentralização das federações.

Já para Kathleen O'Neill (2003), por outro lado, a gênese dos processos de descentralização está mormente relacionada ao calculo eleitoral dos partidos políticos. A descentralização afigura-se, assim para a autora, uma estratégia eleitoral de partidos que têm maiores chances de vitória em eleições subnacionais. Segundo O'Neill, a adoção de eleições diretas para governadores e prefeitos foi o principal motivo para a descentralização política na Bolívia, Equador, Peru, e Colômbia.

Merilee Grindle (2004) trata, mais especificamente, do caso da descentralização do sistemas educacionais de alguns países da America Latina. Grindle baseia sua análise no cálculo estratégico dos atores envolvidos nas políticas de reforma e descentralização; principalmente, dos partidos políticos. A autora enfatiza o papel decisivo da adoção de eleições diretas para os governos locais na Argentina, na Bolívia e na Venezuela nos processos de democratização e de descentralização política nesses três países. Grindle pergunta-se, por que políticos racionais abririam mão do poder em benefício 
de esferas subnacionais? Para concluir: a criação de novas instituições políticas, e a descentralização em particular, precisa ser entendida em uma perspectiva teórica que vá além dos ganhos imediatos dos atores. Segundo a autora, empiricamente as motivações dos partidos e das elites políticas são complexas, não se limitam a seus interesses imediatos, mas também reverberam conflitos mais persistentes de suas sociedades.

Willis, Garman e Haggard (1999) e Garman, Haggard e Willis (2001) apresentam duas análises recentes a respeito da descentralização fiscal na América Latina. Para os autores, a descentralização - e o grau em que esta ocorre - correlaciona-se ao nível de dependência e reciprocidade entre os candidatos dentro dos partidos políticos nacionais. Ou seja, "quanto maior a sensibilidade política dos governantes na esfera central aos resultados eleitorais nos níveis subnacionais, mais alta a probabilidade do sistema fiscal ser mais descentralizado" (1999: 9).

Os trabalhos de Willis, Garman e Haggard, como também a análise de Kent Eaton (2000) sobre as reformas fiscais na Argentina e nas Filipinas, chamam atenção para as relações de dependência, reciprocidade e lealdade entre o executivo nacional e os representantes locais no legislativo nacional. Os autores argumentam que a medida em que os legisladores argentinos dependem do executivo nacional para se manter no poder (devido às regras eleitorais que estabelecem um sistema de lista fechada e representação proporcional, no qual a indicação e a ordem dos candidatos dependem da burocracia partidária nacional) suas preferências sobre descentralização fiscal são frequentemente mais próximas das preferências do presidente do que das preferências dos governadores. Portanto, os legisladores são muitas vezes relutantes em descentralizar gastos e receitas 
em benefício das esferas subnacionais de governo.

Ainda dentro dessa tradição de analise das causas e origens da descentralização; porém, mais especificamente relacionado aos objetivos do presente trabalho, cabe destacar o estudo de Sandra Gomes (2008). Gomes (2008) analisa o processo recente de municipalização da educação fundamental no Brasil. A autora contesta a interpretação dominante de que as mudanças nas regras de financiamento da educação trazidas pelo FUNDEF seriam um fator suficiente para explicar a municipalização da educação fundamental no Brasil. Essa interpretação, prevalente na literatura econômica brasileira, decorre de associação automática entre a implementação do FUNDEF e um aumento significativo da municipalização do ensino fundamental no Brasil. A municipalização, segundo Gomes, só pode ser explicada por um conjunto mais amplo de fatores que incluem outras regras federais e estaduais. Tais como, a situação das contas públicas no momento da implementação do FUNDEF, o patamar inicial das matrículas, o partido político de governadores e prefeitos e outras variáveis de contexto local, como disponibilidade orçamentária e aspectos demográficos.

Em suma, a produção acadêmica na área de ciência política que procura investigar as causas, as características e os efeitos da descentralização tende a destacar o protagonismo do sistema eleitoral, dos partidos políticos e do sistema partidário, mas parecem negligenciar as conseqüências - e os resultados - da política de descentralização. E, mais importante, esses trabalhos sobre a descentralização explicam quase exclusivamente o nível de descentralização fiscal - medido como parcela dos gastos executados e receitas coletadas pelos governos subnacionais -, não há de fato muitos trabalhos devotados à análise da descentralização dos serviços públicos, tais como saúde, educa- 
ção, assistência social de uma perspectiva da ciência política ${ }^{7}$, apesar do peso dessas áreas na composição dos gastos públicos.

Finalmente, nota-se na literatura um terceiro grupo de analises, predominantemente econômicas, que buscam examinar os resultados da descentralização em termos de seus impactos para a qualidade e eficiência da provisão dos serviços públicos. Na literatura econômica há tradições específicas em diferentes áreas que abordam o problema da provisão descentralizada de serviços públicos. De tal sorte que, por exemplo, a economia da saúde, a economia da educação e a economia urbana produziram importantes trabalhos que tratam dessa questão. O presente trabalho põe em evidência apenas os estudos que examinaram a descentralização em educação.

Nesse grupo de estudos encontram-se, sobretudo, trabalhos empíricos que - por meio de técnicas econométricas - procuram avaliar o impacto de fatores variados no desempenho dos estudantes. Assim, estes estudos buscam, sistematicamente, mensurar o efeito de fatores como, por exemplo, recursos familiares, recursos escolares, custos de oportunidade da educação, e o sistema educacional ao qual a escola se vincula (particular, público estadual ou público municipal) têm sobre o desempenho dos estudantes ou das escolas.

Como já observado, se por um lado os trabalhos teóricos oferecem respostas ambíguas (e mesmo contraditórias) quanto aos efeitos da descentralização na provisão da educação pelo setor público; por outro lado, as evidências empíricas reunidas até o momento tampouco são conclusivas. Segundo uma revisão de Faguet e Sánchez (2008), de 24 artigos que apareceram na publicação "World Development" sobre descentralização,

\footnotetext{
${ }^{7}$ Além dos já mencionados trabalhos de Arretche (2000) e Falleti (2005), outras exceção digna de nota é: Ward e Rodrigues (1999).
} 
governos locais e responsabilização (i.e. accountability) desde 1997, 11 posicionaramse favoravelmente aos resultados atingidos pelos programas de descentralização e 13 reportaram resultados negativos.

O trabalho de Faguet e Sanchez é firmemente favorável aos resultados do processo de descentralização da educação na Bolívia e na Colômbia. As evidências empíricas levantadas nesse estudo parecem indicar que a descentralização alterou os padrões dos investimentos públicos nesses dois países tornando-os mais responsivos às demandas das classes populares. Recursos que antes eram majoritariamente destinados a infra-estrutura e indústria local passaram a se concentrar em áreas sociais, tais como: educação, saúde e saneamento básico.

Burki, Perry e Dillinger (1999), em sua análise da descentralização da educação para um grupo de países da América Latina, sugerem que a transferência da responsabilidade pela provisão de educação primária para os governos locais parece não ter sido suficiente para que os resultados (positivos) esperados fossem atingidos. Segundo argumentam, a transferência de autoridade e atribuições deve ser feita diretamente às unidades escolares e aos conselhos de pais e mestres para que as conseqüências positivas da descentralização surtam efeito. A simples transferência da execução dos gastos para os governos locais e regionais, como nos casos de Colômbia e México, raramente viabiliza por si só a melhoria dos resultados escolares. Em contraste, esforços para transferir à gestão do ensino diretamente aos conselhos comunitários ou às unidades escolares como se deu em alguns casos analisados pelos autores, em países tão diversos como a Nicarágua, El Salvador, e Minas Gerais no Brasil, parecem apresentar resultados mais positivos. 
O estudo de Filmer e Eskeland (2002) sobre a Argentina, onde a transferência deu-se do governo central para os governos das províncias, vale-se de um modelo econômico de função de produção para examinar o impacto de programas de autonomia escolar e de políticas de incentivo da participação de pais de alunos na gestão das escolas em testes de aprendizado dos estudantes. Sua análise utiliza dados em corte temporal (cross-section) de testes de aprendizado em matemática e espanhol e um índice de autonomia escolar e participação dos pais. A construção desse índice é feita por meio de vinte e oito variáveis que buscam mensurar o grau de autonomia escolar com base nas decisões acerca de gestão de pessoal, organização do ensino e o grau de participação dos pais de alunos nessas mesmas decisões. Seus resultados são ambíguos. Apontam que a autonomia escolar e a participação dos pais estão positivamente relacionadas com o aprendizado em matemática, porém não com espanhol. Ademais, esses resultados apresentam maior significância estatística para as escolas situadas nos bairros mais pobres e para os alunos oriundos dos segmentos menos favorecidos economicamente.

Entretanto, a maior deficiência do estudo de Filmer e Eskeland parece ser um possível viés em seus resultados devido à endogeneidade entre autonomia, participação e variáveis não observadas. Apesar da riqueza de seu banco de dados - que contém mais de vinte e quatro mil (24.000) observações para os testes de aprendizado dos estudantes de $6 a$ e 7 a séries -, a ausência de informações mais precisas sobre autonomia escolar e participação dos pais forçou os autores a valer-se de variáveis instrumentais fracas. Por exemplo, eles descartam algumas variáveis explicativas importantes de seu modelo de função de produção e as incluem como simples instrumentos (Filmer e Eskland, 2002: 20). Seus resultados, no entanto, são relevantes, pois indicam que os benefícios 
esperados da descentralização (do nível central para os governos locais ou regionais) podem ser potencializados se esta é capaz de criar incentivos à autonomia escolar e à participação dos pais de alunos na gestão das escolas.

No Brasil, há uma vasta literatura empírica ${ }^{8}$ sobre as relações existentes entre desempenho educacional de jovens e crianças e aspectos familiares como instrução dos pais e nível de renda da família; aspectos escolares como formação dos professores e infraestrutura física das escolas e aspectos comunitários como renda média da localidade ou o numero de escolas no município. Dentre os estudos empíricos, o trabalho seminal de Ricardo Paes de Barros e colaboradores (2001) é, seguramente, um dos mais importantes. Valendo-se de dados da Pesquisa Nacional por Amostra de Domicílios (PNAD) e da Pesquisa de Padrões de Vida (PPV), os autores indicam que, mesmo em se controlando por fatores como: recursos familiares, recursos escolares, custos de oportunidade da educação, e o sistema educacional ao qual a escola se vincula (particular, público estadual ou público municipal), a escolaridade do indivíduo (isto é, o número de séries completadas) é mais diretamente afetada pela escolaridade dos pais e pela renda per capita da família. Os Recursos da comunidade (mensurados por meio da escolaridade média e da renda média dos moradores da localidade) e os recursos das escolas (mensurados pelo número de escolas e pelo tempo médio do trajeto até a

\footnotetext{
${ }^{8}$ Os trabalhos empíricos em economia da educação produzidos no Brasil são, usualmente, classificados de acordo com a temática desenvolvida. De sorte que, há um primeiro grupo de estudos que trata da mobilidade social e econômica em termos educacionais (Barros e Lam, (1993); Ferreira e Veloso, (2003); Marteleto, (2004)). Uma segunda linha de pesquisa que aborda a relação de desigualdade de oportunidades e desigualdade de renda (Bourguignon et al. (2003); Menezes-Filho (2001)). Já a terceira vertente investiga a relação entre trabalho infantil, pobreza e escolaridade (Emerson e Souza (2003)(2007)(2011); Kassouf (2001); Barros et al.(1995); Fernandes e Menezes-Filho (Fernandes \& Menezes-Filho 2000)). No presente trabalho, não se faz uma resenha exaustiva dessa literatura. Ao contrário, optou-se tão-somente por destacar aqueles trabalhos (independentemente da abordagem adotada) que dialogam direta ou indiretamente com a questão da descentralização, mais especificamente, ou com a gestão escolar, mais amplamente.
} 
escola) apresentam um impacto positivo, porém estatisticamente não significante. $\mathrm{O}$ nível de instrução dos professores apresenta um resultado ambíguo. Mostra-se positivo para as escolas de ensino fundamental e negativo para as escolas de ensino médio (Barros et al., 2001).

O estudo de Albernaz, Ferreira e Franco (2002) traz algumas importantes contribuições nesse campo. Além dos fatores analisados por Barros (2001), os autores incluem, com base em informações do SAEB de 1999, outras variáveis sobre as escolas, como a qualidade da infra-estrutura física e dados sobre formação e experiência dos professores. A estimação proposta por Albernaz sugere que cerca de $80 \%$ da variância de desempenho médio entre as escolas deve-se a diferenças na composição socioeconômica de seus alunos, refletindo um importante efeito de estratificação socioeconômica das escolas. Segundo, controlado esse efeito de estratificação, o desempenho dos alunos está significativamente relacionado com diferenças na qualidade e na quantidade de insumos escolares. Ao contrário de resultados encontrados em estudos realizados em vários outros países, tanto a qualidade dos professores como a qualidade da infra-estrutura física das escolas afetam o rendimento de forma significativa ${ }^{9}$. Ademais, mesmo controlando por todos esses fatores, alunos de escolas particulares têm um desempenho médio significativamente superior a de seus pares nas escolas publicas municipais ou estaduais.

\footnotetext{
${ }^{9} \mathrm{~A}$ relevância das variáveis escolares tem sido uma característica polêmica, mas persistente, da literatura internacional sobre os fatores determinantes dos resultados educacionais. De acordo com a Tabela 3.23.1, p. 303 do Relatório Coleman (1966), menos de 2 por cento da variância total do desempenho dos alunos (brancos e negros) são atribuídos a características escolares, enquanto menos de 4 por cento são atribuídos a características dos professores. Em uma revisão mais recente dos estudos empíricos, Hanushek (1989) apresenta um resumo das estimativas dos coeficientes dos gastos escolares sobre o desempenho dos alunos em 187 trabalhos da literatura internacional, chegando à conclusão de que a única variável cuja relevância para o aprendizado dos alunos parece ser realmente robusta é a experiência do professor.
} 
Apesar do impacto muito elevado dos recursos familiares, os fatores relacionados a escola e a comunidade também apresentam um efeito não desprezível no resultado educacional do indivíduo. O estudo de Riani e Rios-Neto (2008) traz evidências empíricas eloqüentes que demonstram até que ponto os fatores do perfil escolar do município podem minimizar a importância do ambiente familiar. Os resultados do trabalho de Riani indicam que aspectos relacionados a rede escolar dos municípios, principalmente, os de qualidade dos recursos humanos (tais como, instrução e experiência dos professores) e a infra-estrutura dos serviços educacionais aumentam a probabilidade média do aluno freqüentar a escola na idade correta.

Todos esses trabalhos contribuíram para uma melhor compreensão do impacto de fatores associados aos recursos das famílias, das escolas e das comunidades nos resultados educacionais dos indivíduos no Brasil. Entretanto, as variáveis relacionadas às redes escolares ou ao nível de governo são empregadas nesses estudos tão-somente como variáveis de controle. Particularmente, as variáveis associadas à gestão dos sistemas educacionais e à governança das escolas são raramente tratadas como aspectos centrais da análise desses estudos. ${ }^{10}$ Nesse sentido, os trabalhos de D'Atri (2007), Madeira (2007), Leme e colaboradores (2009) e Orellano e colaboradores (2010) trazem contribuições relevantes ao examinar diretamente o impacto da descentralização das escolas nos resultados do ensino público no Brasil.

O estudo de D'Atri (2007) utiliza dados do Censo Escolar do MEC/INEP para avaliar

\footnotetext{
${ }^{10} \mathrm{O}$ acumulo de evidências empíricas de que as escolas estão longe de verter mais recursos em melhores resultados educacionais (e.g. Hanushek, (1995) (1994) ), levou a um interesse crescente de questões relacionadas à gestão dos sistemas de ensino e à governança das escolas. Dentro desse contexto a questão da descentralização da educação tem merecido um lugar de destaque na agenda de pesquisadores e decisores políticos.
} 
o impacto da municipalização das escolas nas taxas de matricula, taxas de abandono e na distorção idade-série dos alunos. Controlando por características das escolas e dos alunos, D'Atri compara os dados do Censo Escolar de 1998 e 2004. Seus principais resultados indicam que as escolas municipais apresentam desempenho pior do que as escolas estaduais para as variáveis acima mencionadas. Mais importante, o estudo de D'Atri aponta que os resultados inferiores da escolas municipais devem ser atribuídos mais diretamente a rápida expansão dos sistemas municipais de ensino do que a transferência de controle de escolas dos estados para os municípios.

A análise de Madeira (2007) restringe-se às escolas do estado de São Paulo, que vem conduzindo um considerável esforço de municipalização das matriculas. Madeira procura mensurar o impacto da transferência de controle do ensino fundamental sobre as taxas de matricula, taxas de abandono e distorção idade-série. Além disso, busca avaliar o impacto da municipalização sobre a de utilização de alguns insumos escolares, tais como: numero de horas em sala de aula, tamanho das turmas, e utilização de equipamentos e infra-estrutura física das escolas. Para tanto, serve-se dos dados do Censo Escolar de 1996 a 2003. Seus resultados apontam que, se por um lado, verificase um impacto positivo na utilização dos insumos escolares (horas-aula, tamanho das turmas, etc.). Por outro lado, verifica-se um impacto negativo nas taxas de matricula, taxas de abandono e distorção idade-série. Vale lambrar que, seus resultados confirmam o trabalho de D'Atri (2007).

A investigação de Orellano e colaboradores (2010) também vale-se de dados do Censo Escolar do MEC/INEP para estimar os efeitos do aumento das matrículas e dos gastos municipais em educação fundamental sobre três indicadores de rendimento do fluxo 
escolar, as taxas de aprovação, abandono escolar e a distorção idade-série. A principal contribuição desse estudo é incorporar tanto aspectos relativos à autonomia municipal de arrecadação e de gastos, quanto aqueles relacionados à gestão municipal das escolas, o que possibilita aos autores examinar o efeito independente tanto da municipalização das matrículas como da descentralização fiscal sobre os produtos educacionais dos municípios. A despeito de algumas limitações empíricas não desprezíveis, o estudo apresenta uma forte associação positiva entre descentralização fiscal e desempenho em educação, resultado este que não se repete para o nível de municipalização das matrículas. Ou seja, segundo Orellano, quando maior o nível de descentralização fiscal mais altas as taxas de matrícula e menores as taxas de abandono escolar. Porém, quando se considera o nível de municipalização das matrículas como medida de descentralização essa associação positiva desaparece.

As contribuições de D’Atri (2007), Madeira (2007) e Orellano e colaboradores (2010) são, sem dúvida, muito importantes; contudo, apresentam algumas limitações. A principal delas refere-se ao uso exclusivo de indicadores de rendimento dos sistemas de ensino, tais como taxas de matriculas, aprovação ou abandono escolar, abdicando da utilização de indicadores de desempenho dos alunos. O emprego exclusivo de variáveis como taxa de matricula, taxa de abandono ou mesmo a taxa defasagem idade-série como indicadores educacionais pode conduzir a distorções; pois, essas variáveis são afetadas por fatores que não se relacionam diretamente com a gestão da escola, com a família ou mesmo com a comunidade. Essas variáveis são, na verdade, suscetíveis a fatores exógenos (e não observáveis) tais como programas de progressão continuada (isto é, aprovação automática) ou mesmo à rápida expansão do ensino fundamental experimentada pelo Brasil ao longo dos últimos 20 anos. Outra limitação, particu- 
larmente dos estudos de D'Atri e Orellano, diz respeito ao nível de agregação. Ao servir-se tão-somente de dados para os municípios, esses estudos deixam de controlar os efeitos fixos das escolas, o que pode enviesar suas análises.

O estudo de Orellano e colaboradores (2010), em particular, parece sofrer de um problema de endogeneidade entre o indicador de descentralização fiscal proposto pelos autores e os indicadores educacionais examinados, que pode estar enviesando as estimativas. Orellano vale-se da razão entre as transferências do FUNDEF recebidas pelos municípios e os gastos totais dos municípios em educação como medida de descentralização fiscal. Contudo, essas medidas parecem ser endógenas, mesmo com o controle dos efeitos específico dos municípios usado pelos autores. É razoável supor, por exemplo, que os prefeitos elevem seus gastos em educação, afetando o comportamento da razão FUNDEF/gastos, quando confrontados com maus resultados educacionais em seus municípios. Como se assume que essa medida de descentralização fiscal é exogena aos resultados educacionais, as estimativas apresentadas pelos autores podem estar sendo enviesadas por esse problema de endogeneidade dos regressores.

Ademais, há um problema conceitual no trabalho de Orellano e colaboradores. Os autores tratam como equivalentes as transferências do FUNDEF recebidas pelos municípios e a dependência de transferências do governo central. As transferências do FUNDEF para os municípios não está vinculada a geração de receitas fiscais próprias dos municípios. Mas, depende exclusivamente do número de matrículas no ensino fundamental em escolas publicas das redes municipais. Pois, a transferencia dá-se em função de um valor fixo por aluno matriculado na rede pública. Ainda, as transferências do FUNDEF não são compostas por recursos do governo central. Mas, sim, 
por recursos dos próprios estados e municípios. Salvo, um complemento federal, caso as transferências do FUNDEF não atinjam o piso nacional de gasto por aluno. Há, portanto, no estudo de Orellano e colaboradores uma confusão entre transferências do FUNDEF e dependência do governo central.

O estudo de Leme, Paredes e Souza (2009) procura estimar o efeito da municipalização na proficiência dos alunos. Para tanto, serve-se do número de escolas que passaram da gestão estadual para a gestão municipal como medida de descentralização e das avaliações em matemática e em língua portuguesa no MEC/INEP como medida de desempenho educacional. Segundo Leme e colaboradores, a municipalização das escolas parece não ter tido nenhum efeito (positivo ou negativo) relevante no desempenho dos alunos de 4a. série do ensino fundamental. A ausência de efeito notável da municipalização no trabalho de Leme, Paredes e Souza parece decorrer tanto da amostra muito restrita com que trabalham os autores ${ }^{11}$, como também e, principalmente, pode ser que as variáveis de controle dos alunos e de suas famílias e o modelo de efeitos específicos das escolas empregados pelos autores ainda não apresentem a acuidade necessária para se captar o efeito independente da municipalização das escolas sobre a proficiência dos alunos, como, aliás, admitem os próprios autores do trabalho.

Em suma, embora a produção acadêmica esteja em franco processo de expansão e de acumulo de evidências, a revisão dos trabalhos produzidos acerca da descentralização e do provimento de serviços públicos (particularmente, da provisão pública de educação fundamental no Brasil) sugerem não apenas falta de consenso a respeito de seus efei-

\footnotetext{
${ }^{11}$ Leme, Paredes e Souza (2010) identificam apenas 122 escolas que migraram do controle estadual para o controle municipal e que aparecem pelo menos duas vezes nas avaliações do MEC/INEP entre os anos de 1999 e 2005.
} 
tos como também parece indicar que as evidências empíricas reunidas até o presente momento são inconclusivas.

O presente trabalho pretende contribuir com essa literatura investigando, inicialmente, se o nível de governo (e, consequentemente, a rede escolar) importa para o desempenho dos alunos. Em segundo lugar, a estratégia empírica proposta pela tese permiti contornar algumas das limitações apontadas nos trabalhos anteriores.

A estratégia empírica proposta consiste em combinar análises distintas de estimação dos efeitos da municipalização sobre (i) os alunos, (ii) as escolas, e (iii) os insumos e as taxas de rendimento do fluxo escolar nos municípios. Primeiro, servindo-se de um painel de escolas, com dados desagregados ao nível dos alunos, construído com base no SAEB para os anos entre 1997-2005 é estimada a diferença de desempenho dos alunos de escolas públicas municipais e escolas públicas estaduais. Essa estimação é feita com base nas usuais técnicas de Mínimos Quadrados Ordinários, Efeitos Aleatórios e Efeitos Fixos, assegurando-se que os resultados são robustos a diferentes modelos estatísticos. Segundo, utilizando-se dados do SAEB e da Prova Brasil são acompanhados (retrospectivamente) três grupos de escolas em dois pontos no tempo: antes e depois da municipalização. Ou seja, é selecionado um grupo experimental de escolas que estavam sob controle estadual e foram transferidas para o controle municipal, e dois grupos controle de escolas que estavam sob a gestão estadual ou municipal e assim permaneceram. Dessa forma, é comparado, por meio de um modelo de estimação por diferença-em-diferenças, o efeito da municipalização das escolas sobre desempenho dos estudantes. Finalmente, é utilizado um painel de dados de 2837 municípios com informações do Censo Escolar e dos municípios entre os anos 1999 e 2005 para se 
estimar o efeito da municipalização das matrículas e sobre uma série de indicadores de insumos educacionais e rendimento escolar nos municípios. 


\section{Definindo e Medindo Resultados Educacionais}

A avaliação educacional está no centro do debate sobre educação no Brasil e no exterior. Sua importância e seu impacto, seja no debate acadêmico seja nas práticas dos formuladores políticos, dificilmente passa despercebida a uma rápida folheada das gazetas diárias ou artigos dos periódicos especializados. Termos como: exames, instrumentos de avaliação, teoria da resposta ao item e outros oriundos do jargão da área parecem ter ganhado o cotidiano de professores, estudantes, suas famílias e de cidadãos informados.

A extensa produção acadêmica acerca do tema - tanto na tradição anglo-saxônica quanto, mais recentemente, na literatura de língua portuguesa - é uma constatação de sua importância. Entretanto, uma rápida revisão dos trabalhos produzidos no Brasil ou alhures revela que a definição dos conceitos ainda carece de consenso quanto a seu significado e de clara delimitação teórica. Percebe-se que a definição tende a variar acentuadamente não apenas de autor para autor, mas também conforme a tradição disciplinar na qual o trabalho se insere.

Mais especificamente, os termos da lingua inglesa: assessment, evaluation, testing $e$ measurement são muitas vezes usados como sinônimos, como termos intercambiáveis, ou mesmo definidos um tanto tautologicamente por meio de referências reciprocas, como observou com precisão John Keeves (1997). Na verdade, o que assessment, evaluation e measurement têm em comum é que todos são auferidos ou operacionalizados por meio de exames, ou testes. Isto é, assessment, evaluation e measurement são atividades que frequentemente, porém não sempre, se valem de exames ${ }^{12}$. No entanto,

\footnotetext{
${ }^{12}$ No ambito desse trabalho os termos teste e exame são utilizados como sinônimos por questões
} 
vale ressaltar, que nenhuma dessas atividades limita-se à simples aplicação de exames ou mesmo podem ser empregadas como sinônimos desse último. Principalmente, os tipos de exames empregados em cada uma dessas atividades é bastante diferente (Carol, 1988). A seguir são oferecidas breves definições dos termos bem como uma descrição dos processos que compõem cada uma dessas atividades educacionais. Numa segunda etapa, define-se operacionalmente o que se entende, no âmbito desse trabalho, por resultados educacionais. Então, é apresentado o SAEB e um brevíssimo sumário de seus principais resultados.

\subsection{Mensuração}

Segundo o dicionário Houaiss da Língua Portuguesa, a definição de mensuração é "medir, determinar as medidas de". Tal definição poderia ser empregada à grande maioria das aplicações de mensuração educacional sem prejuízos semânticos. Nesse sentido, mensuração educacional refere-se ao conjunto de processos destinados e determinar as medidas de desempenho escolar, aprendizado, avaliação de conhecimentos e avaliação de competências, etc. Entretanto, é importante observar que enquanto instrumentos como cronômetros e fita métricas podem ser utilizados para se determinar medias de velocidade e comprimento quase diretamente; a grande maioria das medidas de interesse educacional são mensuradas apenas incompleta e indiretamente. Mais precisamente, as medidas de desempenho educacional obtidas por meio de testes de avaliação são proxys de uma conjunto mais abrangente de conhecimentos e competências que não podem ser diretamente auferidos (Koretez, 2009).

meramente estilísticas 
No dia 30 de outubro de 2010 ('as vésperas das eleições gerais), o IBOPE divulgou uma pesquisa de opinião eleitoral para a presidência da Republica com os resultados de uma amostra de 3010 eleitores. As estimativas mostravam a candidata do PT, Dilma Rousseff, com $52 \%$ das intenções de voto e o candidato do PSDB, José Serra, com $40 \%$. Os resultados finais das eleições demostraram que a previsão do IBOPE estava razoavelmente correta. A diferença final foi de aproximadamente $12 \%$. A mensuração educacional é em muitos sentidos semelhante às pesquisas eleitorais.

O conjunto mais abrangente de habilidades e conhecimentos a respeito do qual os exames fornecem uma estimativa é usualmente denominado domínio. O domínio seria o equivalente à votação de toda a população de eleitores na pesquisa do IBOPE. Assim como não seria razoável (ou mesmo exequível) que os pesquisadores do IBOPE entrevistassem todo o eleitorado, tampouco seria razoável que um teste de desempenho escolar fosse capaz mensurar exaustivamente o domínio de um aluno ou conjunto de alunos. Simplesmente, porque domínios são, em geral, muito vastos e abrangentes para serem cobertos por um exame. Analogamente, assim como é possível se estimar a intenção de voto do eleitorado de aproximadamente 130 milhões de brasileiros a partir de uma amostra de pouco mais de 3000 possíveis eleitores, é aplicado um teste de desempenho escolar que cobre tão-somente uma pequena amostra do domínio do aluno para se obter uma estimativa de sua compreensão sobre determinado assunto, disciplina acadêmica ou competência cognitiva.

De tal sorte que, tipicamente, exames de proficiência são utilizados para se determinar medias de conhecimento sobre um determinado assunto, tema ou disciplina acadêmica enquanto testes de habilidades ou competências são empregados para se determinar 
medidas de inteligência ou para se obter um padrão de referência em que se analisa nos alunos a capacidade de raciocínio, o uso da língua, a capacidade de expressão e a de resolver determinados tipos de problemas (Keats, 1988). Finalmente, Deve-se ressaltar que a mensuração educacional não se trata de uma finalidade em si mesmo. Mas, ao contrário, trata-se de uma atividade útil no processo de se avaliar conhecimentos e competências, ou como uma atividade de apoio à avaliação escolar, etc. Assim, mensuração refere-se a todos os aspectos e processos de construção de exames e testes educacionais.

\subsubsection{Mensuração no SAEB}

Ao contrário de um exame clássico, como o que um professor aplica regularmente a seus alunos em sala de aula, os testes do SAEB e da Prova Brasil são construídos metodologicamente para avaliar os sistemas de ensino, e não alunos (MEC/INEP, $2005)^{13}$. A proficiência dos estudantes é mensurada em uma escala de desempenho concebida para descrever, em cada nível, as competências e as habilidades que os estudantes desses sistemas demonstram ter desenvolvido ao longo de sua trajetória escolar. Há uma escala descrita para as habilidades em língua portuguesa e outra para matemática. A Tabela 1 descrve as habilidades e competências correspondentes aos diferentes níveis de proficiência em língua portuguesa. Vale ressaltar que, dentro de cada uma das disciplinas, a escala é única e cumulativa, para todas as séries avaliadas. A lógica subjacente a essa estratégia de mensuração é que quanto mais o estudante caminha ao longo da escala, mais habilidades terá acumulado. Portanto, é esperado

\footnotetext{
${ }^{13}$ Como se comentará, mais pormenorizadamente, adiante a amostra do SAEB é representativa para os estados e as redes de ensino no Brasil
} 
Tabela 1: Níveis de Desempenho em Língua Portuguesa: escala única SAEB

\begin{tabular}{|c|c|}
\hline Proficiência & Competência e habilidades \\
\hline $\begin{array}{l}\text { Abaixo do Nível } 1 \\
(P R O F I C<150)\end{array}$ & $\begin{array}{l}\text { Não atingiu as habilidades básicas que o SAEB objetivava } \\
\text { mensurar }\end{array}$ \\
\hline $\begin{array}{l}\text { Nível } 1 \quad(150 \geq \\
\text { PROFIC }<200)\end{array}$ & $\begin{array}{l}\text { Operar preferencialmente com estratégias locais de leitura. } \\
\text { Identificar informações cruciais/centrais em posição desta- } \\
\text { cada. E a finalidade ou tema de um texto. Usar conhecimento } \\
\text { de mundo na percepção do sentido de um texto. }\end{array}$ \\
\hline $\begin{array}{l}\text { Nível } 2 \quad(200 \geq \\
\text { PROFIC }<250)\end{array}$ & $\begin{array}{l}\text { Resolver problemas de leitura a partir da compreensão global } \\
\text { do texto, incluindo inferências. Localizar informações secun- } \\
\text { dárias. Reconstruir uma narrativa, encadeando vários fatos na } \\
\text { ordem de aparição. Reconhecer efeitos de sentido de recursos } \\
\text { variados (repetição, substituição, onomatopéia). }\end{array}$ \\
\hline $\begin{array}{l}\text { Nível } 3 \quad(250 \geq \\
\text { PROFIC }<300)\end{array}$ & $\begin{array}{l}\text { Estabelecer relações coesivas entre partes do texto, inclusive } \\
\text { pelo reconhecimento de tópico e comentário. Distinguir "fato" } \\
\text { de "opinião"; problema de solução; tese de argumento; causa } \\
\text { de efeito. Fazer transformações estruturais e estabelecer rela- } \\
\text { ções de correspondência. Compreender explicações mais abs- } \\
\text { tratas, metalingüísticas. }\end{array}$ \\
\hline $\begin{array}{l}\text { Nível } 4 \quad(300 \geq \\
P R O F I C<350)\end{array}$ & $\begin{array}{l}\text { Comparar textos afins, identificando e avaliando as estratégias } \\
\text { argumentativas e a finalidade de cada um. Estabelecer rela- } \\
\text { ções sintático/semânticas na progressão temática. Mostrar } \\
\text { conhecimento da estrutura e do funcionamento dos gêneros } \\
\text { textuais. Apresentar boa noção da relação entre linguagem e } \\
\text { sociedade. }\end{array}$ \\
\hline $\begin{array}{l}\text { Nível } 5 \quad(350 \geq \\
\text { PROFIC }<400)\end{array}$ & $\begin{array}{l}\text { Trabalhar com linguagem figurada/conotativa em nível global, } \\
\text { articulado. Identificar diferentes níveis de tratamento temá- } \\
\text { tico, reconhecendo tópicos e subtópicos. Analisar o efeito da } \\
\text { seleção lexical em uma argumentação. Aplicar com proprie- } \\
\text { dade conhecimentos metalinguísticos e literários. }\end{array}$ \\
\hline
\end{tabular}

Fonte: MEC/INEP

que alunos da $4^{a}$ série do ensino fundamental ${ }^{14}$ alcancem médias numéricas menores que os alunos de $8^{a}$ série e estes alcancem médias menores que as alcançadas pelos alunos de $3^{\circ}$ ano do ensino médio.

\footnotetext{
${ }^{14}$ Não obstante não exista um nível ideal de desempenho para os estudantes definido pelo MEC, o movimento Todos pela Educação, por exemplo, considera que um aluno de 4a. série do ensino fundamental alcance pelo menos 200 pontos em língua portuguesa e 225 em matemática na escala SAEB. Ver a esse respeito http//: www.todospelaeducacao.org.br/.
} 


\subsection{Avaliação}

Em geral, o uso do termo avaliação educacional (educational evaluation, na língua inglesa) refere-se a avaliação de entidades coletivas ou abstratas; tais como, programas, currículos, situações organizacionais, escolas ou sistemas escolares, etc. Seu emprego envolve não apenas a determinação da qualidade, da extensão ou da intensidade; mas implica também em estimar a valia, em estabelecer o merecimento. "Avaliar é atribuir valor" lembra Brian Barry (1975: 340). A avaliação educacional, assim sendo, vale-se usualmente de comparações com algum tipo de padrão teórico, de objetivos previamente estabelecidos, de outros programas ou de outros currículos.

Nesse sentido, a avaliação educacional diferencia-se das atividades de auditagem financeira e de controle procedimental ligados à administração pública. As atividades consideradas aqui como relacionadas à avaliação são aquelas que buscam caracterizar a validade, utilidade, eficiência e efetividade de, por exemplo, currículos, programas pedagógicos ou políticas educacionais, em termos de seus resultados, impactos e repercussões econômicas e sociais, e que, desse modo, têm como meta a geração de resultados ou recomendações para o aprimoramento das práticas educacionais. Enfim, a avaliação de um objeto qualquer (como um currículo escolar, ou um programa de reforço escolar) é feita para identificar e aplicar critérios defensáveis para determinar seu valor, mérito ou qualidade.

Essa compreensão do objetivo básico da avaliação é hoje a mais aceita na literatura e adotada por organizações de peso que trabalham no campo da avaliação educacional, tendo sido incorporada às "Diretrizes para a Avaliação de Programas" desenvolvidas 
pelo Comitê Conjunto para Diretrizes da Avaliação Educacional ${ }^{15}$ (2010). Embora essa visão seja aceita por muitos, não é consensual. Outros pesquisadores e avaliadores de prestígio, como por exemplo Shadish (1994 e 2002), Talmage (1982) e Fetterman (1994), afirmam que a avaliação tem vários objetivos. Talmage assinala que "três objetivos parecem ser os mais freqüentes nas definições de avaliação: fazer julgamentos de valor de um programa; ajudar os responsáveis pela tomada de decisões a definir suas políticas; e, assumir uma função política" (1982: 594). Talmage nota também que, ainda que esses objetivos não sejam mutuamente exclusivos, são claramente diferentes entre si.

Weiss (1997) aponta que, de modo geral, os estudos e pesquisas de avaliação estão relacionados com os seguintes propósitos: informação para o processo decisório, ou tomada de decisão, e aprendizado organizacional. Como lembra, com exatidão, Sônia Draibe (2001: 18), são objetivos dessa natureza que fazem da avaliação de educacional uma pesquisa interessada - ou, para conservar as palavras da autora, policy oriented -, pois trata-se de uma atividade que busca identificar obstáculos, propor medidas de correção e alteração de políticas e programas. Isto é, a avaliação não constitui uma atividade neutra, imparcial ou impessoal, mas é uma atividade que, por sua própria natureza, condições e métodos, constitui-se numa ação interessada e, necessariamente, conflitiva. Pois, embora sua importância no aprimoramento das práticas educativas seja amplamente reconhecida, seus objetivos, usos e efeitos para estudantes, professores e

\footnotetext{
${ }^{15}$ No original: The Program Evaluation Standards e Joint Committee on Standards for Education Evaluation, tradução do autor. O "Comitê Conjunto para Diretrizes da Avaliação Educacional" é uma associação profissional, com sede na Western Michigan University, que congrega pesquisadores e avaliadores e publica regularmente obras voltadas à disseminação de pesquisas e à padronização das boas práticas no âmbito da avaliação educacional. As "Diretrizes para a Avaliação de Programas" encontram-se atualmente em sua 3a. edição (Sage Publications, 2010). Uma versão resumida dessas diretrizes pode ser consultada na página do órgão na Internet em: www.jcsee.org/
} 
escolas são objeto de intenso debate e conflito político.

Finalmente, cade observar que a avaliação educacional apoia-se metodologicamente na mensuração dos resultados educacionais. Para tanto, pode valer-se do uso de testes de desempenho escolar ou exames de habilidades de indivíduos ou grupos. Assim, a avaliação educacional refere-se a todos os processos de coleta sistemática de informações acerca de atividades, características, resultados e produtos para o uso específico de tomada de decisões a respeito da gestão de políticas, programas e práticas educacionais.

\subsection{Resultados Educacionais}

Desde meados dos anos 1990, os governos no Brasil vêm realizando esforços para o aprimoramento da coleta de informações e produção de estatísticas acerca da provisão dos serviços de educação. Ademais, neste período, assistiu-se a um movimento consistente de formalização e consolidação de programas de avaliação educacional, tanto por parte do Ministério da Educação (MEC), que promove desde 1990 aferições do Sistema de Avaliação da Educação Básica (SAEB), como pelas Secretarias de Educação dos estados e municípios que desenvolvem iniciativas locais de avaliação de suas redes escolares. Esses programas locais assumem aspectos peculiares e se encontram em estágios diferentes de institucionalização nos diversos estados e municípios. ${ }^{16}$

Esses programas de avaliação das redes escolares inserem-se num quadro mais amplo de iniciativas que visavam reestruturar o papel do Estado, principalmente em relação

\footnotetext{
${ }^{16}$ Bahia, Ceará, Minas Gerais, São Paulo, Paraná, Pernambuco e Rio de Janeiro, entre outros, implataram e consolidaram sistemas de avaliação de suas redes escolares nos últimos anos.
} 
as suas funções e atuação no campo social. Este movimento de reformas, no campo educativo, possui dois grandes eixos: a descentralização da gestão das redes de ensino e a implantação de sistemas de avaliação das redes escolares (Castro e Carnoy, 1997). Não obstante tais tentativas, mensurar os resultados em educação continua sendo uma tarefa que apresenta obstáculos não triviais. A provisão de educação básica pelo setor público envolve uma série de atividades e processos governamentais bastante complexos. O objetivo básico da educação - definido amplamente - é preparar os cidadãos (estudantes) para participação da vida em sociedade e na economia por meio do mercado de trabalho. Os resultados do sistema educacional, por sua vez, são afetados por um conjunto de fatores que vão bem além do que se passa entre os muros das escolas e do resultado das políticas educacionais. Características socioeconômicas da família, habilidades dos estudantes, bem como outras variáveis associadas a características pessoais e familiares dos alunos afetam significativamente seu desempenho escolar.

Na literatura os termos resultados, produtos e desempenho educacional são definidos sem exatidão por meio de referências recíprocas. Mais importante, são comumente utilizados indistintamente para se referir a um mesmo conjunto de indicadores. Em geral, resultados educacionais referem-se aos indicadores de desempenho dos alunos ou das escolas, incluindo mensurações dos resultados do aprendizado dos estudantes. Tais medidas de resultados em educação são, em geral, agrupadas em dois conjuntos de indicadores: medidas de volume de recursos (e.g. numero de alunos, fluxo de coortes, investimento por aluno, etc.) e medidas de qualidade (e.g. desempenho em testes de aprendizado padronizados) (Atkinson, 2005). 
Há muitos tipos diferentes de indicadores de desempenho, entre os principais indicadores utilizados, pode-se citar: (i) indicadores da provisão de recursos financeiros; (ii) taxas de acesso ou participação nos níveis pré-escolar, elementar, secundário, vocacional e terciário; (iii) custos de provisão educacional em cada um desses níveis; (iv) tamanho da turma e/ou taxas de alunos por professor; (v) nível de treinamento dos professores e participação no desenvolvimento profissional interno; medidas de aproveitamento dos alunos em áreas chave do currículo em determinados níveis de idade-série; (vi) medidas do aprendizado dos alunos através do tempo, e dos fatores que afetam as taxas de progresso; (vii) medidas de eficácia dos programas para alunos com necessidades especiais e oriundos de condições desfavoráveis. ${ }^{17}$

Optou-se neste trabalho, pela utilização dos indicadores mais comumente empregados pela literatura especializada. Um primeiro conjunto de indicadores diz respeito aos insumos escolares. Isto é, os recursos das escolas, que podem afetar o aprendizado dos alunos: como, por exemplo, escolarização dos professores, experiência dos professores, infraetrutura física das escolas, dentre outros fatores que são regularmente mensurados pelo MEC/INEP por meio do Censo Escolar da Educação Básica. Neste trabalho, deu-se deu-se preferência ao exame de: a formação e experiência dos professores, e a infraestrutura física das escolas. O segundo conjunto de indicadores referem-se às taxas de rendimento do fluxo escolar, esse conjunto de indicadores procura auferir o acesso à educação por meio da taxa de matrícula, e o fluxo dos estudantes por meio das taxas de evasão, repetição, e principalmente, por meio da taxa de defasagem idade-

\footnotetext{
${ }^{17}$ Os tipos a alcances dos indicadores de desempenho educacionais utilizados em diferentes países encontram-se bem ilustrados na página do programa da UNESCO "Avaliação do ano 2000 da Educação para Todos (EFA) na Internet em: http: //www2 . unesco.org/efa/wef/contryreports/ contry.html.
} 
série. Neste trabalho, decidiu-se pelo uso dos indicadores de produtos educacionais mais comumente empregados na literatura, a saber: as taxas de repetição, evasão e a distorção idade-série. Finalmente, o desempenho dos estudantes é auferido por meio dos testes de proficiência em Matemática e Língua Portuguesa conduzidos pelo MEC/INEP, particularmente, pelo SAEB. Assim, no escopo desse trabalho, resultados educacionais referem-se especificamente ao rendimento dos sistemas escolares no municípios em termos de acesso e fluxo dos estudantes e ao desempenho dos estudantes nos testes de proficiência.

O acesso da população ao sistema educativo de um determinado país, região ou município é geralmente medido por meio da(s) taxa(s) de matrícula. A taxa de alfabetização indica os resultados acumulados do sistemas de educação primária e dos programas de alfabetização destinados a capacitar a população com as habilidades mais básicas de leitura e escrita. Entretanto, as taxas de matrículas nos municípios brasileiros se estabilizaram a partir dos anos 2000, quando se atingiu a universalização de matrículas para crianças em idade escolar (6 a 14 anos de idade). Sua flutuação é hoje atribuída, quase que exclusivamente, a fatores demográficos, principalmente à taxa de natalidade (MEC/INEP, 2010). Portanto, optou-se por não se utilizar esse indicador. Outro conjunto de indicadores de "produtos"educacionais utilizados neste trabalho são as taxas de fluxo de coorte: taxas de evasão, repetição e defasagem idade-série. Embora esse conjunto de indicadores de fluxo sejam alegadamente medidas de eficiência interna dos sistemas de educação, são também utilizados na literatura como medidas da qualidade dos sistemas educacionais (Lee e Barro, 2001).

A taxa de repetição é a medida como a razão do número de estudantes que são 
reprovados em relação ao número total de estudantes de um determinado nível. A taxa de evasão, como a razão do número de estudantes que abandonam os estudos antes de completar determinado nível em relação ao número total de alunos desse mesmo nível. A taxa de graduação é a porcentagem de alunos que concluem determinado nível em relação ao número total de alunos desse mesmo nível. A taxa de defasagem escolar procura captar a diferença entre a idade da criança e a série esperada para sua faixa etária. Por exemplo, uma criança com nove anos de idade deveria estar matriculada na 4a. série do nível fundamental e não em uma série anterior. Ainda, segundo Horowitz e Souza (2004), como o processo de acumulação de capital humano das crianças não está completo, a taxa de defasagem idade-série pode ser uma boa medida para captar o aprendizado; isto é, pode também ser utilizada como uma boa "proxy" para mensurar a qualidade dos sistemas educacionais na ausência de testes de aprendizado padronizados. A literatura educacional tem como estabelecido o fato de que quanto maior o atraso educacional menor o nível de escolaridade atingido. Esses indicadores de fluxo de coorte são criticados por serem muito suscetíveis aos padrões de promoção dos estudantes. ${ }^{18}$ O Censo Escolar da Educação Básica (doravante, Censo Escolar) do Ministério da Educação coloca à disposição dados para todas essas medidas para os anos compreendidos no período 1995-2010.

As medidas de qualidade compõem um segundo grupo de indicadores de desempenho dos sistemas educacionais. Em geral, essas medidas referem-se a testes de aprendizado padronizados, ou testes de proficiência. Preocupado em mensurar a qualidade do

\footnotetext{
${ }^{18}$ Assim, por exemplo, se um sistema de educação estabelece o fim das repetições para a primeira série do ensino primário, a taxa de repetição deve cair à zero para esse município/série. Para uma definição, revisão e discussão dessa e de outros indicadores utilizados em educação ver o documento "Education Indicators - Technical Guidelines", UNESCO Institute for Statistics (UIS), 2003.
} 
ensino no Brasil - e subsidiar a tomada de decisão dos governos estaduais e locais - o MEC criou e consolidou redes nacionais de avaliação educacional ao longo da década de 1990. Esses testes procuram avaliar o nível de aprendizado dos alunos em determinadas disciplinas e níveis de ensino.

Neste trabalho, optou-se pela utilização dos testes do Sistema Nacional de Avaliação da Educação Básica (SAEB). Pois, estes permitem não apenas a comparação entre estados e redes de ensino no Brasil. Mas, principalmente, porque é possível identificar um subgrupo de escolas que foi mantido na amostra do SAEB ao longo dos anos. A partir desses dados, é possível construir um painel de escolas que possibilita o acompanhamento da proficiência média dos alunos das mesmas escolas ao longo dos anos, assim como informações oriundas dos questionários dos professores, das turmas e do diretor da unidade escolar. Ademais, os dados do SAEB, quando agregados aos dados da Prova Brasil, possibilitam seguir um grupo de escolas em dois pontos no tempo: antes e depois da municipalização. Ou seja, os dados do SAEB e da Prova Brasil possibilitam, dessa forma, estabelecer um grupo experimental de escolas que estavam sob controle estadual e migraram para o controle municipal e dois grupos controle de escolas que estavam sob o controle estadual e municipal e assim permaneceram.

Em resumo, neste trabalho é procura-se decompor efeito da descentralização sobre (i) o desempenho dos alunos nos testes de avaliação do MEC/INEP; sobre (ii) as escolas que foram municipalizadas (que são cotejadas àquelas que permaneceram sob controle dos estados e municípios); e, finalmente, sobre (iii) os insumos e produtos dos sistemas educacionais nos municípios em termos dos recursos escolares e fluxo de coortes. Os recursos escolares são auferidos por meio da infraestrutura física das escolas. Ou seja, 
é verificado se houve alteração na proporção de escolas com quadras de esportes, bibliotecas, laboratórios de ciências e laboratórios de informática. Ademais, também procura-se captar de houve mudança na proporção de professores com curso superior completo e na proporção de professores com mais de 5 anos de experiência. O fluxo das coortes é medido por meio das taxas de evasão e defasagem idade-série. Não obstante a deficiência de algumas dessas medidas, todas elas já foram amplamente utilizadas em trabalhos prévios como "proxies" para a mensuração de resultados educacionais (Lee e Barro, 2001; Lobo et al. 1995; Mahal, Srivasta e Sanan, 2000; Prawda, 1993 e Faguet e Sanches, 2008). 


\section{Definindo e Medindo Descentralização}

A revisão dos trabalhos produzidos sobre descentralização da educação evidencia que há não apenas grande variedade de definições do termo como também diversas maneiras como a provisão dos serviços educacionais pode ser transferida das esferas centrais de governo para as subnacionais. Amplamente, pode-se definir descentralização como o processo de transferência de gastos e de determinados poderes de decisão sobre aspectos financeiros, administrativos ou pedagógicos de um nível superior de governo para um nível inferior de governo. Neste trabalho, mais especificamente, consideramse quatro níveis distintos de autoridade: o governo central (ou nacional); o nível intermediário de governo que se refere à esfera estadual; os governos locais que se referem às esferas municipais; e, finalmente, as autoridades escolares.

Definições alternativas de descentralização da educação aparecem na literatura sob a rubrica de delegação e desconcentração. Delegação é, em geral, entendida como o processo de "transferência da responsabilidade de gestão dos serviços para agências não-vinculadas ao governo central, mantido o controle dos recursos pelo governo central" (Arretche, 1996). Desconcentração é entendida como o processo de transferência da responsabilidade de execução dos serviços para unidades fisicamente descentralizadas. ${ }^{19}$

A literatura reconhece que devido à natureza multidimensional do processo de descentralização mensurá-lo não é uma tarefa simples. Pelo contrário, essa dificuldade tem sido muito enfatizada nos trabalhos que abordam a descentralização fiscal; e embora

\footnotetext{
${ }^{19}$ Para uma discussão abrangente das diferenças entre descentralização, desconcentração, delegação e devolução ver, entre outros, Fiske (1996); Guess, Loehr e Martinez-Vasquez (1997); Hanson (1997); McGinn e Welsh (1999); além do já citado Arretche (1996).
} 
numa escala mais modesta, também nos trabalhos sobre descentralização da provisão dos serviços de educação. ${ }^{20}$ Contudo, tal como se dá com a descentralização fiscal, a descentralização do ensino é comumente mensurada como a parcela de gastos dos governos subnacionais em relação aos gastos governamentais totais em educação. ${ }^{21}$ Essa medida, porém, captura tão-somente a faceta fiscal da descentralização da educação. O poder de decisão sobre a alocação dos gastos em educação nos diferentes níveis de governo, simplesmente, não entra no cálculo dessa medida.

Ainda que essa abordagem despreze a importância de se levar em consideração a esfera de autoridade que detêm o poder de decisão acerca dos gastos e das políticas em educação, dada a pouca disponibilidade de informações a respeito das competências específicas de cada órgão governamental, as medidas de execução dos gastos em educação são, muitas vezes, a única "proxy" disponível para se mensurar a descentralização de maneira a possibilitar a comparação entre diferentes municípios, estados, ou países (Faguet e Sanchez, 2008). Como já foi notado, as estratégias de descentralização na provisão dos serviços em educação variaram bastante entre os diferentes estados do Brasil e mesmo entre os municípios em um único estado (Gomes, 2008). Segundo a literatura internacional, podem-se identificar, pelo menos, as seguintes estratégias de descentralização nas últimas duas décadas ${ }^{22}$ : políticas de incentivo à participação de pais de alunos e da comunidade na gestão escolar; programas de autonomia esco-

\footnotetext{
${ }^{20}$ Ver a esse respeito, por exemplo: Bird (2000); Guess, Loerh e Martinez-Vazquez (1997); e Martinez-Vazquez e McNab (2003).

${ }^{21}$ Alternativamente, também é usual distinguir a parcela dos gastos em educação que advêm de fontes fiscais próprias das que tem origem em transferências verticais.

${ }^{22}$ Para revisões mais abrangentes das políticas educacionais dos países da America Latina nas últimas quatro décadas consultar Aguerrondo (1992); Castro e Carnoy (1997) e Carnoy (2000). Para revisões do caso dos Estados Unidos, ver Pulliam and Van Patten (2006). Para os países da OCDE ver o já mencionado OCDE (1998)
} 
lar; programas de bolsas para escolas particulares (vouchers) e programas de escolha escolar (school choice); programas de delegação da gestão escolar às chamadas "organizações sociais" ou simplesmente "charter schools" e, finalmente, as políticas de transferência de recursos e autonomia decisória aos órgãos governamentais locais ou regionais.

A abordagem metodológica mais comum para se comparar os efeitos das diferentes estratégias de descentralização tem sido mensurá-las simplesmente por meio de uma série de variáveis binárias. As quais são capazes de indicar tão-somente se as escolas são (ou não) geridas por organizações sociais; se há (ou não) algum programa de participação comunitária na gestão das escolas; se as escolas são (ou não) juridicamente autônomas para gerir seus recursos; se houve (ou não) transferência de recursos e poder de decisão para os governos subnacionais; e assim por diante. Essa abordagem é empregada, principalmente, em estudos de caso de países específicos pela literatura econômica e comumente também é associada à mensuração da descentralização fiscal (Lee e Barro, 2001; Hanushek e Rivkin, 2003; Hoxby, 2000 e Hanushek, 1986).

Mais especificamente no caso do Brasil, como já apontado, o processo de descentralização da educação é associado à transferência de controle das escolas das esferas estaduais para as municipais. Cabe observar, como será discutido mais pormenorizadamente adiante, que a transferência ganhou características particulares nos diferentes estados da federação. Nos países da OCDE, nos quais os processos de sistematização e coleta de dados estão mais consolidados, a descentralização tem sido mensurada não apenas em seu aspecto fiscal; isto é, com base na parcela de gastos sob responsabilidade dos governos subnacionais; mas, sobretudo, com base nas atribuições de 
determinados poderes de decisão acerca da gestão do ensino. Ou seja, procura-se auferir o grau de autonomia decisória das instâncias subnacionais na área educacional quanto a funções específicas de gestão do sistema de ensino. Quais as decisões tomadas autonomamente pelos órgãos governamentais subnacionais acerca da gestão do ensino? Quais as competências dos órgãos regionais, locais e das unidades escolares? Quais as esferas de governo responsáveis por cada uma das funções dos sistemas de educação? São algumas das perguntas que são propostas para mensurar o grau de autonomia política e administrativa das esferas subnacionais.

Segundo a metodologia elaborada pela Diretoria de Educação da OCDE, a descentralização do ensino pode ser mensurada com base na identificação da instância ou no órgão governamental que, de fato, detêm o poder de decisão acerca de cada uma das seguintes funções dos sistemas públicos de educação: (i) organização da instrução que envolve currículo, adoção de livros-texto, modelos de ensino, período letivo; (ii) gestão de pessoal que envolve contratação e demissão de professores e funcionários, organização de carreiras e salários, treinamento e atribuições de responsabilidades; (iii) planejamento e estrutura; e, (iv) gestão de recursos (OCED, 1998). A Tabela 2 descreve mais detalhadamente o conjunto de decisões que compõem cada uma dessas funções e que podem ser transferidas aos órgãos governamentais subnacionais ou mesmo diretamente às unidades escolares.

Mesmo para os países que fazem parte da OCDE, a formalização, coleta e disponibilização de informações específicas para cada uma dessas funções e atribuições assume características peculiares e, mais importante, encontram-se em estágios diferentes de institucionalização. Para os estados e municípios brasileiros, no entanto, esse tipo de 
Tabela 2: Tipos de decisão em educação que podem ser alocadas em diferentes esferas ou orgãos de governo

\begin{tabular}{|c|c|}
\hline Função & Tipos de decisão \\
\hline $\begin{array}{l}\text { Organização } \\
\text { da instrução }\end{array}$ & $\begin{array}{l}\text { Definição das regras que estabelecem a seleção de alunos pe- } \\
\text { las escolas; definição do currículo; definição dos livros texto; } \\
\text { definição do período letivo; definição dos modelos de ensino }\end{array}$ \\
\hline $\begin{array}{ll}\text { Gestão de } \\
\text { pessoal }\end{array}$ & $\begin{array}{l}\text { contratação e demissão de pessoal (diretores, professores e } \\
\text { demais funcionários); definição da escala de trabalho dos pro- } \\
\text { fessores; definição das carreiras, salários e atribuições profissi- } \\
\text { onais, treinamento. }\end{array}$ \\
\hline $\begin{array}{l}\text { Planejamento } \\
\text { e estrutura }\end{array}$ & $\begin{array}{l}\text { Criação e fechamento de unidades escolares; definição dos pro- } \\
\text { gramas oferecidos pelas escolas; definição dos programas de } \\
\text { avaliação escolar; definição dos programas de avaliação dos } \\
\text { alunos. }\end{array}$ \\
\hline $\begin{array}{l}\text { Gestão de re- } \\
\text { cursos }\end{array}$ & $\begin{array}{l}\text { definição dos planos de bonificação e incentivos; alocação de } \\
\text { recursos para folha de pagamento (gasto com pessoal); alo- } \\
\text { cação de recursos para investimento, custeio e manutenção; } \\
\text { alocação de recursos para treinamento. }\end{array}$ \\
\hline
\end{tabular}

Fonte: OCED

informação ainda não se encontra disponível, ou sequer formalizada pelas secretarias de educação. Entretanto, é importante observar que o modelo proposto pela OCDE estabelece uma metodologia de mensuração mais abrangente e, sobretudo, mais adequada para a comparação entre diferentes países ou mesmo para a comparação entre unidades subnacionais que compõe um determinado país. Pois, como observado alhures $^{23}$ enquanto algumas dessas funções podem permanecer centralizadas em sistemas educacionais significativamente descentralizados do ponto de vista fiscal, outras funções podem ser transferidas diretamente às autoridades escolares dentro de sistemas centralizados do ponto de vista da execução dos gastos.

Uma pesquisa da OCDE com seus membros, por exemplo, constatou que mesmo em sistemas educacionais fiscalmente centralizados - como os da Itália, Grécia e Turquia

${ }^{23} \mathrm{~A}$ esse respeito ver, por exemplo, Rodden (2004) e OCDE (1998) 
- as escolas são responsáveis pela maioria das decisões acerca da organização da instrução. Por outro lado, em países com sistemas educacionais significativamente descentralizados do ponto de vista fiscal - como Canadá e Noruega - as decisões acerca da gestão de pessoal continuam sendo quase exclusivamente atribuição do governo central (OCDE, 1998).

Em suma, fica claro a partir dessa breve revisão da literatura acerca da definição e da mensuração da descentralização que, há não apenas diversas definições do termo, mas também que o próprio fenômeno de interesse - a descentralização da educação se manifesta empiricamente de maneiras bastante distintas. Ademais, a mensuração da descentralização em educação, no caso brasileiro em particular, apresenta desafios significativos devido, principalmente, a (i) pouca disponibilidade de dados dos estados e, principalmente, dos municípios brasileiros para construção de uma medida abrangente, a la OCDE; e (ii) ao alcance limitado do uso de medidas de execução de gastos dissociadas da análise da autoridade decisória para as diferentes funções dos sistemas de ensino.

\subsubsection{Os estudos no Brasil}

Face à ausência de dados a respeito da gestão descentralizada das escolas nos estados e municípios brasileiros, os trabalhos empíricos acerca da descentralização da educação no Brasil têm se valido de diferentes estratégias de mensuração. Madeira (2007), que se restringe à análise do estado de São Paulo, para o qual logra obter dados administrativos do sistema escolar, constrói uma medida que leva em conta o tempo (medido em número de anos) que uma determinada escola foi transferida do 
controle estadual para o municipal. D'Atri (2007), que se serve de dados agregados por municípios dos Censos Escolares, faz uso da proporção de matrículas em escolas municipais em relação ao total de matrículas em escolas públicas nos municípios como medida de descentralização. Leme, Paredes e Souza (2009), usando dados do SAEB e da Prova Brasil de 2005, valem-se do número de escolas estaduais que passaram para a gestão municipal como medida de descentralização.

Orellano e colaboradores (2010), por sua vez, desenvolvem três medidas de descentralização que procuram captar não apenas a transferência de responsabilidade na prestação dos serviços de educação; mas buscam também combinar uma medida de descentralização fiscal à municipalização das matrículas. Dessa forma, Orellano e colaboradores valem-se (1) da proporção de alunos do ensino fundamental que frequentam escolas municipais no município; (2) da proporção de escolas municipais do ensino fundamental no município; como também fazem uso da (3) razão entre as transferências do FUNDEF para o município e os gastos em educação e cultura realizados pelo município.

Não obstante o esforço em incorporar uma medida que de conta da dimensão fiscal às medidas baseadas nas taxas de municipalização de matrículas e escolas, as três medidas propostas por Orellano e colaboradores (2010) apresentam correlações positivas e crescentes ao longo do período analisado (1999-2006). Mais importante, a correlação entre a medida de descentralização fiscal (razão FUNDEF/gastos em educação) e as medidas de municipalização de matrículas e escolas é decorrente do próprio mecanismo de transferências do FUNDEF. Haja vista o critério de partilha dos recursos do FUNDEF, que vincula as transferências de recursos aos municípios à oferta de vagas no 
ensino fundamental. Ou seja, é esperado que os municípios que apresentem maiores taxas de expansão das matrículas municipais sejam aqueles mais beneficiados pelas transferências do FUNDEF. Contudo, a principal limitação das medidas propostas por Orellano e colaboradores (2010) é que essas medidas parecem ser endógenas, mesmo com o controle dos efeitos específicos dos municípios. É razoável supor, por exemplo, que os prefeitos elevem seus gastos em educação, afetando por conseguinte o comportamento da razão FUNDEF/gastos, frente a maus resultados educacionais experimentados pelos municípios. Como se assume que essa medida de descentralização fiscal é exógena aos resultados educacionais, as estimativas apresentadas por Orellano e colaboradores (2010) podem estar sendo enviesadas devido a endogeneidade dos regressores. O que possivelmente restringe a contribuição do trabalho.

No pesente trabalho, são empregadas diferentes medidas de descentralização e municipalização. Como mencionado, a estratégia de identificação adotada aqui consiste em decompor o efeito da municipalização sobre os alunos, as escolas e os municípios. De tal sorte que, para cada um desses exercícios de estimação do efeito da descentralização sobre a qualidade do ensino público oferecido à população será adotada uma medida de descentralização que mais se adeque teórica e operacionalmente à investiçação. Nesse sentido, inicialmente, para se investigar se há, de fato, alguma diferença de desempenho entre os alunos de escolas públicas estaduais e escolas públicas municipais. E, principalmente, para se examinar se essa diferença de desempenho pode ser atribuída a algum tipo de estratificação do alunado, ou a diferenças nos recursos escolares. Simplesmente, faz-se uso de variáveis binárias que identificam os alunos às redes escolares. Isto é, utiliza-se uma variável dummy para se identificar as escolas estaduais e uma outra para as escolas municipais. 
Num segundo momento, quando se procura estimar o efeito da municipalização sobre o grupo de escolas que migraram do controle estadual para o controle municipal, a estratégia adotada foi, primeiro, construir um painel de escolas, em que se identifica a mesma escola pública (municipal ou estadual) em dois pontos no tempo: o período inicial, que corresponde aos testes do SAEB para os anos de 1997, 1999, 2001, 2003 e 2005; e um período final, que corresponde a Prova Brasil de 2007. Dessa forma, foram construídos, na verdade, painéis de escolas por pares de anos 1997-2007, 19992007, 2001-2007, 2003-2007 e 2005-2007. Uma vez montado esse painel de escolas públicas de ensino fundamental por pares de anos, as escolas são classificadas de acordo com a rede de ensino a que pertencem - municipal ou estadual - nos anos iniciais e no ano final. Assim, são compostos três grupos de escolas: um primeiro grupo controle de escolas que estavam sob gestão do estado no ano inicial e que permaneceram sob o estado no ano final; um segundo grupo de controle de escolas que eram municipais no ano inicial e permaneceram municipais no ano final; e, finalmente, um grupo de tratamento para aquelas escolas que eram estaduais no ano inicial e foram transferidas para o controle do estado no ano final. Assim, todas as escolas que aparecem nesse painel foram observadas pelo menos em dois pontos no tempo. Aqui novamente empregam-se duas variáveis do tipo dummy para se identificar a rede de ensino a qual as escolas se vinculam.

Para se estimar o efeito da municipalização sobre a qualidade dos serviços de educação ${ }^{24}$ oferecidos pelos municípios brasileiros, opta-se pela utilização da taxa de matrículas no ensino fundamental em escolas públicas municipais em relação ao total de

\footnotetext{
${ }^{24}$ Como já mencionado, o que, de fato, se pretende estimar é o efeito da municipalização sobre os insumos e produtos escolares, que afetam o desempenho acadêmico dos estudantes
} 
matrículas em escolas públicas no município. Essa medida, não obstante sua evidente limitação em apreender aspectos relacionados à autonomia decisória dos municípios na gestão dos sistemas de educação, é suficientemente compreensiva para captar o aspecto central da descentralização da educação no Brasil. Ou seja, essa medida indica a extensão em que a gestão da educação foi transferida para os municípios por meio do aumento proporcional de matrículas em escolas municipais. Enfim, quando maior for a taxa de matrículas em escolas públicas municipais para um determinado município, mais descentralizada é a provisão pública do ensino fundamental nesse município. Uma vez que, maior é a responsabilidade do governo municipal na provisão dos serviços de educação fundamental em relação à responsabilidade do governo estadual. Ademais, como comentado, essa medida tem sido amplamente empregada na literatura. O que possibilita cotejar os resultados da presente investigação com os estudos prévios sobre o tema. 


\section{A Descentralização da educação no Brasil}

Na presente seção do trabalho são brevemente expostos os principais números e fatos do processo de municipalização da educação no Brasil. Procura-se, assim, dar relevo não apenas à evolução do processo de descentralização; mas, sobretudo, evidenciar o papel central desempenhado pela descentralização na política de reforma da provisão pública de educação fundamental no Brasil ao longo dos últimos anos.

\subsubsection{As matrículas}

Em 1991, havia aproximadamente 29 milhões de estudantes matriculados no ensino fundamental no Brasil. Ao longo da década de 1990, testemunha-se uma grande expansão dessas matrículas. Em 1999, as matrículas no ensino fundamental atingem 36 milhões. A partir de então, verifica-se um pequeno, porém constante, declínio no número total de matrículas no ensino fundamental no Brasil. Em 2010, havia aproximadamente 31 milhões de matriculados. O decréscimo observado decorre, da acomodação do sistema educacional, em especial na modalidade regular ${ }^{25}$ do ensino fundamental, a dois fatores principais. De uma lado, nota-se que essa etapa de ensino apresenta histórico de retenção e, consequentemente, altos índices de distorção idade-série. Segundo o MEC, essa distorção vem sendo paulatinamente corrigida no período mais recente, para o qual se verifica uma melhoria do fluxo escolar das coortes (MEC/INEP, 2010).

\footnotetext{
${ }^{25} \mathrm{~A}$ modalidade regular do ensino fundamental não lava em conta a Educação para Jovens e Adultos (EJA), como também as classes especiais e escolas exclusivas para crianças portadoras de necessidades especiais.
} 
Essa melhoria no fluxo escolar aponta para uma tendência de acomodação do número de matrículas do ensino fundamental ao patamar equivalente ao da população na faixa etária de 6 a 14 anos, que segundo segundo a Pesquisa Nacional por Amostra de Domicílios (PNAD/IBGE 2009), corresponde a 30.229.090 crianças. De acordo com o Censo Escolar de 2010, o número de alunos matriculados no ensino fundamental regular ainda é cerca de 3 por cento superior à população na faixa etária adequada a esta etapa de ensino. Entretando, vale observar que, este percentual é significativamente menor do que os 20 por cento observados no final da década de 1990, levando-se em conta que, naquela época, a população em idade escolar era dos 7 a 14 anos de idade, para um ensino fundamental de 8 anos (MEC/INEP, 2010).

Por outro lado, a redução na taxa de fecundidade e a consequente redução do ritmo de crescimento da população brasileira registrada nos últimos anos (PNAD/IBGE 2009), também pode ser apontada como um fator que tem contribuído para o decréscimo do número de alunos matriculados no ensino fundamental no Brasil.

A figura 2 apresenta os números de alunos matriculados no ensino fundamental no Brasil entre os anos 1991 e 2010 por dependência administrativa em relação ao total de matriculados.

Verifica-se que a grande maioria dos alunos está matriculada nas escolas públicas, estaduais ou municipais. O número de matrículas na rede privada de educação fundamental conserva-se praticamente invariável em torno de pouco mais de 3 milhões. A partir dos números apresentados na figura 2, pode-se concluir que a grande expansão do número de alunos matriculados no ensino fundamental deve-se, quase que exclusivamente, à ampliação da rede pública de ensino. Particularmente, à expansão do 
Figura 2: Evolução das matrículas em escolas privadas e públicas estaduais e municipais em relação ao total de matrículas do ensino

fundamental no Brasil (1991-2010)

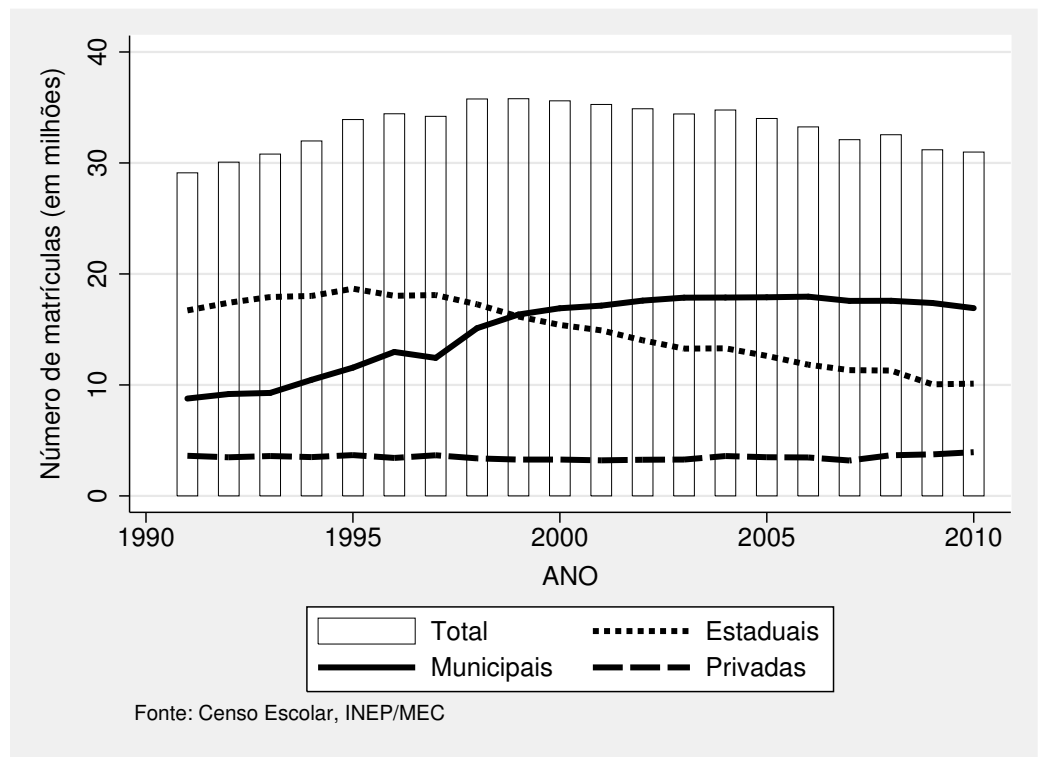

número de matriculados em escolas públicas municipais. Em 1991, havia cerca de 25 milhões de alunos matriculados em escolas públicas estaduais e municipais. No final da década de 1990, esse número ultrapassa os 32 milhões de matriculados. Em 2010, devido a queda no número de matriculados no ensino fundamental, esse número se reduz para pouco mais de 27 milhões de alunos.

Dentro da rede pública de ensino, verifica-se um expressivo crescimento do número de matrículas nas escolas municipais. Em 1991, havia aproximadamente, 16, 7 milhões de alunos matriculados nas escolas estaduais e 8,7 milhões em escolas municipais. Em 2010, os municípios passam a atender aproximadamente 17 milhões de alunos. Os restantes 10 milhões de matriculados na rede pública encontram-se em escolas mantidas pelos estados. Conclui-se, portanto, que ao longo das duas últimas décadas, as escolas municipais foram responsáveis pela incorporação de aproximadamente 15,5 
milhões de alunos. Na medida em que, as redes municipais cresceram, absorvendo tanto matrículas novas (cerca de 9 milhões) como parte significativa das matrículas estaduais (aproximadamente 6,5 milhões).

Em suma, o processo que se denomina aqui municipalização das matrículas dá-se tanto por meio da incorporação de novos alunos, como também por meio da transferência de matrículas das escolas públicas estaduais para as escolas públicas municipais.

Nota-se ainda que, a municipalização das matrículas no ensino fundamental não ocorre paulatinamente ao longo das duas últimas décadas. Mas, pelo contrário, ele se intensifica a partir de 1996 e parece se estabilizar novamente em 2006.

Figura 3: Divisão das matrículas do ensino fundamental em escolas privadas e públicas estaduais e municipais no Brasil (1991-2010)

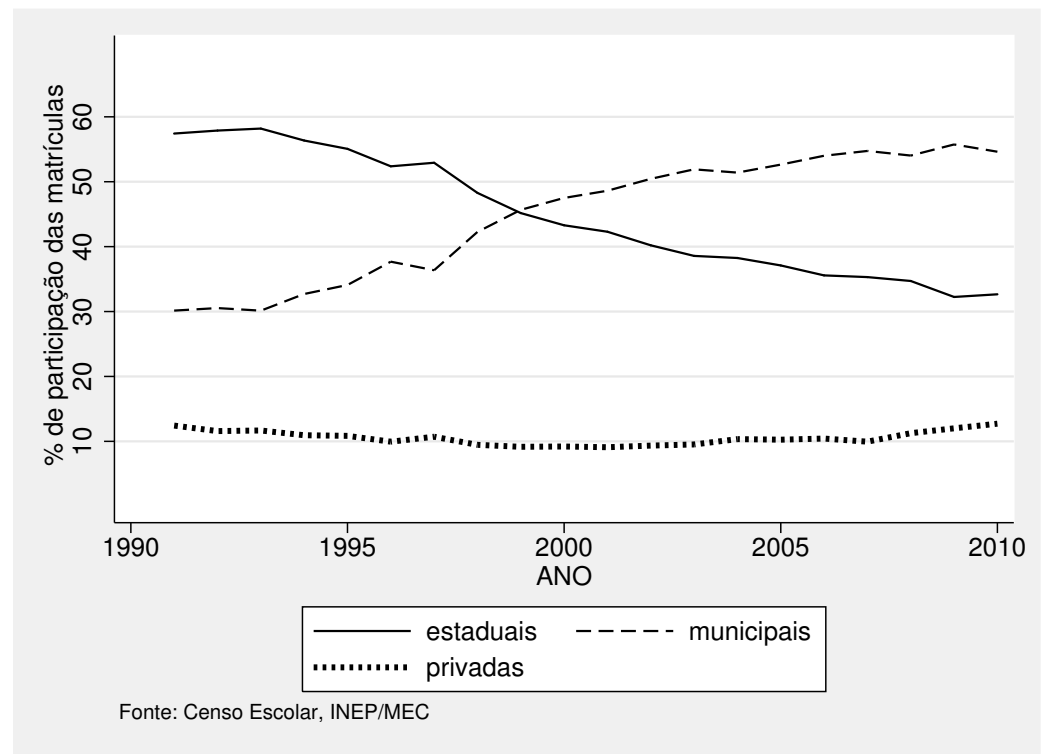

Como pode se inferir a partir da figura 3, em 1996, apenas 37 por cento dos alunos matriculados no ensino fundamental público no país frequentavam escolas municipais. 
O restante, 63 por cento, frequentava escolas das redes estaduais de ensino. Dez anos depois, em 2006, tal cenário havia se invertido totalmente. Os municípios passaram a atender aproximadamente 60 por cento dos alunos matriculados no ensino público no país. Ademais, cabe ressaltar que, a participação da rede privada de ensino no total de matrículas do ensino fundamental permanece estável por volta dos 10 por cento ao longo de todo o período compreendido entre os anos 1991 e 2010.

Figura 4: Número de estabelecimentos públicos de ensino fundamental segundo a dependência administrativa (1991-2010)

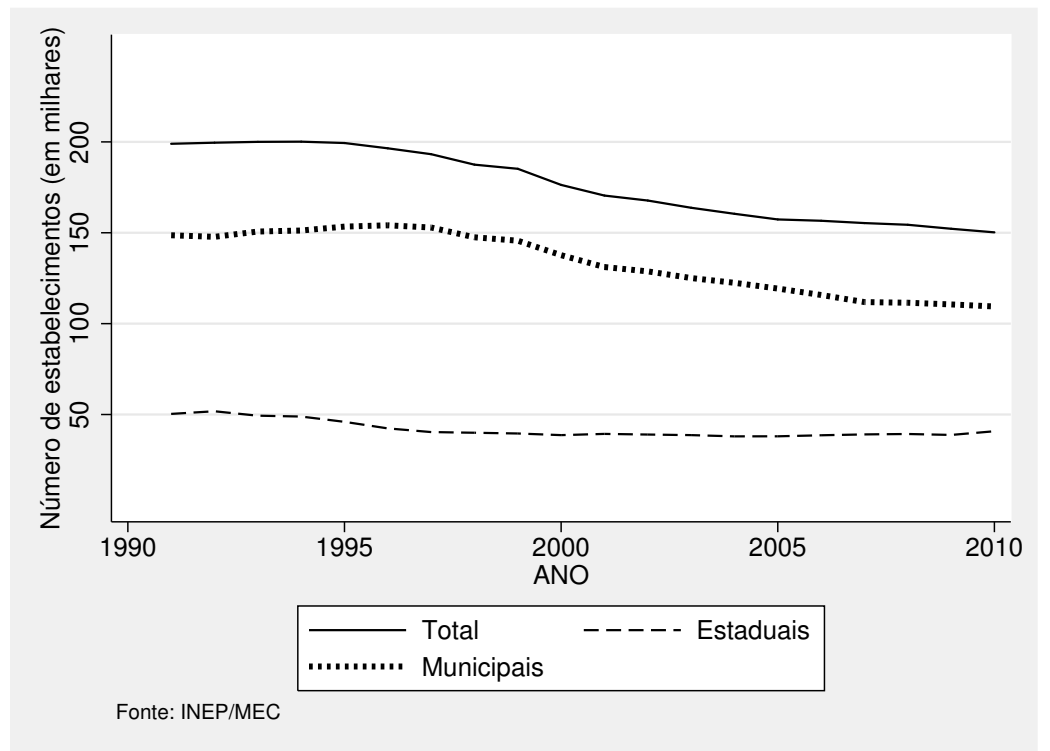

\subsubsection{As escolas}

Outro aspecto do processo de municipalização das matrículas do ensino fundamental que merece relevo, é que a descentralização ocorre concomitantemente a uma redução do número de estabelecimentos públicos que ofereciam vagas no ensino fundamental, 
como já foi observado com precisão por Leme, Paredes e Souza (2009: 267). A figura 4 exibe o número de estabelecimentos de ensino público, segundo a dependência administrativa, entre os anos de 1991 e 2010.

Nota-se uma clara queda no número de estabelecimentos de ensino público no período. Em 1991, havia aproximadamente 200 mil escolas públicas de ensino fundamental, cerca de 150 mil escolas públicas municipais e 50 mil escolas estaduais. Em 2010, o número de estabelecimentos públicos de ensino fundamental cai para aproximadamente 150 mil, das quais por volta de 110 mil eram escolas municipais e o restante 40 mil, estaduais. Como pode se observar na figura 4, a redução no número de estabelecimentos de ensino se manifesta tanto nas redes escolares estaduais como nas municipais.

\subsubsection{As turmas}

Uma terceira dinâmica do ensino público no Brasil que deve ser aqui destacada é o aumento do número de turmas do ensino fundamental. O aumento das turmas está, evidentemente, vinculado a expansão das matrículas e a redução do número de escolas. Houve no período um significativo aumento do número de turmas por estabelecimento, principalmente nas escolas municipais. A partir do dados do Censo Escolar, podese inferir que, se por um lado, houve uma redução do número de estabelecimentos, principalmente pela eliminação de escolas rurais ou de pequeno porte. Por outro lado, verifica-se um significativo aumento do número de turmas por estabelecimento de ensino. Ou seja, os alunos foram concentrados em escolas maiores.

Conforme pode se observar na figura 5 (FALTA ACRESCENTAR!!!!!), o número total de turmas se mantém praticamente inalterado, em torno de 1,2 milhão de turmas no 
ensino fundamental da rede pública. O total do número de turmas nas escolas municipais tem um crescimento de mais de 50 por cento, pulando de aproximadamente 470 mil turmas em 1997 para mais de 720 mil turmas em 2007. De tal sorte que, o número médio de turmas por estabelecimento nas escolas municipais tem um aumento de 3,5 turmas/estabelecimento em 1997 para 5,3 turmas/estabelecimento em 2007.

Figura 5: Número de turmas do ensino fundamental público segundo a dependência administrativa (1991-2010)

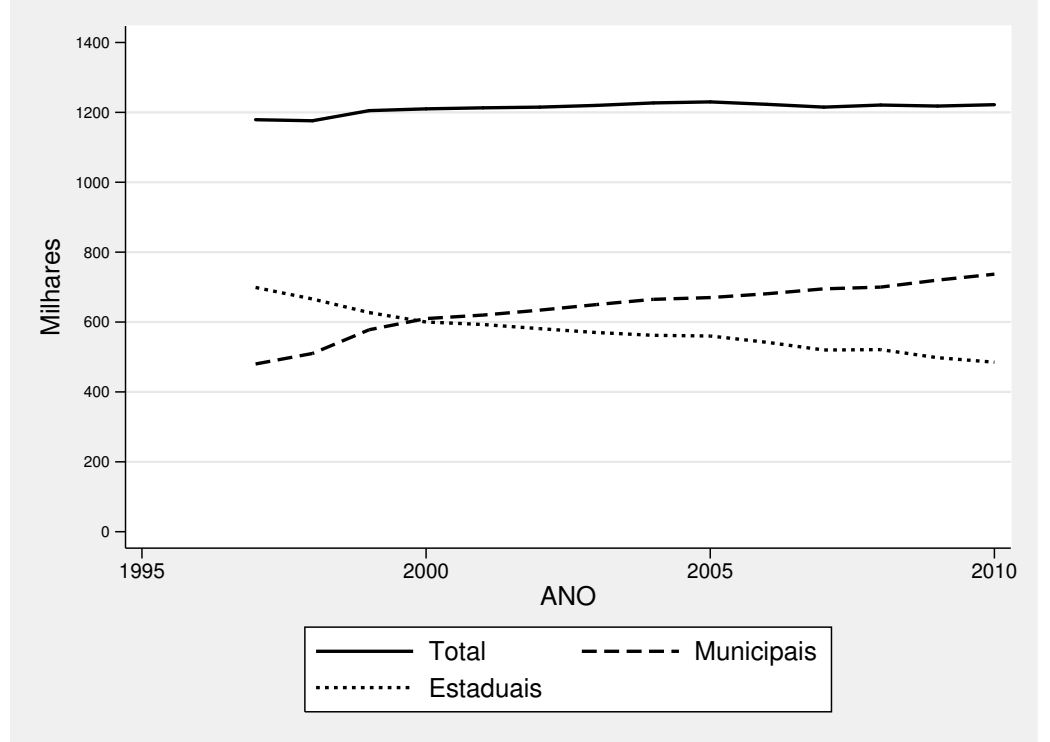

Nas escolas estaduais, por outro lado, esse aumento não se repete. Pelo contrário, havia, em 1997, pouco menos de 600 mil turmas de ensino fundamental nas escolas estaduais. Em 2007, esse total cai para pouco menos de 400 mil turmas. Ou seja, houve uma redução no total de turmas do ensino fundamental de aproximadamente 30 por cento nas escolas estaduais.

Finalmente, cabe destacar que esse expressivo aumento do número de turmas por 
estabelecimento de ensino que se observa para as escolas municipais não ocasiona um aumento do número médio de alunos por turma. O número médio de alunos por turma para as escolas municipais era de pouco mais de 26 alunos/turma, em 1997. Esse número se mantém praticamente estável. Em 2007, encontra-se em pouco mais de 24 alunos/turma. 


\section{Dados e Métodos}

Os dados utilizados nessa pesquisa provêm do Sistema Nacional de Avaliação da Educação Básica (SAEB), da Prova Brasil e do Censo Escolar da Educação Básica. Na presente seção do trabalho, são apresentadas as fontes de dados, que são utilizadas em todos os três exercícios de estimação do efeito da municipalização descritos neste capítulo. Como discutido anteriormente, a estratégia empírica proposta neste estudo baseia-se na decomposição de efeito da municipalização sobre: $(i)$ a diferença de desempenho dos alunos de escolas municipais e estaduais nos exames de avaliação do SAEB, (ii) a proficiência média das escolas que tiveram seu controle transferido dos estados para os municípios; e, finalmente, (iii) sobre os indicadores de insumos escolares e rendimento do fluxo escolar dos municípios.

Nas seções seguintes deste capítulo, após apresentar as fontes de dados e algumas estatísticas descritivas, são apresentadas mais detalhadamente cada uma das análises empíricas propostas. Os resultados dessas análises são apresentados separadamente, no sexto quinto do trabalho.

\subsection{O SAEB}

O Sistema Nacional de Avaliação da Educação Básica (SAEB) foi criado pelo INEP em 1988. Em 1990, foi aplicada a primeira avaliação a uma amostra de escolas representativas, para cada unidade da federação, das redes pública e privada. A avaliação foi repetida em 1993, e, desde então, o SAEB tornou-se um exame bienal de proficiência, em Matemática (com ênfase em resolução de problemas) e em Língua Portuguesa 
(com ênfase em leitura), aplicado em amostras de alunos de 4a e 8a séries do ensino fundamental e da 3a série do ensino médio.

Desde 1995, a técnica de mensuração do desempenho dos alunos utilizada no SAEB baseia-se na Teoria de Resposta ao Item (TRI). Uma das grandes vantagens da TRI sobre a Teoria Clássica das Medidas é que a TRI possibilita comparações de desempenho entre populações submetidas a provas que tenham alguns itens em comum, ou, ainda, entre indivíduos da mesma população que tenham sido submetidos a provas diferentes. Ou seja, os resultados obtidos a partir da TRI são independentes de grupos e não são afetados pela dificuldade dos testes. A comparabilidade dos resultados é garantida pela inclusão de itens comuns nos instrumentos de avaliação. A utilização de itens comuns às avaliações de edições anteriores é denominada de "equalização de grupos não equivalentes com itens comuns". Faz-se uso de matrizes de referência para a construção dos instrumentos de avaliação. Essas matrizes funcionam como orientação para a seleção dos itens que compõem os instrumentos de avaliação. Dessa maneira, é possível comparar o desempenho dos alunos ou das escolas brasileiras ao longo dos anos entre 1995 e 2005 e tentar diagnosticar quais os fatores relevantes à qualidade da educação (INEP, 2008).

Também a partir do SAEB de 1995, os teste são compostos de um total de 169 itens de múltipla escolha para cada uma das séries e das disciplinas avaliadas. Esses itens são divididos em 13 blocos de 13 itens cada, organizados em grupos de três diferentes combinações. Isto é, combinados três a três. Cada combinação resulta em um caderno de prova. Ao final do processo combinatório, têm-se, portanto, um total de 26 cadernos de provas diferentes. A composição dos cadernos de provas do SAEB 
baseia-se no modelo de "Blocos Incompletos Balanceados", ou Balanced Incomplete Block, no original em inglês. Procura-se, por meio dessa metodologia, compor blocos e cadernos de provas com dificuldades semelhantes e, mais importante, variabilidade e ordenamento dos itens em função da sua dificuldade (INEP, 2008).

As figuras 6 e 7 apresentam a evolução das proficiências médias em Língua Portuguesa e Matemática no SAEB entre os anos de 1995 e 2005. Nas figuras é possível observar a trajetória descendente dos resultados ao longo do período. Os resultados demonstram uma queda na média obtida nos exames padronizados de Matemática e Língua Portuguesa. Seja na 4a ou 8a série do ensino fundamental, seja na 3a série do ensino médio.

Figura 6: Proficiências médias em Língua Portuguesa nos exames do SAEB (1995-2005)

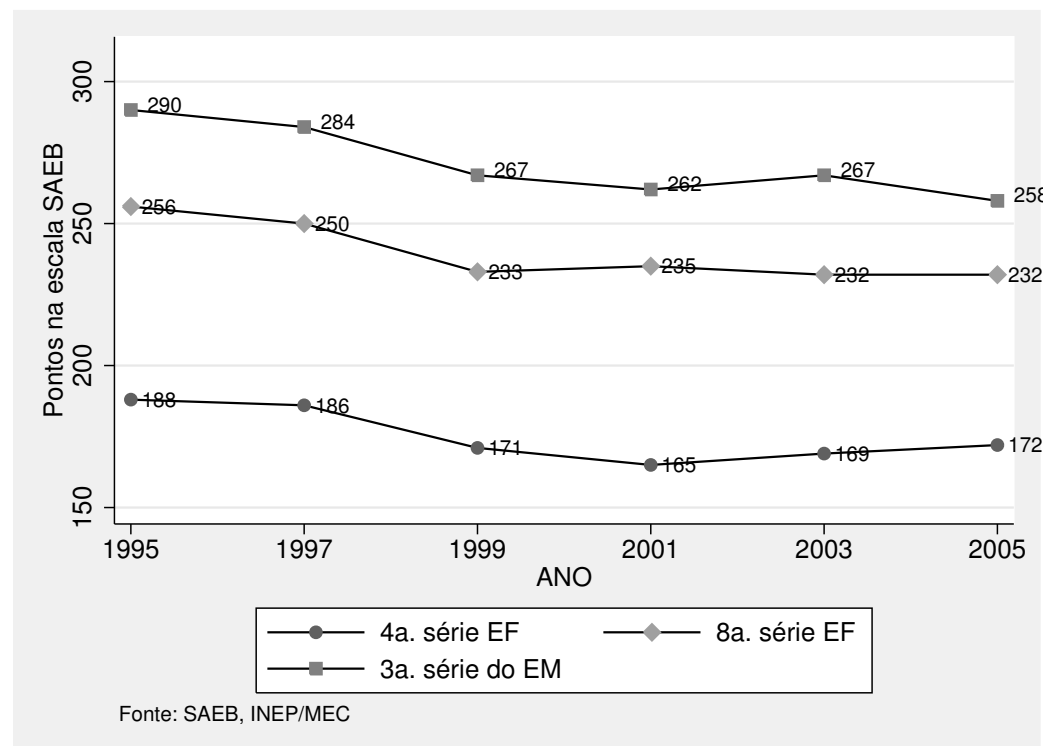

Adicionalmente aos testes padronizados de conhecimento específico, o SAEB também aplica questionários socioeconômicos. Estes questionários são respondidos por alunos, 
Figura 7: Proficiências médias em Matemática nos exames do

SAEB (1995-2005)

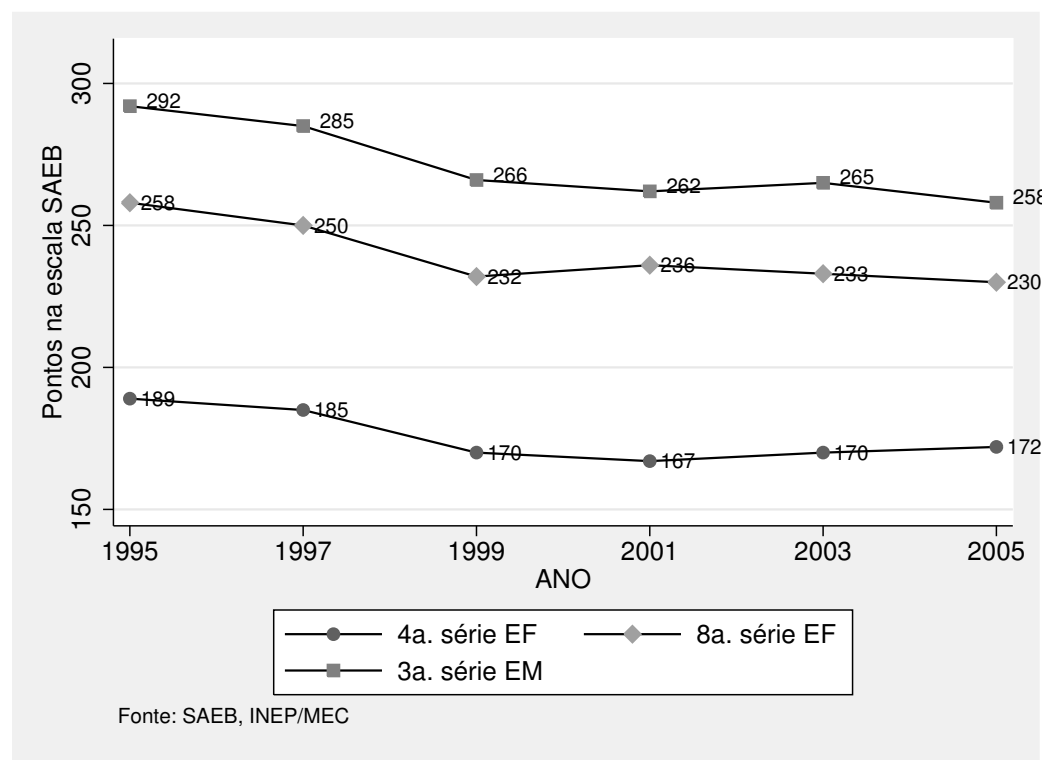

professores e diretores das escolas que compõem à amostra, possibilitando o conhecimento de informações mais amplas sobre o sistema educacional, as condições das escolas brasileiras e das famílias dos estudantes.

Os microdados do SAEB estão disponíveis para os anos de 1995 até 2005. Estes dados podem ser obtidos diretamente do sítio do INEP na internet. Entretanto, como foi observado por Biondi e Felício (2007), há um subgrupo de escolas que se repete nas amostras. De tal sorte que, é possível compor um painel de dados com esse subgrupo de escolas que aparecem repetidas vezes nas avaliações. A montagem dos dados em painel permite acompanhar a evolução dos testes de proficiência e das condições socioeconômicas extraídas dos questionários respondidos pelos alunos, professores e diretores, para esse subgrupo de escolas que é mantido na amostra do SAEB.

Cabe destacar que, a possibilidade de explorar a metodologia para dados em painel 
assegura maior precisão na investigação dos parâmetros de interesse. As estimativas de variáveis regressoras observáveis, como o caso, por exemplo, da municipalização das escolas, baseadas tão somente em dados de corte temporal (isto é, em cross-section), como é bastante comum em trabalhos acadêmicos a respeito do efeito de insumos de educação no Brasil, não permitem o controle dos efeitos específicos das escolas. Isto é, não permitem o controle de características não observáveis das escolas. A ausência de controles dos efeitos específicos das escolas, por sua vez, pode conduzir a estimativas inconsistentes e enviesadas. Mais especificamente, pode produzir estimativas com problemas de viés de variáveis omitidas, na medida em que as variáveis omitidas (não observadas) estiverem correlacionadas com os demais regressores.

Uma complicação adicional ao se trabalhar com os dados do SAEB em painel é compatibilizar as respostas dos dicionários de alunos, de professores, de diretores, de escolas e de turmas para os diferentes anos sem invalidar ou abrir mão de variáveis que são relevantes. A variável "educação da mãe", por exemplo, aparece categorizada de forma diversa e incompatível entre os diferentes anos. Nesse caso, a solução encontrada foi a recodificação da variável de forma a harmonizar e compatibilizar as respostas entre os diferentes cortes temporais.

O ano de 1997, em particular, apresenta complicações extraordinárias. Pois, não apenas a quase totalidade das variáveis que compõem os questionários de alunos, professores, diretores e escolas estão categorizadas de maneira diversa dos demais cortes temporais, como ainda não há um questionário específico para as turmas. Por conseguinte, para 1997, não foi possível obter variáveis que fossem passíveis de comparação com os demais anos, que detalhassem a quantidade de alunos presentes na sala, a quantidade 
de horas de aula por dia, se a turma ficou sem professor por algum período (mais de um mês) e se a turma teve mais de um professor (de matemática ou de português) durante o período letivo.

Outros trabalhos ${ }^{26}$ que fizeram uso dos dados do SAEB e se valeram das metodologias para dados em painel, usualmente, reportam os resultados para o painel completo (1997-2005), como também para um painel mais curto, que exclui as observações de 1997. Esse painel mais curto (1999-2005) traz a vantagem de uma maior a harmonização nas perguntas que compõem as variáveis, o que possibilita a investigação de um maior número de variáveis. ${ }^{27}$ Ademais, também é maior o número de escolas que se repetem entre os anos de 1999 e 2005, o que garante um melhor balanceamento ao painel. $^{28}$

\subsection{O Censo Escolar}

Um dos diferenciais desta tese é a utilização conjunta dos dados do SAEB e do Censo Escolar de forma a incorporar um conjunto mais completo de informações a respeito das escolas. O Censo Escolar é realizado anualmente pelo INEP em parceria com os governos estaduais e municipais. Sua base de dados contém informações acerca das

\footnotetext{
${ }^{26}$ a esse respeito ver Biondi e Felício, 2007 e Franco e Menezes-Filho, 2009, entre outros estudos que se valem do uso dos dados do SAEB em painel.

${ }^{27}$ Nesse sentido, foram selecionados dois conjuntos de variáveis: (1) aquelas que se repetiam nos questionários entre os anos de 1997 e 2005; e (ii) um conjunto mais amplo de variáveis que se repetiam nos questionários entre os anos de 1999 e 2005.

${ }^{28}$ É importante observar, como será comentado mais detalhadamente adiante, que nenhum dos painéis é realmente balanceado, no entanto o painel mais curto (1999-2005) tem um maior número de escolas que se repetem ao longo dos anos.
} 
escolas, de seus alunos e de seus professores. ${ }^{29}$

Os dados contidos no Censo Escolar possibilitam associar informações acerca da infraestrutura, do tamanho e das condições de oferta do ensino nas escolas às informações socioeconômicas contidas nos questionários do SAEB. Ainda, o Censo Escolar traz informações sobre características das escolas, como insumos de produção e resultados escolares, tais como: taxas de matrícula, repetição, abandono e defasagem idade-série nas escolas, composição do corpo docente segundo a modalidade de ensino, nível de instrução dos professores, número de matrículas por série, por turma e por turno, dentre outras informações. Vale destacar que, para construir um painel de escolas, os dados do SAEB relativos aos alunos e aos docentes (nos casos onde mais de um professor de uma mesma disciplina respondeu ao questionário socioeconômico) podem ser agregados por escola ou, alternativamente, pode-se também apenas utilizar uma série de variáveis do tipo dummy para se identificar as escolas e trabalhar com os dados desagregados dos alunos. Como, por exemplo, no caso da análise empírica conduzida nesta tese a respeito do efeito da rede escolar (se municipal ou estadual) sobre o desempenho dos alunos nos exames de proficiência do SAEB.

\footnotetext{
${ }^{29}$ Os dados do Censo Escolar foram agregados a base de dados por meio dos códigos de máscaras das escolas. Esses códigos, que permitem identificar individualmente as escolas amostradas no SAEB, possibilitam que os dados do SAEB sejam cruzados com as informações do Censo Escolar e da Prova Brasil. Os códigos de máscaras das escolas podem ser solicitados ao MEC/INEP. Os dados são cedidos (exclusivamente para fins de pesquisa acadêmica) mediante à assinatura de um termo de compromisso de confidencialidade dos dados por parte do pesquisador.
} 


\subsection{Variáveis e estatísticas descritivas}

Como já foi mencionado, o SAEB é uma pesquisa de avaliação em larga escala que tem caráter amostral. A maioria das escolas que compõem a amostra de um corte temporal não se repete no corte consecutivo e, consequentemente, uma parcela considerável das escolas avaliadas não se repete em mais do que 2 anos para os quais o SAEB foi realizado. Assim, para fazer uso adequado das técnicas de análise de dados em painel faz-se necessário seccionar os dados em dois subconjuntos:

- Painel "longo": um painel não balanceado de escolas composto por dados do SAEB e do Censo Escolar para os anos 1997, 1999, 2001, 2003 e 2005.

- Painel "curto": um painel não balanceado de escolas composto por dados do SAEB e do Censo Escolar para os anos 1999, 2001, 2003 e 2005.

Desse subconjunto de escolas, foram ainda excluídas as escolas que só apareciam uma única vez durante o período coberto pela análise (1997-2005): as quais somam aproximadamente 41 por cento da amostra total de escolas avaliadas pelo SAEB. Além disso, também foram retiradas as escolas federais, que representavam menos de 0.4 por cento do total de escolas que compõem a amostra do SAEB.

Evidentemente, a opção de restringir a análise a tão-somente um subgrupo de escolas - aquelas que são mantidas nas amostras do SAEB - enseja a questão de quão representativo seria o subgrupo que compõe o painel quando comparado a amostra total de escolas que compõem o SAEB. Nesse sentido, deve-se salientar que a comparação de médias dos testes de proficiência nas disciplinas de Português e Matemática, entre o total das escolas amostradas e as escolas que compõem o painel, indica que as últimas 
representam, de maneira adequada, o total das escolas. Esse equilíbrio concede maior suporte estatístico às análises realizadas no presente trabalho, baseadas na amostra de escolas comuns entre os anos, e possibilita a extensão dos resultados encontrados às demais escolas amostradas no SAEB. Por conseguinte, as inferências obtidas podem ser estendidas ao universo das escolas brasileiras.

Tabela 3: Proficiência SAEB, 4a. série do ensino fundamental Língua Portuguesa

\begin{tabular}{|c|c|c|c|c|c|c|}
\hline & $\begin{array}{c}(1) \\
\text { SAEB } \\
\text { Privadas }\end{array}$ & $\begin{array}{c}(2) \\
\text { SAEB } \\
\text { Estaduais }\end{array}$ & $\begin{array}{c}(3) \\
\text { SAEB } \\
\text { Municipais }\end{array}$ & $\begin{array}{c}\text { (4) } \\
\text { Painel } \\
\text { Privadas }\end{array}$ & $\begin{array}{c}(5) \\
\text { Painel } \\
\text { Estaduais }\end{array}$ & $\begin{array}{c}(6) \\
\text { Painel } \\
\text { Municipais }\end{array}$ \\
\hline 1997 & 215,33 & 174,68 & 170,58 & 217,64 & 173,71 & 168,92 \\
\hline 1999 & 205,90 & 161,62 & 157,34 & 208,17 & 161,82 & 158,70 \\
\hline 2001 & 204,72 & 159,35 & 153,25 & 206,79 & 159,06 & 152,50 \\
\hline 2003 & 212,72 & 166,38 & 162,96 & 212,93 & 165,42 & 161,17 \\
\hline 2005 & 209,74 & 167,09 & 162,85 & 211,14 & 168,27 & 163,54 \\
\hline$N$ & 45.568 & 50.785 & 56.662 & 29.787 & 32.381 & 34.546 \\
\hline \multicolumn{7}{|c|}{$\begin{array}{l}\text { Fonte: Calculos próprios a partir de dados do SAEB/INEP } \\
\text { Tabela 4: Proficiência SAEB, 4a. série do ensino fundamental } \\
\text { Matemática }\end{array}$} \\
\hline & $\begin{array}{c}(1) \\
\text { SAEB } \\
\text { Privadas }\end{array}$ & $\begin{array}{c}(2) \\
\text { SAEB } \\
\text { Estaduais }\end{array}$ & $\begin{array}{c}(3) \\
\text { SAEB } \\
\text { Municipais }\end{array}$ & $\begin{array}{c}\text { (4) } \\
\text { Painel } \\
\text { Privadas }\end{array}$ & $\begin{array}{c}(5) \\
\text { Painel } \\
\text { Estaduais }\end{array}$ & $\begin{array}{c}(6) \\
\text { Painel } \\
\text { Municipais }\end{array}$ \\
\hline 1997 & 221,51 & 178,35 & 173,88 & 224,71 & 176,60 & 171,86 \\
\hline 1999 & 214,78 & 172,67 & 169,61 & 216,89 & 173,07 & 170,95 \\
\hline 2001 & 217,74 & 169,53 & 163,89 & 220,31 & 169,57 & 163,33 \\
\hline 2003 & 221,25 & 173,75 & 169,38 & 221,85 & 167,49 & 167,49 \\
\hline 2005 & 222,86 & 176,37 & 171,19 & 225,26 & 177,30 & 172,06 \\
\hline$N$ & 45.568 & 50.785 & 56.662 & 29.787 & 32.381 & 34.546 \\
\hline
\end{tabular}

As Tabelas 3 e 4 abaixo trazem a comparação de médias nos testes de proficiência em Língua Portuguesa e Matemática entre o total de escolas amostradas no SAEB 
e o subgrupo de escolas repetidas entre os anos 1997 e 2005 incluídas no painel de dados.

A Tabela 5 abaixo apresenta o número de escolas segundo a frequência nos anos e segundo o ano que foram mantidas na subamostra de escolas que compõem os paines utilizados na presente investigação.

Tabela 5: Número de alunos e de escolas por ano e por frequência em que aparecem nas avaliações do SAEB (1997-2005)

\begin{tabular}{lcccccc}
\hline & Total de & Total de & \multicolumn{5}{c}{ Frequência de Escolas nas Avaliações } \\
& Alunos & Escolas & 2 anos & 3 anos & 4 anos & 5 anos \\
\hline 1997 & 9.407 & 361 & 184 & 116 & 51 & 10 \\
1999 & 7.906 & 1.216 & 705 & 394 & 107 & 10 \\
2001 & 27.583 & 1.798 & 1.140 & 528 & 120 & 10 \\
2003 & 17.233 & 1.162 & 647 & 398 & 107 & 10 \\
2005 & 21.089 & 1.333 & 776 & 436 & 111 & 10 \\
\hline Total & 83.218 & 5.875 & 3.462 & 1.987 & 591 & 50 \\
\hline
\end{tabular}

As seguintes tabelas foram elaboradas a partir da amostra total do SAEB e do painel de escolas que se repetem nas amostras do SAEB entre os anos 1997 e 2005. Nestas tabelas é possível cotejar as características de alunos, professores, diretores, turmas e escolas que compõem a amostra total do SAEB ao subgrupo de escolas que fazem parte do painel. As estatísticas descritivas, tanto para amostra total do SAEB como também para o subgrupo de escolas que compõem o painel, estão discriminadas segundo a rede escolar, se privadas ou pública, e segundo a dependência administrativa, se pública municipal ou pública estadual. 
As estatísticas descritivas referentes às características dos alunos da 4a. série do ensino fundamental que foram avaliados em Português entres os anos 1997 e 2005 são apresentadas na Tabela 6 abaixo.

Tabela 6: Variáveis dos alunos da 4a. série do ensino fundamental Língua Portuguesa

\begin{tabular}{|c|c|c|c|c|c|c|}
\hline & $\begin{array}{c}(1) \\
\text { SAEB } \\
\text { Privadas }\end{array}$ & $\begin{array}{c}(2) \\
\text { SAEB } \\
\text { Estaduais }\end{array}$ & $\begin{array}{c}(3) \\
\text { SAEB } \\
\text { Municipais }\end{array}$ & $\begin{array}{c}(4) \\
\text { Painel } \\
\text { Privadas }\end{array}$ & $\begin{array}{c}(5) \\
\text { Painel } \\
\text { Estaduais }\end{array}$ & $\begin{array}{c}(6) \\
\text { Painel } \\
\text { Municipais }\end{array}$ \\
\hline Homens & $50,6 \%$ & $50,1 \%$ & $50,3 \%$ & $50,6 \%$ & $49,9 \%$ & $50,1 \%$ \\
\hline Idade: 9 anos & $12,7 \%$ & $7,1 \%$ & $6,0 \%$ & $12,6 \%$ & $7,1 \%$ & $6,1 \%$ \\
\hline Idade: 10 anos & $63,9 \%$ & $40,1 \%$ & $35,3 \%$ & $64,2 \%$ & $40,3 \%$ & $36,0 \%$ \\
\hline Idade: 11 anos & $17,8 \%$ & $23,9 \%$ & $24,9 \%$ & $17,5 \%$ & $23,8 \%$ & $25,1 \%$ \\
\hline Idade: 12 anos ou + & $5,0 \%$ & $28,0 \%$ & $32,9 \%$ & $4,5 \%$ & $27,8 \%$ & $31,8 \%$ \\
\hline Branco & $50,6 \%$ & $36,8 \%$ & $35,9 \%$ & $50,9 \%$ & $36,7 \%$ & $36,0 \%$ \\
\hline Pardo & $35,7 \%$ & $42,2 \%$ & $41,7 \%$ & $35,7 \%$ & $42,3 \%$ & $41,7 \%$ \\
\hline Negro & $4,7 \%$ & $12,4 \%$ & $13,7 \%$ & $4,3 \%$ & $12,3 \%$ & $13,6 \%$ \\
\hline Amarelo ou Indigena & $7,9 \%$ & $6,9 \%$ & $7,0 \%$ & $8,0 \%$ & $6,9 \%$ & $6,9 \%$ \\
\hline Mãe (nunca estudou) & $0,08 \%$ & $6,2 \%$ & $8,6 \%$ & $0,07 \%$ & $6,1 \%$ & $8,5 \%$ \\
\hline Mãe (1-4 EF) & $5,4 \%$ & $23,8 \%$ & $28,7 \%$ & $4,9 \%$ & $23,5 \%$ & $28,5 \%$ \\
\hline Mãe (5-8 EF) & $8,9 \%$ & $19,4 \%$ & $18,1 \%$ & $8,3 \%$ & $19,3 \%$ & $18,2 \%$ \\
\hline Mãe (EM) & $17,1 \%$ & $12,9 \%$ & $10,4 \%$ & $16,6 \%$ & $13,1 \%$ & $10,6 \%$ \\
\hline Mãe (superior) & $39,8 \%$ & $9,2 \%$ & $6,7 \%$ & $41,6 \%$ & $9,6 \%$ & $7,1 \%$ \\
\hline Mãe (não sabe) & $40,6 \%$ & $39,2 \%$ & $36,6 \%$ & $40,6 \%$ & $38,3 \%$ & $35,5 \%$ \\
\hline Trabalha fora & $6,1 \%$ & $16,1 \%$ & $20,8 \%$ & $5,6 \%$ & $15,9 \%$ & $20,2 \%$ \\
\hline Mora c/ pai e mãe & $73,1 \%$ & $63,5 \%$ & $65,9 \%$ & $73,5 \%$ & $63,6 \%$ & $65,4 \%$ \\
\hline Tem computador & $49,9 \%$ & $10,5 \%$ & $7,8 \%$ & $52,3 \%$ & $10,8 \%$ & $7,9 \%$ \\
\hline$N$ & 45.568 & 50.785 & 56.662 & 29.787 & 32.381 & 34.546 \\
\hline
\end{tabular}

Fonte: Calculos próprios a partir de dados do SAEB/INEP

Notas: Para o ano de 2005 trata-se de computador com Internet

Algumas estatísticas descritivas referentes às características dos professores são apresentadas na tabela 7 .

Algumas estatísticas descritivas referentes às características dos diretores são apresentadas na tabela 8. 
Tabela 7: Variáveis dos Professores da 4a. série do ensino fundamental

\begin{tabular}{lcccccc}
\hline & $\begin{array}{c}(1) \\
\text { SAEB } \\
\text { Privadas }\end{array}$ & $\begin{array}{c}(2) \\
\text { SAEB } \\
\text { Estaduais }\end{array}$ & $\begin{array}{c}(3) \\
\text { SAEB } \\
\text { Municipais }\end{array}$ & $\begin{array}{c}(4) \\
\text { Painel } \\
\text { Privadas }\end{array}$ & $\begin{array}{c}(5) \\
\text { Painel } \\
\text { Estaduais }\end{array}$ & $\begin{array}{c}\text { Painel } \\
\text { Municipais }\end{array}$ \\
\hline Homens & $4,68 \%$ & $5,01 \%$ & $10,3 \%$ & $9,61 \%$ & $9,91 \%$ & $10,1 \%$ \\
até 30 anos(a) & $27,4 \%$ & $26,8 \%$ & $21,7 \%$ & $19,9 \%$ & $22,1 \%$ & $23,0 \%$ \\
de 30 a 40 anos(b) & $39,1 \%$ & $41,2 \%$ & $34,7 \%$ & $35,7 \%$ & $32,3 \%$ & $34,6 \%$ \\
40 anos ou mais(c) & $29,8 \%$ & $30,9 \%$ & $39,7 \%$ & $38,3 \%$ & $32,3 \%$ & $33,6 \%$ \\
Curso superior & $61,8 \%$ & $66,2 \%$ & $41,6 \%$ & $43,0 \%$ & $46,1 \%$ & $45,5 \%$ \\
Capacitação(d) & $82,4 \%$ & $82,7 \%$ & $78,7 \%$ & $74,2 \%$ & $73,5 \%$ & $68,3 \%$ \\
Leciona - 15 anos(e) & $68,9 \%$ & $69,4 \%$ & $48,1 \%$ & $48,3 \%$ & $49,3 \%$ & $48,2 \%$ \\
Leciona + 15 anos(f) & $37,1 \%$ & $39,9 \%$ & $40,4 \%$ & $39,6 \%$ & $43,1 \%$ & $41,6 \%$ \\
\hline \hline
\end{tabular}

Fonte: Calculos próprios a partir de dados do SAEB/INEP

Notas: (a) 1997 a 1999 incluem 30 anos
(b)1997 a 1999 incluem 40 anos
(c) 1997 e 1999 a partir dos 41 anos
(d) 1997 no próprio ano
(e) 2001 há até 14 anos
(f) 2001 há mais 14 anos

Tabela 8: Variáveis dos Diretores

\begin{tabular}{|c|c|c|c|c|c|c|}
\hline & $\begin{array}{c}(1) \\
\text { SAEB } \\
\text { Privadas }\end{array}$ & $\begin{array}{c}(2) \\
\text { SAEB } \\
\text { Estaduais }\end{array}$ & $\begin{array}{c}(3) \\
\text { SAEB } \\
\text { Municipais }\end{array}$ & $\begin{array}{c}(4) \\
\text { Painel } \\
\text { Privadas }\end{array}$ & $\begin{array}{c}(5) \\
\text { Painel } \\
\text { Estaduais }\end{array}$ & $\begin{array}{c}(6) \\
\text { Painel } \\
\text { Municipais }\end{array}$ \\
\hline Exp. - 5 anos & $21,4 \%$ & $20,9 \%$ & $53,1 \%$ & $54,3 \%$ & $49,4 \%$ & $50,1 \%$ \\
\hline Exp de 5 a 10 anos & $26,6 \%$ & $25,2 \%$ & $31,3 \%$ & $32,3 \%$ & $28,3 \%$ & $29,4 \%$ \\
\hline Exp. +10 anos & $50,1 \%$ & $52,3 \%$ & $14,5 \%$ & $13,8 \%$ & $16,6 \%$ & $15,7 \%$ \\
\hline Na escola - 5 anos & $35,5 \%$ & $36,7 \%$ & $68,5 \%$ & $67,3 \%$ & $65,3 \%$ & $64,9 \%$ \\
\hline Na escola 5-10 anos & $25,9 \%$ & $27,2 \%$ & $23,6 \%$ & $22,1 \%$ & $21,9,4 \%$ & $23,2 \%$ \\
\hline $\mathrm{Na}$ escola +10 anos & $34,4 \%$ & $34,2 \%$ & $6,78 \%$ & $7,31 \%$ & $8,81 \%$ & $9,13 \%$ \\
\hline Eleição & $61,3 \%$ & $63,2 \%$ & $49,8 \%$ & $51,3 \%$ & $56,7 \%$ & $58,1 \%$ \\
\hline Indicação & $22,3 \%$ & $23,7 \%$ & $51,4 \%$ & $49,7 \%$ & $44,1 \%$ & $42,3 \%$ \\
\hline Proj. Pedagógico (não) & $3,61 \%$ & $2,93 \%$ & $14,3 \%$ & $13,7 \%$ & $11,2 \%$ & $10,5 \%$ \\
\hline Proj. Pedagógico (sec.) & $9,61 \%$ & $8,52 \%$ & $19,7 \%$ & $21,4 \%$ & $17,2 \%$ & $18,3 \%$ \\
\hline Proj. Pedagógico (dir+prof) & $82,2 \%$ & $83,3 \%$ & $59,3 \%$ & $58,9 \%$ & $63,2 \%$ & $65,5 \%$ \\
\hline Rotatividade & $11,1 \%$ & $10,2 \%$ & $28,8 \%$ & $28,3 \%$ & $25,5 \%$ & $24,9 \%$ \\
\hline Prof. faltosos & $6,61 \%$ & $6,43 \%$ & $22,7 \%$ & $23,1 \%$ & $19,9 \%$ & $20,1 \%$ \\
\hline
\end{tabular}

Fonte: Cálculos próprios a partir de dados do SAEB/INEP 
Algumas estatísticas descritivas referentes às características das turmas são apresentadas na tabela 9 .

Tabela 9: Variáveis das Turmas

\begin{tabular}{lcccccc}
\hline & $\begin{array}{c}(1) \\
\text { SAEB } \\
\text { Privadas }\end{array}$ & $\begin{array}{c}(2) \\
\text { SAEB } \\
\text { Estaduais }\end{array}$ & $\begin{array}{c}(3) \\
\text { SAEB } \\
\text { Municipais }\end{array}$ & $\begin{array}{c}(4) \\
\text { Painel } \\
\text { Privadas }\end{array}$ & $\begin{array}{c}\text { Painel } \\
\text { Estaduais }\end{array}$ & $\begin{array}{c}\text { Painel } \\
\text { Municipais }\end{array}$ \\
\hline Sem prof de mat. & $3,78 \%$ & $3,92 \%$ & $6,1 \%$ & $5,9 \%$ & $4,35 \%$ & $4,64 \%$ \\
Apenas 1 prof mat & $88,3 \%$ & $89,2 \%$ & $74,3 \%$ & $75,5 \%$ & $78,3 \%$ & $76,4 \%$ \\
2 ou + prof mat & $7,35 \%$ & $8,72 \%$ & $16,5 \%$ & $17,8 \%$ & $15,2 \%$ & $14,7 \%$ \\
Sem prof port & $3,8 \%$ & $3,9 \%$ & $6,6 \%$ & $7,4 \%$ & $5,3 \%$ & $4,9 \%$ \\
Apenas 1 prof port & $85,2 \%$ & $87,2 \%$ & $73,6 \%$ & $78,0 \%$ & $78,4 \%$ & $77,6 \%$ \\
2 ou mais prof port & $6,4 \%$ & $6,7 \%$ & $15,7 \%$ & $14,3 \%$ & $13,7 \%$ & $12,8 \%$ \\
Até 4 horas/dia & $39,6 \%$ & $36,3 \%$ & $56,2 \%$ & $58,4 \%$ & $47,5 \%$ & $48,9 \%$ \\
De 4 a 5 horas/dia & $64,2 \%$ & $69,5 \%$ & $39,4 \%$ & $39,7 \%$ & $37,1 \%$ & $38,3 \%$ \\
+ de 5 horas/dia & $2,2 \%$ & $2,3 \%$ & $4,3 \%$ & $3,5 \%$ & $4,3 \%$ & $4,7 \%$ \\
No. médio de alunos & 25,8 & 27,5 & 32,8 & 34,1 & 30,6 & 31,7 \\
\hline \hline
\end{tabular}

Fonte: Cálculos próprios a partir de dados do SAEB/INEP

Notas: Não há questionário para turmas no SAEB 1997

Algumas estatísticas descritivas referentes às características das escolas são apresentadas na tabela 10 .

Tabela 10: Variáveis das Escolas

\begin{tabular}{lcccccc}
\hline & $\begin{array}{c}(1) \\
\text { SAEB } \\
\text { Privadas }\end{array}$ & $\begin{array}{c}(2) \\
\text { SAEB } \\
\text { Estaduais }\end{array}$ & $\begin{array}{c}(3) \\
\text { SAEB } \\
\text { Municipais }\end{array}$ & $\begin{array}{c}(4) \\
\text { Painel } \\
\text { Privadas }\end{array}$ & $\begin{array}{c}(5) \\
\text { Painel } \\
\text { Estaduais }\end{array}$ & $\begin{array}{c}(6) \\
\text { Painel } \\
\text { Municipais }\end{array}$ \\
\hline Rural & $1,07 \%$ & $0,91 \%$ & $26,1 \%$ & $27,1 \%$ & $16,2 \%$ & $13,7 \%$ \\
Biblioteca & $86,2 \%$ & $91,3 \%$ & $51,5 \%$ & $56,2 \%$ & $58,8 \%$ & $59,1 \%$ \\
Lab. informática & $70,1 \%$ & $76,3 \%$ & $14,2 \%$ & $13,5 \%$ & $17,8 \%$ & $20,3 \%$ \\
Lab. ciências & $56,3 \%$ & $52,1 \%$ & $9,50 \%$ & $8,37 \%$ & $15,3 \%$ & $14,9 \%$ \\
Qd. esportes & $75,6 \%$ & $87,1 \%$ & $43,1 \%$ & $42,0 \%$ & $51,9 \%$ & $48,9 \%$ \\
Merenda & $9,41 \%$ & $8,65 \%$ & $96,45 \%$ & $98,1 \%$ & $98,3 \%$ & $96,3 \%$ \\
Transporte & $6,32 \%$ & $6,27 \%$ & $64,8 \%$ & $67,9 \%$ & $41,7 \%$ & $40,3 \%$ \\
\hline$N$ & 1.029 & 3.764 & 2.036 & 843 & 1565 & 968 \\
\hline
\end{tabular}

Fonte: Cálculos próprios a partir de dados do SAEB/INEP 
O ponto fundamental que se gostaria de destacar da leitura das tabelas $4,5,6$ e 7 , é que a comparação entre as colunas 1, 2 e 3 das referidas tabelas, que trazem as estatísticas descritivas da amostra total do SAEB, às colunas 4, 5 e 6, que trazem as estatísticas descritivas para o subgrupo de escolas que compõem o painel, demonstra que não há problemas aparentes de seleção nos bancos de dados desenvolvidos no presente estudo.

\subsection{Metodologia}

A pergunta básica que o presente estudo pretende responder é: o nível de governo importa para a qualidade da política pública? No caso específico da análise da municipalização da educação fundamental no Brasil, essa pergunta pode ser reformulada nas seguintes palavras: O nível de governo importa para a qualidade da política educacional oferecida à população? Como já comentado no primeiro capítulo, a descentralização pode ser apontada como uma das principais políticas governamentais para o ensino fundamental implementadas no Brasil nos últimos anos. Entretanto, existe ainda muita controvérsia a respeito dos efeitos da municipalização sobre a qualidade do ensino público oferecido no Brasil.

Para responder essa pergunta básica, a estratégia empírica adotada no presente estudo consiste em examinar o diferencial de desempenho entre as redes públicas de ensino. Mais importante, busca-se examinar o efeito da municipalização das matrículas e gastos em educação sobre:

- o desempenho escolar do alunos das redes públicas municipais e estaduais; 
- o desempenho das escolas que foram transferidas dos estados para os municípios;

- e, finalmente, sobre o desempenho das redes escolares.

Esta escolha deriva do pressuposto de que os efeitos da municipalização podem se fazer sentir de forma diversa sobre os alunos, as escolas e os municípios. Por conseguinte, a pergunta inicial acerca efeito da municipalização sobre a qualidade da educação é desdobrada em perguntas específicas acerca:

- do efeito da municipalização sobre os alunos, tais como: existe alguma diferença na proficiência dos alunos de escolas públicas municipais e escolas públicas estaduais? Qual a magnitude dessa diferença? Essa diferença pode ser atribuída a disparidades nos recursos familiares do alunado, ou deve-se a disparidades nos insumos escolares?

- do efeito da municipalização sobre as escolas, tais como: a municipalização das escolas tem algum impacto sobre a proficiência média de seus alunos? Qual a diferença na proficiência média das escolas que foram transferidas do estado para o município vis-à-vis as escolas que permaneceram sobre controle estatal ou municipal?

- do efeito da municipalização sobre as redes municipais de ensino público: qual o efeito da expansão das matriculas municipais sobre os insumos escolares e as taxas de rendimento do fluxo escolar das coortes nos municípios brasileiros?

Idealmente, para se responder a tais perguntas poder-se-ia comparar os mesmos alunos e escolas em duas situações distintas: primeiramente, sob a gestão estadual e, posteriormente, sob a gestão municipal, mantendo-se tudo o mais constante. Isto é, num 
desenho "experimental" de pesquisa buscar-se-ia comparar a situação dos mesmos alunos, escolas e municípios antes e depois da descentralização, mantendo-se constantes ao longo do tempo todas as demais variáveis que podem afetar os resultados educacionais. Nesse exercício hipotético, poder-se-ia simplesmente comparar a situação pré-tratamento - antes da descentralização - com o situação pós-tratamento - depois da descentralização - para se verificar como se comportariam os alunos, as escolas e os indicadores educacionais dos municípios sob o controle municipal e sob o controle estadual. Como foi observado por Leme, Paredes e Souza (2009), a diferença entre essas duas situações é o que se denomina de efeito da municipalização.

Evidentemente, esse é tão somente um exercício hipotético. Na prática, não se pode observar essas duas situações ao mesmo tempo. Isto é, na realidade não se pode comparar ao mesmo tempo uma situação observada, como, por exemplo, o desempenho acadêmico dos alunos numa escola sob controle municipal, com seu contrafactual, o desempenho dos mesmos alunos na (mesma) escola sob controle estadual.

Portanto, um dos desafios não triviais do presente estudo, como, aliás, de todas as pesquisas de avaliação de impacto de políticas públicas (educacionais ou não), é na ausência de dados experimentais ser justamente capaz de construir esse "contrafactual" a partir de dados observados de diferentes alunos e escolas ao longo do tempo.

As bases de dados em painel do SAEB e do Censo Escolar, afortunadamente, possibilitam a construção de um "contrafactual estatístico", que seguramente não assevera a existência de relações causais robustas como aquelas erigidas por meio do emprego de dados experimentais; mas, por certo, é capaz de fornecer evidências sólidas acerca da prevalência e da magnitude do efeito da municipalização, seja por meio emprego de 
variáveis de controle para as características observáveis dos alunos e das escolas, seja por meio do controle dos efeitos específicos das variáveis não observadas das escolas ou dos municípios.

Vale observar, no entanto, que o presente estudo não se encontra totalmente desprovido de problemas decorrentes da utilização de dados observados como subsídio empírico para o estabelecimento de proposições e inferências causais. Como se comentará adiante, é razoável admitir que há características não observáveis dos alunos ou das escolas que também influenciam o aprendizado e, por conseguinte, os resultados educacionais e que podem estar correlacionadas com a descentralização cujo efeito se pretende captar. Particularmente, o terceiro exercício de estimação do efeito da municipalização no municípios é possivelmente acometido por problemas decorrentes da utilização de regressores endógenos.

A seguir são detalhados os procedimentos metodológicos dos três exercícios de estimação do efeito da municipalização das matrículas e dos gastos educacionais sobre: os alunos, as escolas e os municípios, respectivamente.

\subsubsection{O desempenho escolar dos alunos: o nível de governo importa?}

Uma primeira pergunta diz respeito a diferença na proficiência dos alunos matriculados nas redes públicas estaduais e municipais. Há, de fato, um diferencial de desempenho entre os alunos das redes estaduais e municipais? Secundariamente, também se procura investigar se a diferença de desempenho entre alunos de escolas públicas estaduais e escolas públicas municipais pode ser atribuída a diferenças nos recursos familiares, ou a diferenças nos insumos escolares, ou ainda a diferenças em outras características 
observáveis dos professores, diretores e turmas.

A estratégia empírica utilizada nesta análise consiste em tirar proveito dos dados em painel, que permitem o controle dos efeitos específicos não observáveis das escolas. Pretende-se com esse exercício simplesmente observar se há, de fato, uma diferença estatisticamente significante na proficiência em língua portuguesa e matemática dos alunos de 4a. série matriculados em escolas das redes estaduais e municipais. Está consolidado na literatura sobre o tema (Glewe e Kremer, 2006 e Hanushek, 1995) que, as características socioeconômicas dos alunos estão altamente correlacionadas com o desempenho acadêmico. Portanto, estas características, juntamente com outras características observáveis dos professores, do diretores, das turmas e da escola são incluídos nas análises estatísticas como variáveis de controle.

As técnicas de análise de dados em painel de Mínimos Quadrados Ordinários agrupados (MQA), Efeitos Fixos (EF) e Efeitos Aleatórios (EA) foram empregadas neste exercício para se estimar a equação 1 abaixo, que modela o desempenho dos alunos de 4 a. série do ensino fundamental nas provas de Matemática e Língua Portuguesa do SAEB:

$$
Y_{i j r}^{t}=\alpha_{0}+\beta_{1} E S T_{i j}^{t}+\beta_{2} A_{i j r}^{t}+\beta_{3} P_{i j r}^{t}+\beta_{4} D_{i j r}^{t}+\beta_{5} T_{i j r}^{t}+\beta_{6} E_{i j r}^{t}+\theta_{i}+\epsilon_{i k r}^{t}
$$

Onde:

- $Y_{i j r}^{t}$ é a proficiência do aluno $i$, na escola $j$, da rede $r$, no tempo $t$

- $\alpha_{0}$ é uma constante 
- $E S T_{i j r}^{t}$ é uma variável do tipo dummy que indica se a escola $j$, do aluno $i$, no tempo $t$ está sob controle do estado

- $A_{i j r}^{t}$ é o vetor de características do aluno $i$, na escola $j$, da rede $r$, no tempo $t$

- $P_{i j r}^{t}$ é o vetor de características do professor do aluno $i$, na escola $j$, da rede $r$, no tempo $t$

- $D_{i j r}^{t}$ é o vetor de características do diretor do aluno $i$, na escola $j$, da rede $r$, no tempo $t$

- $T_{i j r}^{t}$ é o vetor de características da turma do aluno $i$, na escola $j$, da rede $r$, no tempo $t$

- $E_{i j r}^{t}$ é o vetor de características de infraestrututa da escola do aluno $i$, na escola $j$, da rede $r$, no tempo $t$

- $\theta_{i}$ é o efeito específico não observado da escola

- $\epsilon_{i j r}^{t}$ é o termo de erro aleatório

O parâmetro de interesse aqui é dado por $\beta_{1}$, o qual indica a diferença de desempenho acadêmico entre os alunos matriculados nas escolas estaduais e municipais. O vetor de parâmetros de controles $\beta^{\prime}$, tal que $\beta^{\prime}=\left(\beta_{2}^{\prime} \beta_{3}^{\prime} \beta_{4}^{\prime} \beta_{5}^{\prime} \beta_{6}^{\prime}\right)$, reporta as relações condicionais dos insumos escolares sobre o desempenho dos alunos. A equação 1 é a função de produção da educação, tal como conhecida na literatura (Hanushek, 1996).

Após se verificar se existe mesmo diferença entre as proficiências médias de estudantes da redes públicas estaduais e municipais, busca-se, então examinar se essa diferença 
de desempenho pode ser atribuída a disparidades nos fatores que podem afetar o rendimento acadêmico dos alunos. Isto é, procura-se investigar se a diferença de rendimento escolar deve-se à um problema de seleção dos alunos entre as redes ou, pelo contrário, deve-se a desigualdades nos insumos escolares das redes públicas estaduais e municipais.

Para tanto, se ajustou um modelo de regressão probabilística, dado pela equação 2 , que busca captar a correlação entre os atributos observáveis dos alunos, do ambiente familiar, das escolas, dos professores e diretores e a probabilidade de estarem vinculados às redes públicas municipais.

$$
M U N I_{j}^{t}=\alpha_{0}+\beta_{1} A_{i j r}^{t}+\beta_{2} P_{i j r}^{t}+\beta_{3} D_{i j r}^{t}+\beta_{4} T_{i j r}^{t}+\beta_{6} E_{i j r}^{t}+U F_{j}+t_{t}+\epsilon_{i k r}^{t}
$$

Na equação 2:

- $M U N I_{i j}^{t}$ é uma variável do tipo dummy que identifica se a escola $j$ está sob o controle do município no tempo $t$

- $\alpha_{0}$ é uma constante

- $A_{i j r}^{t}$ é o vetor de características do aluno $i$, na escola $j$, da rede $r$, no tempo $t$

- $P_{i j r}^{t}$ é o vetor de características do professor do aluno $i$, na escola $j$, da rede $r$, no tempo $t$

- $D_{i j r}^{t}$ é o vetor de características do diretor do aluno $i$, na escola $j$, da rede $r$, no tempo $t$ 
- $T_{i j r}^{t}$ é o vetor de características da turma do aluno $i$, na escola $j$, da rede $r$, no tempo $t$

- $E_{i j r}^{t}$ é o vetor de características de infraestrututa da escola do aluno $i$, na escola $j$, da rede $r$, no tempo $t$

- $U F_{j}$ é é um conjunto de variáveis do tipo dummy indicador da UF

- $t_{t}$ é um conjunto de variáveis do tipo dummy indicador do ano

- $\epsilon_{i j r}^{t}$ é o termo de erro aleatório

\subsubsection{O efeito da municipalização nas escolas}

Esta segunda parte da análise empírica busca responder a pergunta a respeito da diferença que a mudança do nível de governo pode exercer sobre o desempenho médio das escolas. Ou seja, procura-se estimar, por meio da metodologia de diferença-emdiferenças, o efeito da municipalização sobre as escolas que foram transferidas da gestão estadual para a gestão municipal. Procura-se examinar se houve algum impacto na proficiência média dos alunos dessas escolas decorrente da transferência do controle da gestão escolar. Para tanto, foram agregados à base de dados do painel de escolas os dados da Prova Brasil de 2007. Como mencionado, o SAEB é um exame de avaliação de base amostral estratificada (e aleatória) das escolas, representativa para os estados e as redes de ensino. A Prova Brasil é um exame de avaliação em proficiência em língua portuguesa e matemática obrigatório para todas as escolas públicas do país. A Prova Brasil foi aplicada em 2005 e 2007. A presente análise empírica vale-se tão somente da base de dados da Prova Brasil para o ano de 2007. 
O método de estimação por diferença-em-diferenças foi inicialmente aplicado em Card (1990) e, posteriormente, descrito em Angrist e Krueger (1999). No Brasil, foi aplicado por Andrade e colaboradores (2007) para analisar o impacto do FUNDEF sobre a taxa de reprovação dos alunos, por Menezes-Filho e Pazello (2007) na investigação dos impactos do FUNDEF sobre os salários dos professores e o aprendizado dos alunos, em Franco e Menezes-Filho (2008) para estimar o impacto do FUNDEF sobre os indicadores educacionais e, finalmente, por Leme, Paredes e Souza (2009) para se estimar o efeito da municipalização sobre os resultados educacionais. A abordagem adotada no presente estudo é similar àquelas utilizadas em Menezes-Filho e Pazello (2007) e em Leme, Parede e Souza (2009).

Inicialmente, buscou-se construir um painel de escolas, em que se identifica a mesma escola pública (municipal ou estadual) em dois pontos no tempo: o período inicial, que corresponde aos testes do SAEB para os anos de 1997, 1999, 2001, 2003 e 2005; e um período final, que corresponde à Prova Brasil de 2007. Dessa forma, são montados, na verdade, painéis de escolas por pares de anos 1997-2007, 1999-2007, 2001-2007, 2003-2007 e 2005-2007. Uma vez montado esse painel de escolas públicas de ensino fundamental por pares de anos, as escolas são classificadas de acordo com a rede de ensino a que pertencem - municipal ou estadual - nos anos iniciais e no ano final. Assim, são compostos três grupos de escolas: um primeiro grupo controle de escolas que estavam sob gestão do estado no ano inicial e que permaneceram sob o estado no ano final, o grupo EE; um segundo grupo controle de escolas que eram municipais no ano inicial e permaneceram municipais no ano final, o grupo $M M$; e, finalmente, um grupo de tratamento para aquelas escolas que eram estaduais no ano inicial e foram 
transferidas para o controle dos municípios no ano final, o grupo $\mathrm{EM}^{30}$. Assim, todas as escolas que aparecem nesse painel foram observadas pelo menos em dois pontos no tempo.

A tabela 11 traz o número de escolas que compõem esse painel.

Tabela 11: Número de escolas por ano no painel (1997-2007)

\begin{tabular}{ccccc}
\hline & EE & EM & MM & Total \\
\hline 1997 & 206 & 9 & 256 & 471 \\
1999 & 538 & 33 & 794 & 1.365 \\
2001 & 679 & 40 & 880 & 1.599 \\
2003 & 725 & 36 & 795 & 1.556 \\
2005 & 695 & 21 & 696 & 1.412 \\
2007 & 1726 & 86 & 2171 & 3.722 \\
\hline Total & 3.452 & 550 & 3.442 & 7.444 \\
\hline
\end{tabular}

Fonte: Cálculos próprios

a partir de dados do MEC/INEP

Na presente análise, o efeito da municipalização que se pretende estimar é exatamente o efeito médio do grupo EM em comparação com os grupos controle EE e MM. Isto é, trata-se da diferença nas proficiências médias do grupo de escolas que foi transferido do controle estadual para o controle municipal cotejada à diferença nas proficiências médias dos grupos de escolas que permaneceram sob o controle dos estados e municípios. Uma observação importante é que o efeito estimado da municipalização das escolas não leva em conta o tempo em que as escolas do grupo de tratamento (EM) estiveram sob controle dos municípios. Ou seja, a análise ignora o tempo de exposição à gestão municipal.

\footnotetext{
${ }^{30}$ Existe ainda a possibilidade de um quarto grupo: aquele formado pelas escolas que foram estadualizadas; isto é, foram transferidas da gestão municipal para a estadual. Identificou-se apenas um número muito reduzido de escolas que passaram por esse processo de centralização. Este grupo foi, portanto, descartado da presente análise.
} 
A estimação por diferença-em-diferenças baseia-se na comparação das diferenças no desempenho médio nos exames do SAEB em matemática e língua portuguesa entre o grupo de tratamento e os dois grupos controle EE e MM. Intuitivamente, a estimação por diferença-em-diferenças é a comparação das mudanças ao longo do período de 1997 a 2007 na proficiência média das escolas que foram municipalizadas (grupo EM) com as mudanças ao longo do mesmo período na proficiência média das escolas que permaneceram sob controle dos estados (grupo EE) e dos municípios (grupo $\mathrm{MM})$.

A equação 3 abaixo procura modelar efeito da municipalização sobre a proficiência média das escolas que foram transferidas da gestão estadual para a gestão municipal, quando comparadas às escolas que não sofreram mudanças quanto à dependência administrativa a qual se encontram subordinadas.

$$
Y_{i j r}^{t}=\alpha_{0}+\beta_{1} E M_{i j}+\beta_{2} T_{i j}+\beta_{3} E M_{i j} * T_{i j}+\theta_{i}+\sum x_{i s}+\epsilon_{i k}^{t}
$$

Na equação 3:

- $Y_{i j r}^{t}$ é a proficiência do aluno $i$, na escola $j$, da rede $r$, no tempo $t$

- $\alpha_{0}$ é uma constante

- $E M_{i j}$ é uma variável do tipo dummy que indica se a escola $j$, do aluno $i$, migrou do controle do estado para o controle município no decurso do período de 1997 a 2007

- $T_{i j}$ é uma variável do tipo dummy, $T_{i j}=0$ se o ano $=1997,1999,2001,2003$ 
ou 2005 e $T_{i j}=1$ se o ano $=2007$

- $x_{i j}$ é o vetor de características do aluno $i$, na escola $j$,

- $\theta_{i}$ é o efeito específico não observado da escola

- $\epsilon_{i j}^{t}$ é o termo de erro aleatório

Primeiramente, é necessário notar que a proficiência média das escolas dos grupos controle e do grupo tratamento para o período inicial $\left(T_{i j}=0\right)$ e para o período final $\left(T_{i j}=1\right)$ é definida conforme as equações a seguir:

para o grupo controle EE:

$$
\begin{array}{ll}
t_{i j}=0: & E \bar{Y}_{i j}^{t}\left[E M_{i j}=0, T_{i j}=0, \theta_{j}^{E E}\right]=\beta_{0}+\theta_{j}^{E E} \\
t_{i j}=1: & E \bar{Y}_{i j}^{t}\left[E M_{i j}=0, T_{i j}=1, \theta_{j}^{E E}\right]=\beta_{0}+\beta_{2}+\theta_{j}^{E E}
\end{array}
$$

para o grupo controle MM:

$$
\begin{array}{ll}
t_{i j}=0: & E \bar{Y}_{i j}^{t}\left[E M_{i j}=0, T_{i j}=0, \theta_{j}^{M M}\right]=\beta_{0}+\theta_{j}^{M M} \\
t_{i j}=1: & E \bar{Y}_{i j}^{t}\left[E M_{i j}=0, T_{i j}=1, \theta_{j}^{M M}\right]=\beta_{0}+\beta_{2}+\theta_{j}^{M M}
\end{array}
$$

para o grupo tratamento EM:

$$
\begin{array}{ll}
t_{i j}=0: & E \bar{Y}_{i j}^{t}\left[E M_{i j}=1, T_{i j}=0, \theta_{j}^{E M}\right]=\beta_{0}+\beta_{1}+\theta_{j}^{E M} \\
t_{i j}=1: & E \bar{Y}_{i j}^{t}\left[E M_{i j}=1, T_{i j}=1, \theta_{j}^{E M}\right]=\beta_{0}+\beta_{1}+\beta_{2}+\beta_{3}+\theta_{j}^{E M}
\end{array}
$$

De tal sorte que se pode, simplesmente, subtrair a equação 4 da equação 5 para se 
obter a diferença (entre $T_{i j}=0$ e $T_{i j}=1$ ) nas proficiências médias das escolas do grupo controle, que permaneceu sob a gestão dos estados para todo o período da análise (1997-2007). O estimador dessa diferença é dado pela equação 10:

$$
\Delta_{E E}=\beta_{2}
$$

Analogamente, pode-se subtrair a equação 6 da equação 7 para se obter a diferença (entre $T_{i j}=0$ e $T_{i j}=1$ ) nas proficiências médias das escolas do grupo controle, que permaneceu a gestão dos municípios para todo o período da análise (1997-2007). O estimador dessa diferença é dado pela equação 11:

$$
\Delta_{M M}=\beta_{2}+\beta_{3}
$$

Finalmente, pode-se subtrair a equação 8 da equação 9 para se obter a diferença (entre $T_{i j}=0$ e $\left.T_{i j}=1\right)$ nas proficiências médias das escolas do grupo de tratamento, que migrou do controle dos estados para o controle dos municípios no decurso do período da análise (1997-2007). O estimador dessa diferença é dado pela equação 12:

$$
\Delta_{E M}=\beta_{1}+\beta_{2}+\beta_{3}
$$

A partir desses três estimdores das diferenças entre os períodos inicial $\left(T_{i j}=0\right)$ e final $\left(T_{i j}=1\right)$ para os grupos controle (EE e MM) e tratamento (EM), pode-se obter outros três estimadores de diferença-em-diferenças (doravante DID).

Primeiramente, pode-se calcular o estimador de DID entre os dois grupos controle 
EE - MM. Isto é, entre as escolas estaduais e municipais que não sofreram nenhuma alteração quanto à dependência administrativa a que estão subordinadas. Assim, temse:

$$
\Delta_{E E}-\Delta_{M M}=\beta_{3}
$$

Em seguida, pode-se determinar o estimador de DID entre o grupo tratamento (EM) e o grupo controle das escolas municipais (MM) que permaneceram sob gestão dos municípios durante todo o período coberto pela análise (1997-2007), Assim, nesse caso, tem-se:

$$
\Delta_{E M}-\Delta_{M M}=\beta_{1}
$$

Por fim, pode-se calcular o estimador de DID entre o grupo tratamento (EM) e o grupo controle das escolas estaduais (EE) que permaneceram sob gestão dos estados durante todo o período coberto pela análise (1997-2007), Assim, nesse caso, tem-se:

$$
\Delta_{E M}-\Delta_{E E}=\beta_{1}+\beta_{3}
$$

\subsubsection{O efeito da municipalização sobre as redes escolares nos municí- pios}

Este terceiro exercício de estimação do efeito da municipalização procura captar o impacto da descentralização de matrículas e gastos em educação nas redes escolares dos 
municípios brasileiros. Mais especificamente, procura-se aqui estimar o efeito da taxa de municipalização das matrículas sobre alguns indicadores de insumos e rendimento do fluxo escolar. Para tanto, na presente análise, utiliza-se uma base de dados em painel onde as unidades de observação são os municípios brasileiros. Essa base de dados dos municípios compreende o período de 1999 a 2005.

Como mencionado no capítulo 3 do presente estudo, a medida de descentralização (ou a variável explicativa) empregada nesta análise é a proporção de matrículas no ensino fundamental nas escolas municipais em função do número total de matrículas no ensino fundamental público no município. Aqui denominada de taxa de municipalização das matrículas.

As variáveis respostas, por outro, são subagrupadas em dois conjuntos de indicadores: os (1) insumos escolares e os (2) as taxas de rendimento do fluxo escolar ou, simplesmente, os resultados escolares. O primeiro conjunto compreende: indicadores a respeito da infraestrutura física das escolas, como, por exemplo, se as escolas possuem biblioteca, quadra de esportes, laboratório de ciências, laboratório de informática, a razão computador por aluno, se a escola oferece merenda aos alunos, entre outros; indicadores acerca da composição e formação do corpo docente, como, por exemplo, razão professor por aluno e proporção de professores com curso superior. O segundo conjunto de variáveis, referentes ao rendimento do fluxo escolar, inclui: taxa de reprovação, taxa de abandono e a taxa de distorção idade-série. ${ }^{31}$

Como comentado no segundo capítulo do presente estudo, idealmente, quando se busca mensurar a qualidade da educação, a melhor estratégia é trabalhar com resultados de

\footnotetext{
${ }^{31} \mathrm{~A}$ tabela 12 adiante apresenta uma descrição completa das variáveis usadas na presente análise, bem como suas fontes.
} 
exames de avaliação padronizados, tais como o SAEB ou a Prova Brasil. Infelizmente, não há dados disponíveis de avaliações padronizadas para o período de 1999 a 2005 com representatividade para os municípios no Brasil. Os dados do SAEB são representativos para os estados e para as redes escolares (municipal, estadual e privada). Os dados da Prova Brasil, que têm representatividade para os municípios e para as redes escolares, estão disponíveis tão somente para os anos de 2005 e 2007. Ademais, uma limitação adicional quando se trabalha com os dados de gastos em educação fundamental no Brasil, é que, a partir de 2007, o FUNDEB ${ }^{32}$ substitui o FUNDEF e altera as regras de financiamento da educação básica (que engloba as modalidades de ensino fundamental e médio). As transferências, que até 2006, eram destinadas exclusivamente ao ensino fundamental, passam, a partir de 2007, a cobrir também o ensino médio.

Foram ainda excluídos informações de algumas escolas que compunham a base de dados original do Censo Escolar. Inicialmente, excluiu-se os dados para todas as escolas que não ofereciam ensino fundamental. Em seguida, foram excluídas as informações acerca das escolas que traziam o código de funcionamento descrito como "extinto" ou "paralisado", mantendo-se apenas as escolas com o código de funcionamento "ativo" e que apresentavam o "número de matrículas no ensino fundamental" maior ou igual a dez. Além disso, também foram excluídas as escolas da rede federal.

As características das escolas foram agregadas para o nível do município, por sua média ou proporção, segundo o ano e a dependência administrativa a que se referiam, se municipal, estadual ou privada. Por fim, foi montado um painel de municípios com dados para os anos de 1999, 2001, 2003, e 2005. Neste banco de dados restaram os

\footnotetext{
${ }^{32}$ O FUNDEB é o Fundo de Manutenção e Desenvolvimento da Educação Básica e de Valorização dos Profissionais de Educação.
} 
2837 municípios para os quais haviam informações tanto na base de dados do FINBRA como do Censo Escolar. A tabela ?? apresenta o número de escolas segunda a rede escolar e a dependência administrativa que compõem o painel de municípios.

Finalmente, vale observar que, no presente exercício foram mantidas na base de dados as escolas da rede privada, diferentemente das duas análises prévias que trabalhavam exclusivamente com as escolas da rede pública. Esta escolha, deve-se ao juízo de que as escolas privadas podem funcionar como um grupo controle no presente exercício. Já que não foram afetadas pelo processo de expansão das matrículas que se verificou na rede pública e tampouco pela municipalização de matrículas e gastos em educação cujos efeitos aqui se pretende analisar.

A tabela 12 apresenta a lista de variáveis que fazem parte desse painel de 2.837 municípios, bem como suas respectivas fontes.

A Taxa de municipalização é, para esse exercício empírico, a principal variável de interesse. Como comentado anteriormente, trata-se da proporção de matrículas do ensino fundamental em escolas municipais no município $i$ no ano $t$. Ela procura captar o esforço do município em incorporar novas matrículas no ensino fundamental, seja por meio da municipalização de escolas estaduais, seja pela criação de novas vagas em escolas municipais. Quanto maior for essa taxa, mais descentralizado o ensino fundamental do município. Pois, maior a responsabilidade do município na prestação dos serviços públicos de ensino fundamental vis-à-vis a responsabilidade do estado.

O primeiro conjunto de variáveis dependentes é composto pelas taxas de rendimento do fluxo escolar no município $i$ no ano $t$ segundo a rede $r$. São elas: taxa de aban- 
Tabela 12: Base de dados dos municípios: as variáveis e suas fontes

\begin{tabular}{|c|c|c|}
\hline Variáveis & Descrição & Fonte \\
\hline $\begin{array}{l}\text { Taxa de municipa- } \\
\text { lização }\end{array}$ & $\begin{array}{l}\text { proporção de matrículas do ensino fundamental em escolas } \\
\text { municipais no município } i \text {, no ano } t\end{array}$ & $\begin{array}{l}\text { Censo Escolar } \\
\text { (MEC/INEP) }\end{array}$ \\
\hline Taxa de abandono & $\begin{array}{l}\text { proporção de alunos do ensino fundamental que abandonaram } \\
\text { a escola no município } i \text {, ano } t \text { e na rede } r\end{array}$ & $\begin{array}{l}\text { Censo Escolar } \\
\text { (MEC/INEP) }\end{array}$ \\
\hline $\begin{array}{l}\text { Taxa de reprova- } \\
\text { ção }\end{array}$ & $\begin{array}{l}\text { proporção de alunos do ensino fundamental que foram repro- } \\
\text { vados no município } i \text {, ano } t \text { e na rede } r\end{array}$ & $\begin{array}{l}\text { Censo Escolar } \\
\text { (MEC/INEP) }\end{array}$ \\
\hline $\begin{array}{l}\text { Defasagem idade- } \\
\text { série }\end{array}$ & $\begin{array}{l}\text { proporção de alunos do ensino fundamental com idade superior } \\
\text { a idade recomendada no município } i \text {, ano } t \text { e na rede } r\end{array}$ & $\begin{array}{l}\text { Censo Escolar } \\
\text { (MEC/INEP) }\end{array}$ \\
\hline Biblioteca & $\begin{array}{l}\text { proporção de escolas municipais de ensino fundamental com } \\
\text { biblioteca no município } i \text {, ano } t \text { e na rede } r\end{array}$ & $\begin{array}{l}\text { Censo Escolar } \\
\text { (MEC/INEP) }\end{array}$ \\
\hline $\begin{array}{l}\text { Quadra de espor- } \\
\text { tes }\end{array}$ & $\begin{array}{l}\text { proporção de escolas municipais de ensino fundamental com } \\
\text { quadra de esportes no município } i \text {, ano } t \text { e na rede } r\end{array}$ & $\begin{array}{l}\text { Censo Escolar } \\
\text { (MEC/INEP) }\end{array}$ \\
\hline $\begin{array}{l}\text { Laboratório de ci- } \\
\text { ências }\end{array}$ & $\begin{array}{l}\text { proporção de escolas municipais de ensino fundamental com } \\
\text { laboratório de ciências no município } i \text {, ano } t \text { e na rede } r\end{array}$ & $\begin{array}{l}\text { Censo Escolar } \\
\text { (MEC/INEP) }\end{array}$ \\
\hline $\begin{array}{l}\text { Laboratório de in- } \\
\text { formática }\end{array}$ & $\begin{array}{l}\text { proporção de escolas municipais de ensino fundamental com } \\
\text { Laboratório de informática no município } i \text {, ano } t \text { e na rede } r\end{array}$ & $\begin{array}{l}\text { Censo Escolar } \\
\text { (MEC/INEP) }\end{array}$ \\
\hline Aluno/computador & $\begin{array}{l}\text { razão de alunos por computador no ensino fundamental no no } \\
\text { município } i \text {, ano } t \text { e na rede } r\end{array}$ & $\begin{array}{l}\text { Censo Escolar } \\
\text { (MEC/INEP) }\end{array}$ \\
\hline Aluno/professor & $\begin{array}{l}\text { razão de alunos por professor no ensino fundamental no mu- } \\
\text { nicípio } i \text {, ano } t \text { e na rede } r\end{array}$ & $\begin{array}{l}\text { Censo Escolar } \\
\text { (MEC/INEP) }\end{array}$ \\
\hline $\begin{array}{l}\text { Educação do pro- } \\
\text { fessor }\end{array}$ & $\begin{array}{l}\text { proporção de professores do ensino fundamental com curso } \\
\text { superior no no município } i \text {, ano } t \text { e na rede } r\end{array}$ & $\begin{array}{l}\text { Censo Escolar } \\
\text { (MEC/INEP) }\end{array}$ \\
\hline População 07-14 & total da população de 7 a 14 anos no município & DataSUS \\
\hline População 25-64 & total da população de 25 a 64 anos no município & DataSUS \\
\hline População $>25$ & total da população de 7 a 14 anos no município & DataSUS \\
\hline População & população total do município & DataSUS \\
\hline Vacinas & total de doses de vacinas aplicadas no município $i$ no ano $t$ & DataSUS \\
\hline $\begin{array}{l}\text { Mortalidade infan- } \\
\text { til }\end{array}$ & $\begin{array}{l}\text { razão entre o total de óbitos infantis até } 1 \text { ano idade por } 1000 \\
\text { nascidos vivos no município } i \text {, ano } t\end{array}$ & DataSUS \\
\hline PIB per capita & PIB per capita no município & IPEAdata \\
\hline
\end{tabular}

Fonte: Formulação própria a partir de dados do Cendo Escolar, FINBRA, Datasus e IPEAdata

* Banco de dados da FINBRA da Secretaria di Tesouro Nacional do Ministério da Fazenda

dono, taxa de reprovação e a distorção idade-série. Quanto menores essas taxas, mais positivos os resultados de fluxo escolar no município e na rede escolar.

O segundo conjunto de variáveis dependentes refere-se aos insumos escolares no município $i$, no ano $t$, para a rede $r$. Os insumos escolares são compostos por: bibli- 
Tabela 13: Insumos escolares segundo a rede escolar

\begin{tabular}{lcccc}
\hline & $(1)$ & $(2)$ & $(3)$ & $(4)$ \\
& Total & Municipais & $\begin{array}{c}\text { Estaduais } \\
\text { Privadas }\end{array}$ \\
\hline Biblioteca & $71,60 \%$ & $51,77 \%$ & $64,88 \%$ & $86,29 \%$ \\
Quadra de esportes & $56,7 \%$ & $41,10 \%$ & $52,17 \%$ & $77,44 \%$ \\
Laboratório de Ciências & $31,90 \%$ & $17,89 \%$ & $25,34 \%$ & $71,90 \%$ \\
Laboratório de informática & $37,8 \%$ & $13,90 \%$ & $16,95 \%$ & $56,91 \%$ \\
Aluno/computador & 366,4 & 812,9 & 674,2 & 81,56 \\
Aluno/Professor & 21,69 & 19,76 & 23,48 & 13,72 \\
Educação do professor & $25,75 \%$ & $16,82 \%$ & $17,71 \%$ & $35,78 \%$ \\
\hline$N$ & 26.068 & 12.698 & 8.051 & 5.337 \\
\hline Fonte: Calculos próprios a partir de dados do Censo Escolar \\
Desvio padrão entre parênteses & \multicolumn{4}{|}{} \\
Notas: Para o ano de 2005 trata-se de computador com Internet
\end{tabular}

oteca, quadra de esportes, laboratório de ciências, laboratório de informática, taxa aluno/professor, taxa aluno/computador e proporção de professores com curso superior.

A tabela 13 apresenta as estatísticas descritivas para as variáveis de insumos escolares empregadas nessa análise para o total das escolas no painel e para as escolas segundo a rede escolar.

A tabela 14 apresenta as estatísticas descritivas para as variáveis de rendimento de fluxo escolar empregadas nessa análise para o total das escolas do painel e para as escolas segundo a rede escolar.

Quando se examina as taxas de fluxo apresentadas na tabela 14 , nota-se que as taxas médias de reprovação, abandono e distorção idade-série são significativamente inferiores nas escolas privadas relativamente às públicas municipais e estaduais. Ainda, dentro da rede pública, parece que as escolas estaduais tem menores taxas médias de abandono, reprovação e defasagem idade-série, embora as diferenças não sejam tão 
Tabela 14: Rendimento do fluxo escolar segundo a rede

\begin{tabular}{lcccc}
\hline & $(1)$ & $(2)$ & $(3)$ & $(4)$ \\
& Total & Municipais & Estaduais & Privadas \\
\hline Taxa de abandono & $9,66 \%$ & $11,44 \%$ & $9,89 \%$ & $1,82 \%$ \\
Taxa de Repetição $13,7 \%$ & $17,1 \%$ & $16,0 \%$ & $3,73 \%$ & \\
Distorção idade-série & $29,9 \%$ & $32,1 \%$ & $38,3 \%$ & $2,21 \%$ \\
\hline$N$ & 26.068 & 12.698 & 8.051 & 5.337 \\
\hline Fonte: Calculos próprios a partir de dados do Censo Escolar & \\
Desvio padrão entre parênteses
\end{tabular}

acentuadas como quando cotejadas às escolas da rede privada e os desvios padrão bastante elevados para ambos os grupos de escolas.

Além dessas variáveis, também foi utilizado um conjunto de variáveis controle relacionadas às características populacionais e ao perfil socioeconômico dos municípios. A tabela 15 apresenta as estatísticas descritivas para essas variáveis.

Tabela 15: Características populacionais e socioeconômicas do municípios

\begin{tabular}{lcc}
\hline \multicolumn{1}{c}{$(1)$} & $(2)$ & $(3)$ \\
\multicolumn{1}{c}{ Variáveis } & Média & Desvio padrão \\
\hline Taxa de municipalização & $75,6 \%$ & $20,1 \%$ \\
População de 07 a 14 anos & 5.108 & 25.585 \\
População feminina de 25 a 64 anos & 7.195 & 49.452 \\
População com mais de 65 anos & 1825 & 12.707 \\
População & 31.577 & 189.558 \\
Vacinas & 12.210 & 66.960 \\
Mortalidade infantil & 20,1 & 21,6 \\
PIB per capita (R\$1.000,00) & 4,50 & 5,23 \\
\hline$N$ & 2.837 & 2.837 \\
\hline
\end{tabular}

Fonte: Calculos próprios a partir de dados do Censo Escolar, DataSUS e IPEAdata

A equação 16 abaixo procura modelar o efeito da taxa de municipalização sobre os insumos educacionais nas redes escolares pública municipal, pública estadual e privada para o painel de 2.837 municípios: 


$$
\bar{Y}_{i r}^{t}=\alpha_{0}+\beta_{1} M U N I_{i t}+\beta_{3} M_{i t}+\theta_{i}+d_{r}+t_{t}+\epsilon_{i k}^{t}
$$

Na equação 16:

- $\bar{Y}_{i r}^{t}$ é a média da variável dependente para o município $i$, na rede de escolas $r$, no tempo $t$

- $\alpha_{0}$ é uma constante

- $M U N I_{i t}$ é a taxa de municipalização das matrículas no município $i$, no tempo $t$

- $M_{i t}$ é o vetor de características do município $i$, no tempo $t$

- $\theta_{i}$ é o efeito específico não observado do município

- $d_{r}$ é um conjunto de variáveis do tipo dummy indicador da rede escolar, se pública municipal, pública estadual ou privada

- $t_{t}$ é um conjunto de variáveis do tipo dummy indicador do ano

- $\epsilon_{i r}^{t}$ é o termo de erro aleatório

A equação 17 abaixo procura modelar o efeito da taxa de municipalização sobre as taxas de rendimento do fluxo escolar nas redes escolares pública municipal, pública estadual e privada para o painel de 2.837 municípios:

$$
\bar{Y}_{i r}^{t}=\alpha_{0}+\beta_{1} M U N I_{i t}+\beta_{2} E_{i r t}+\beta_{3} M_{i t}+\theta_{i}+d_{r}+t_{t}+\epsilon_{i k}^{t}
$$

Na equação 17 : 
- $\bar{Y}_{i r}^{t}$ é a média da variável dependente para o município $i$, na rede de escolas $r$, no tempo $t$

- $\alpha_{0}$ é uma constante

- $M U N I_{i t}$ é a taxa de municipalização das matrículas no município $i$, no tempo $t$

- $E_{i r t}$ é o vetor de características das escolas da rede $r$, no município $i$, no tempo $t$

- $M_{i t}$ é o vetor de características do município $i$, no tempo $t$

- $\theta_{i}$ é o efeito específico não observado do município

- $d_{r}$ é um conjunto de variáveis do tipo dummy indicador da rede escolar, se pública municipal, pública estadual ou privada

- $t_{t}$ é um conjunto de variáveis do tipo dummy indicador do ano

- $\epsilon_{i r}^{t}$ é o termo de erro aleatório 


\section{Resultados}

Nesse capítulo são apresentados e discutidos os principais resultados da presente investigação. Seguindo a mesma lógica de exposição adotada até aqui serão apresentados separadamente, nas seguintes seções, os resultados para os exercícios de estimação do efeito da municipalização sobre os alunos, as escolas e os municípios, respectivamente.

\subsection{O Efeito da rede escolar sobre a proficiência dos alunos: o nível de governo importa?}

Vale lembrar que a pergunta básica que se pretende responder nessa seção do trabalho, especificamente, é se há de fato diferenças nas proficiências médias nos exames do SAEB entre os alunos de escolas públicas municipais e os alunos das escolas públicas estaduais. Se há mesmo diferença, qual sua magnitude?

Para tanto, se ajustou o modelo estatístico dado pela equação 1. Esse modelo, de função de produção em educação, traz como variável dependente a proficiência do aluno $i$, na escola $j$, da rede $r$, no tempo $t$, dada pelo termo $Y_{i j r}^{t}$. A principal variável de interesse aqui é a rede escolar, dada por $E S T_{i j r}^{t}$, é uma variável do tipo dummy que indica se a escola $j$, do aluno $i$, no ano $t$ está vinculada as redes estaduais de ensino público.

A tabela 16 apresenta os resultados da estimação por MQO agrupados para os alunos da 4a. série do ensino fundamental para a prova de língua portuguesa do SAEB ${ }^{33}$,

\footnotetext{
${ }^{33}$ Nesta seção do trabalho, para se preservar a clareza na exposição dos resultados serão apresen-
} 
Tabela 16: Resultados da estimação por MQA usando dados de alunos, painel de escolas (1997-2005), Português 4a. série

\begin{tabular}{|c|c|c|c|c|c|}
\hline & $\begin{array}{c}(1) \\
\text { Modelo } 1\end{array}$ & $\begin{array}{c}(2) \\
\text { Modelo } 2\end{array}$ & $\begin{array}{c}(3) \\
\text { Modelo } 3\end{array}$ & $\begin{array}{c}(4) \\
\text { Modelo } 4\end{array}$ & $\begin{array}{c}(5) \\
\text { Modelo } 5\end{array}$ \\
\hline Estaduais & $\begin{array}{c}5.280^{* * *} \\
(0.600)\end{array}$ & $\begin{array}{c}4.287^{* * *} \\
(0.569)\end{array}$ & $\begin{array}{c}2.513^{* * *} \\
(0.493)\end{array}$ & $\begin{array}{l}1.641^{*} \\
(0.685)\end{array}$ & $\begin{array}{c}0.295 \\
(0.764)\end{array}$ \\
\hline Mãe (1-4 EF) & & $\begin{array}{c}2.116^{* * * *} \\
(0.353)\end{array}$ & $\begin{array}{c}1.584^{* * *} \\
(0.347)\end{array}$ & $\begin{array}{c}2.110^{* * * *} \\
(0.490)\end{array}$ & $\begin{array}{c}2.250^{* * * *} \\
(0.544)\end{array}$ \\
\hline Mãe (5-8 EF) & & $\begin{array}{c}5.423^{* * *} \\
(0.374)\end{array}$ & $\begin{array}{c}2.648^{* * * *} \\
(0.366)\end{array}$ & $\begin{array}{c}2.114^{* * *} \\
(0.532)\end{array}$ & $\begin{array}{c}2.223^{* * *} \\
(0.596)\end{array}$ \\
\hline Mãe (EM) & & $\begin{array}{c}13.55^{* * *} \\
(0.488)\end{array}$ & $\begin{array}{c}8.587^{* * *} \\
(0.464)\end{array}$ & $\begin{array}{c}9.813^{* * *} \\
(0.634)\end{array}$ & $\begin{array}{c}9.823^{* * *} \\
(0.700)\end{array}$ \\
\hline Mãe (Superior) & & $\begin{array}{c}14.96^{* * * *} \\
(0.641)\end{array}$ & $\begin{array}{c}8.429^{* * * *} \\
(0.576)\end{array}$ & $\begin{array}{c}6.198^{* * * *} \\
(0.709)\end{array}$ & $\begin{array}{c}6.032^{* * *} \\
(0.796)\end{array}$ \\
\hline Mãe (não sabe) & & $\begin{array}{c}4.992^{* * * *} \\
(0.343)\end{array}$ & $\begin{array}{c}1.744^{* * * *} \\
(0.325)\end{array}$ & $\begin{array}{l}-0.223 \\
(0.426)\end{array}$ & $\begin{array}{c}-0.00961 \\
(0.482)\end{array}$ \\
\hline 10 anos & & & $\begin{array}{c}5.052^{* * *} \\
(0.560)\end{array}$ & $\begin{array}{l}2.584^{* *} \\
(0.813)\end{array}$ & $\begin{array}{l}2.138^{*} \\
(0.881)\end{array}$ \\
\hline 11 anos & & & $\begin{array}{c}-5.966^{* * *} \\
(0.608)\end{array}$ & $\begin{array}{c}-7.800^{* * *} \\
(0.875)\end{array}$ & $\begin{array}{c}-7.668^{* * *} \\
(0.954)\end{array}$ \\
\hline 12 anos ou mais & & & $\begin{array}{c}-12.59^{* * *} \\
(0.594)\end{array}$ & $\begin{array}{c}-16.87^{* * *} \\
(0.891)\end{array}$ & $\begin{array}{c}-16.29^{* * *} \\
(0.979)\end{array}$ \\
\hline Homens & & & $\begin{array}{c}-8.616^{* * *} \\
(0.244)\end{array}$ & $\begin{array}{c}-10.02^{* * *} \\
(0.369)\end{array}$ & $\begin{array}{c}-10.16^{* * *} \\
(0.411)\end{array}$ \\
\hline Pardo & & & $\begin{array}{c}-0.970^{* *} \\
(0.314)\end{array}$ & $\begin{array}{l}-0.879 \\
(0.453)\end{array}$ & $\begin{array}{l}-0.665 \\
(0.493)\end{array}$ \\
\hline Negro & & & $\begin{array}{c}-11.67^{* * *} \\
(0.414)\end{array}$ & $\begin{array}{c}-11.85^{* * *} \\
(0.617)\end{array}$ & $\begin{array}{c}-12.33^{* * *} \\
(0.680)\end{array}$ \\
\hline Amarelo ou Indigena & & & $\begin{array}{c}-2.580^{* * *} \\
(0.516)\end{array}$ & $\begin{array}{c}-3.739^{* * *} \\
(0.777)\end{array}$ & $\begin{array}{c}-3.693^{* * *} \\
(0.852)\end{array}$ \\
\hline Possui computador & & & $\begin{array}{c}4.431^{* * *} \\
(0.676)\end{array}$ & $\begin{array}{c}7.477^{* * *} \\
(0.876)\end{array}$ & $\begin{array}{c}7.197^{* * *} \\
(0.995)\end{array}$ \\
\hline Mora com o pai e a mãe & & & $\begin{array}{c}0.385 \\
(0.265)\end{array}$ & $\begin{array}{c}-1.861^{* * *} \\
(0.384)\end{array}$ & $\begin{array}{c}-2.148^{* * *} \\
(0.436)\end{array}$ \\
\hline Trabalha(ou) fora de casa & & & $\begin{array}{c}-14.87^{* * *} \\
(0.367)\end{array}$ & $\begin{array}{c}-15.50^{* * *} \\
(0.545)\end{array}$ & $\begin{array}{c}-15.21^{* * *} \\
(0.616)\end{array}$ \\
\hline Escola rural & & & & $\begin{array}{c}-3.985^{* * *} \\
(1.048)\end{array}$ & $\begin{array}{c}-3.674^{* *} \\
(1.119)\end{array}$ \\
\hline Constante & $\begin{array}{c}160.2^{* * *} \\
(0.399)\end{array}$ & $\begin{array}{c}155.7^{* * *} \\
(0.440)\end{array}$ & $\begin{array}{c}173.5^{* * *} \\
(0.715)\end{array}$ & $\begin{array}{c}170.5^{* * *} \\
(1.468)\end{array}$ & $\begin{array}{c}164.9^{* * * *} \\
(2.237)\end{array}$ \\
\hline$N$ & 130.448 & 122.521 & 107.060 & 47.899 & 38.570 \\
\hline$R^{2}$ & 0.004 & 0.020 & 0.107 & 0.145 & 0.146 \\
\hline
\end{tabular}

Erros padrão robustos em parênteses

Fonte: Calculos próprios a partir de dados do SAEB/INEP

${ }^{*} p<0.05,{ }^{* *} p<0.01,{ }^{* * *} p<0.001$ 
Tabela 17: Resultados da estimação por MQA usando dados de alunos, painel de escolas (1997-2005), Português 4a. série, Continuação da página anterior

\begin{tabular}{|c|c|c|c|c|c|}
\hline & $\begin{array}{c}(1) \\
\text { Modelo } 1\end{array}$ & $\begin{array}{c}(2) \\
\text { Modelo } 2\end{array}$ & $\begin{array}{c}(3) \\
\text { Modelo } 3\end{array}$ & $\begin{array}{c}(4) \\
\text { Modelo } 4\end{array}$ & $\begin{array}{c}(5) \\
\text { Modelo } 5\end{array}$ \\
\hline Estaduais & $\begin{array}{c}5.280^{* * *} \\
(0.600)\end{array}$ & $\begin{array}{c}4.287^{* * *} \\
(0.569)\end{array}$ & $\begin{array}{c}2.513^{* * * *} \\
(0.493)\end{array}$ & $\begin{array}{l}1.641^{*} \\
(0.685)\end{array}$ & $\begin{array}{c}0.295 \\
(0.764)\end{array}$ \\
\hline Quadra de esportes & & & & $\begin{array}{c}1.324 \\
(0.749)\end{array}$ & $\begin{array}{c}0.349 \\
(0.838)\end{array}$ \\
\hline Laboratório de ciências & & & & $\begin{array}{c}3.551^{* * * *} \\
(1.069)\end{array}$ & $\begin{array}{l}3.160^{* *} \\
(1.218)\end{array}$ \\
\hline Laboratório de informática & & & & $\begin{array}{l}2.032^{*} \\
(0.935)\end{array}$ & $\begin{array}{l}2.139^{*} \\
(1.061)\end{array}$ \\
\hline Biblioteca & & & & $\begin{array}{c}4.337^{* * *} \\
(0.688)\end{array}$ & $\begin{array}{c}3.576^{* * *} \\
(0.762)\end{array}$ \\
\hline Livros didáticos & & & & $\begin{array}{c}0.797 \\
(0.658)\end{array}$ & $\begin{array}{c}0.799 \\
(0.739)\end{array}$ \\
\hline Merenda & & & & $\begin{array}{c}1.415 \\
(0.965)\end{array}$ & $\begin{array}{c}1.343 \\
(1.029)\end{array}$ \\
\hline Transporte & & & & $\begin{array}{c}4.038^{* * * *} \\
(0.681)\end{array}$ & $\begin{array}{c}3.463^{* * *} \\
(0.742)\end{array}$ \\
\hline Curso Superior & & & & & $\begin{array}{c}2.156 \\
(1.102)\end{array}$ \\
\hline Capacitação & & & & & $\begin{array}{c}0.251 \\
(1.359)\end{array}$ \\
\hline Experiência ( 5-10 anos) & & & & & $\begin{array}{c}1.161 \\
(0.833)\end{array}$ \\
\hline Experiência (+ 10 ano) & & & & & $\begin{array}{l}2.981^{*} \\
(1.169)\end{array}$ \\
\hline Concursado ou eleito & & & & & $\begin{array}{c}2.911^{* * *} \\
(0.772)\end{array}$ \\
\hline Projeto pedagógico (Sec.) & & & & & $\begin{array}{c}1.927 \\
(1.346)\end{array}$ \\
\hline Projeto pedagógico (Dir. e Prof.) & & & & & $\begin{array}{c}4.007^{* * *} \\
(1.005)\end{array}$ \\
\hline Rotatividade & & & & & $\begin{array}{l}-0.0772 \\
(1.662)\end{array}$ \\
\hline Absenteísmo & & & & & $\begin{array}{c}0.584 \\
(1.388)\end{array}$ \\
\hline Constante & $\begin{array}{c}160.2^{* * *} \\
(0.399)\end{array}$ & $\begin{array}{c}155.7^{* * *} \\
(0.440)\end{array}$ & $\begin{array}{c}173.5^{* * *} \\
(0.715)\end{array}$ & $\begin{array}{c}170.5^{* * *} \\
(1.468)\end{array}$ & $\begin{array}{c}164.9 * * * \\
(2.237)\end{array}$ \\
\hline$N$ & 130.448 & 122.521 & 107.060 & 47.899 & 38.570 \\
\hline$R^{2}$ & 0.004 & 0.020 & 0.107 & 0.145 & 0.146 \\
\hline
\end{tabular}

Erros padrão robustos em parênteses

Fonte: Calculos próprios a partir de dados do SAEB/INEP

${ }^{*} p<0.05,{ }^{* *} p<0.01,{ }^{* * *} p<0.001$ 
para o painel de escolas (1997-2005). O modelo 1 da tabela 16 indica que há uma diferença média positiva de 5,30 pontos (na escala SAEB) em favor dos alunos das escolas estaduais. Essa diferença corresponde aproximadamente a um desempenho médio dos alunos das escolas estaduais de 3 pontos percentuais acima, se comparados aos alunos das escolas municipais (a categoria omitida nesse modelo). Esse resultado, que corresponde ao teste $t$ de comparação de médias, é estatisticamente significante ao nível de 1 por cento.

Contudo, como já comentado, a literatura tem demonstrado que há uma série de fatores ligados aos recursos familiares e insumos escolares, entre outros, que podem afetar significativamente o aprendizado dos alunos. Assim, pode-se objetar que essa diferença, apesar de significativa, pode estar ligada a fatores extra sala de aula, tais como: a educação dos pais. De fato, o modelo 2 da tabela 16 indica que, quando se controla o efeito da rede escolar pela educação da mãe, a diferença de desempenho entre estudantes das redes estaduais e municipais decresce cerca de 1 ponto (na escala SAEB), não obstante permaneça positiva e estatisticamente significante ao nível de 1 por cento.

Os resultados dos modelos apresentados nas colunas (3) e (4) das tabelas 16 e $17^{34}$ reforçam essa constatação. A medida que se acrescentam novas variáveis na especificação dos modelos de regressão, a diferença entre o desempenho acadêmico de alunos das escolas públicas estaduais e municipais vai perdendo força. Ou seja, a medida que tados apenas os resultados das estimações para os exames de língua portuguesa. Os resultados para os exames de matemática, que em geral não desviam dos resultados de língua portuguesa, são apresentados no Anexo A do presente trabalho. No caso de eventuais discrepâncias entre os resultados estas são aqui destacadas.

${ }^{34} \mathrm{~A}$ tabela 11 é apenas uma continuação da tabela 1o, que foi cortada tão somente para se manter a clareza e a inteligibilidade das tabelas de resultados 
são inseridos nos modelos outros fatores que podem explicar o desempenho escolar, a variável de interesse - a rede escolar - vai paulatinamente perdendo sua força explicativa para a diferença de desempenho entre alunos das escolas públicas estaduais e municipais nos exames do SAEB.

A coluna 3 da tabela 16 apresenta os resultados para a especificação que, além da rede escolar e da educação da mãe, inclui também as demais características do aluno (gênero, idade e cor) e de sua família. Nota-se que, em se controlando pelas características dos alunos e do ambiente familiar, a diferença de desempenho entre alunos das redes estaduais e municipais decresce para memos da metade da diferença estimada pelo modelo 1 , embora ainda continue estatisticamente significante a 1 por cento. A coluna (4) da tabela 16 exibe os resultados para o modelo 4, que inclui além das características do aluno e do ambiente familiar, as recursos das escolas. Nota-se, então, que a diferença de desempenho nos exames do SAEB não apenas torna-se praticamente nula, como também passa a ser significante a um nível de apenas 10 por cento. No modelo 5, que inclui além das variáveis do aluno, do ambiente escolar e das características observáveis da escola, também as variáveis a respeito do diretor escolar, o efeito da rede escolar desaparece por completo, tanto sua magnitude se aproxima de zero $(0,29)$, como também deixa de ser estatisticamente significante.

O que explica os resultados reportados nas tabelas 16 e 17 ? Em suma, os resultados mostram que $(i)$ há uma diferença significativa da ordem de 3 por cento entre o desempenho acadêmico em língua portuguesa ${ }^{35}$ dos estudantes da 4 a. série do ensino

\footnotetext{
${ }^{35}$ a diferença no exame de matemática é de exatamente 5,108; o que corresponde a aproximadamente um desvio de 3 por cento nas proficiências médias dos alunos das escolas públicas municipais e públicas estaduais. Como no caso do exame de língua portuguesa essa diferença é favorável às escolas das redes estaduais.
} 
fundamental de escolas públicas estaduais e públicas municipais, em favor da rede pública estadual. (ii) Quando, além da rede escolar na qual o aluno está vinculado, são utilizadas características dos alunos (cor, gênero e idade), do ambiente familiar (educação da mãe e outras características socioeconômicas) e da infraestrutura das escolas (presença de biblioteca, quadra de esportes, laboratório de ciências, entre outros) para se explicar a proficiência nos exames do SAEB, o efeito independente da rede escolar perde relevância, tanto em termos de magnitude como de significância estatística. Ou seja, a relação positiva entre o pertencimento à rede pública estadual e a proficiência média em língua portuguesa dos alunos de 4a. série diminui a medida que características dos estudantes, da família e da escola são utilizadas como controles. Em suma, a relação condicional positiva entre proficiência média nos exames do SAEB e a matrícula em escolas das redes públicas estaduais é mediada pelo efeito das características dos alunos (incluindo seu ambiente familiar) e pelo efeito dos insumos escolares.

Logo, parece haver evidências empíricas de que disparidades nas características dos alunos, ambiente familiar e infraestrutura das escolas poderiam explicar a diferença de desempenho acadêmico nos exames do SAEB entre alunos das redes públicas estaduais e públicas municipais. Entretanto, para se evitar conclusões precipitadas deve-se investigar se o modelo de estimação por MQO agrupados é o mais adequado para se obter estimadores não enviesados e consistentes. Pois, seria lógico argumentar que há características não observáveis das escolas que podem estar correlacionadas com o desempenho de seus alunos; portanto, nesse caso, o método mais adequado de estimação, que produz estimadores consistentes seria o método de Efeitos Fixos. ${ }^{36}$

\footnotetext{
${ }^{36}$ Outro pressuposto necessário para que o método de estimação por Efeitos Fixos produza esti-
} 
A tabela 18 apresenta os resultados da estimação por Efeitos Fixos para o painel de escolas (1997-2005) com os resultados do exame de língua portuguesa da 4a. série do ensino fundamental. Como seria razoável supor, a estimação pelo método de Efeitos Fixos (EF) tampouco gera resultados muito diferentes daqueles apresentados nas tabelas 16 e 17 . Nota-se, entretanto, que já para o Modelo 6, no qual se utiliza exatamente a mesma especificação empregada no Modelo 1: a regressão da proficiência na rede escolar, não se encontra uma diferença estatisticamente significante. Isso era esperado, uma vez que o termo $\theta_{i}$, que representa o efeito específico não observado da escola - o que incluí todas as características escolares e características médias dos alunos da escola que são invariantes no tempo -, absorve o efeito de todas as variáveis omitidas do modelo. Ou seja, na estimação pelo método de EF, o termo de efeito específico das escolas dá conta de toda a heterogeneidade das variáveis omitidas do modelo.

Vale apontar que, os coeficientes estimados para a variável $E S T_{i j r}^{t}$, que indica que as escolas estão subordinadas às redes estaduais, permanecem positivos e com uma magnitude de aproximadamente de 5 (pontos na escala SAEB) para todas as especificações estimadas por EF; contudo, para nenhuma dessas especificações o coeficiente estimado exibe significância estatística aos níveis de 1, 5 ou 10 por cento.

Os modelos 7 e 8 da tabela 18 pouco acrescentam para a compreensão da diferença de desempenho dos alunos das redes públicas estaduais e municipais. Contudo, os resultados desses modelos não são contra intuitivos e, ainda, vão ao encontro do que tem sido reportado na literatura, que se vale das bases de dados do SAEB ou do Censo madores não enviesados é que as variáveis das escolas afetem a proficiência média de seus alunos, enquanto a proficiência média dos seus alunos não afetem as características das escolas. 
Tabela 18: Resultados da estimação por EF, painel de escolas (1997-2005) Português, 4a. série

\begin{tabular}{|c|c|c|c|}
\hline & $\begin{array}{c}(1) \\
\text { Modelo } 6\end{array}$ & $\begin{array}{c}(2) \\
\text { Modelo } 7\end{array}$ & $\begin{array}{c}(3) \\
\text { Modelo } 8\end{array}$ \\
\hline Estaduais & $\begin{array}{c}4.616 \\
(5.617)\end{array}$ & $\begin{array}{c}5.707 \\
(5.659)\end{array}$ & $\begin{array}{c}4.756 \\
(5.822)\end{array}$ \\
\hline Mãe (1-4 EF) & & $\begin{array}{c}0.197 \\
(2.562)\end{array}$ & $\begin{array}{l}-0.753 \\
(2.429)\end{array}$ \\
\hline Mãe (5-8 EF) & & $\begin{array}{l}-1.170 \\
(2.890)\end{array}$ & $\begin{array}{l}-2.445 \\
(2.727)\end{array}$ \\
\hline Mãe (EM) & & $\begin{array}{c}13.81^{* * *} \\
(3.633)\end{array}$ & $\begin{array}{l}8.552^{*} \\
(3.655)\end{array}$ \\
\hline Mãe (Superior) & & $\begin{array}{l}12.79^{* *} \\
(3.955)\end{array}$ & $\begin{array}{l}11.23^{* *} \\
(3.931)\end{array}$ \\
\hline Mãe (não sabe) & & $\begin{array}{l}4.113^{* *} \\
(1.265)\end{array}$ & $\begin{array}{c}2.049 \\
(1.217)\end{array}$ \\
\hline 10 anos & & & $\begin{array}{l}9.885^{* *} \\
(3.172)\end{array}$ \\
\hline 11 anos & & & $\begin{array}{l}-0.476 \\
(3.398)\end{array}$ \\
\hline 12 anos ou mais & & & $\begin{array}{c}0.912 \\
(3.149)\end{array}$ \\
\hline Homens & & & $\begin{array}{c}-10.26^{* * *} \\
(2.124)\end{array}$ \\
\hline Pardo & & & $\begin{array}{l}4.413^{*} \\
(1.824)\end{array}$ \\
\hline Negro & & & $\begin{array}{c}-10.32^{* * *} \\
(2.811)\end{array}$ \\
\hline Amarelo ou indígena & & & $\begin{array}{c}6.608 \\
(3.577)\end{array}$ \\
\hline Possui computador & & & $\begin{array}{c}-11.88^{* *} \\
(3.724)\end{array}$ \\
\hline Mora com o pai e a mãe & & & $\begin{array}{c}6.547^{* * *} \\
(1.931)\end{array}$ \\
\hline Trabalha fora & & & $\begin{array}{c}-7.942^{* * *} \\
(1.868)\end{array}$ \\
\hline Constante & $\begin{array}{c}157.2^{* * *} \\
(2.569)\end{array}$ & $\begin{array}{c}153.1^{* * *} \\
(3.112)\end{array}$ & $\begin{array}{c}154.4^{* * * *} \\
(4.701)\end{array}$ \\
\hline$N$ & 5347 & 5346 & 5334 \\
\hline$R^{2}$ within & 0.0002 & 0.017 & 0.073 \\
\hline$R^{2}$ Between & 0.0269 & 0.110 & 0.195 \\
\hline$R^{2}$ Overall & 0.0154 & 0.075 & 0.149 \\
\hline
\end{tabular}


Escolar, ${ }^{37}$ a respeito dos fatores condicionantes do aprendizado nas escolas brasileiras. O que, por conseguinte, confere mais credibilidade aos resultados estimados no presente trabalho.

Estabelecido que existe realmente uma diferença de cerca de 3 pontos percentuais entre as proficiências médias de estudantes das redes públicas estaduais e municipais e, mais importante, que esta diferença não é independente das características dos alunos e dos insumos escolares. Pode-se, então, avançar em direção ao objetivo secundário da presente seção; qual seja, investigar se a diferença de desempenho dos alunos das redes públicas estaduais e públicas municipais pode ser atribuída a disparidades em características dos alunos, de suas famílias, ou ainda, a disparidades nos insumos escolares. Mais especificamente, busca-se investigar se diferença na proficiência média das redes públicas de ensino pode ser explicada pelas disparidades em características dos alunos e de suas famílias ou, alternativamente, pode ser atribuída a desigualdades nos insumos escolares das redes de ensino.

Para tanto se ajustou um modelo regressão probabilística dado pela equação 2. Onde, a variável resposta - $M U N I_{j}^{t}$ - é uma variável do tipo dummy que identifica as escolas municipais e as variáveis explicativas são as características dos alunos (modelo 9), do ambiente familiar (modelo 10), das escolas (modelo 11), dos diretores (modelo 12) e, finalmente, dos professores (modelo 13). O exame dos fatores condicionantes de estar matriculado em escolas das redes públicas municipais é capaz de apontar a correlação condicional entre a lista de atributos analisados e a probabilidade de estar "vinculado" às redes municipais. Procura-se, assim, identificar os atributos dos

\footnotetext{
${ }^{37}$ A esse respetio ver, entre outros, Franco e Menezes-Filho, 2009, Felício e Fernandes, 2006 e Menezes-Filho, 2007.
} 
alunos, das famílias, das escolas, dos professores e dos diretores que compõem o perfil das escolas das redes municipais, quando comparadas às escolas das redes públicas estaduais (categoria omitida para esses modelos). As tabelas 19, 20 e $21^{38}$ apresentam os resultados dessas estimações via regressão probabilística.

Os resultados do modelo 9 , apresentados na coluna (1) da tabela de 19, parecem confirmar a hipótese de que pode haver, de fato, disparidades na composição do alunato entre as redes públicas estaduais e municipais. Quando consideradas apenas as características dos alunos, as escolas municipais parecem receber mais alunos negros, se comparadas às escolas estaduais ${ }^{39}$. O coeficiente estimado é positivo e significante a 10 por cento para todas as especificações apresentadas na tabela 19 , o que assevera consistência e robustez ao achado. Quanto às demais categorias de cor, não parece haver disparidades adicionais na composição racial declarada pelos alunos entre as duas redes. Vale ressaltar, ainda, que no cômputo geral das categorias de cor, as escolas municipais parecem receber menos alunos que se declaram brancos (categoria omitida).

Quando se analisa a idade dos alunos, percebem-se maiores desvios na composição do alunato entre as duas redes. Os coeficientes estimados para as categorias "11 anos" e "12 anos ou mais" são positivos e estatisticamente significantes ao nível de

\footnotetext{
${ }^{38}$ As tabelas 14 e 15 são apenas a continuação dos resutlados reportados na tabela 13. As tabelas foram cortadas apenas para se preservar a clareza e a inteligibilidade na exposição dos resultados.

${ }^{39}$ Para ser mais rigoroso, o que a estimação via regressão probabilística informa é que, se o aluno $i$ matriculado na 4a série do ensino fundamental, declarou-se negro, ele tem maiores chances, mantidas todas as demais variáveis constantes, de estar matriculado numa escola das redes públicas municipais do que numa escola das redes públicas estaduais. Feito esse esclarecimento, vale observar que na presente seção, por meras questões estilísticas, afirmar-se-á, por exemplo que a prevalência de alunos negros é maior (tudo o mais constante) nas escolas das redes públicas municipais, se comparadas às escolas das redes públicas estaduais. Admite-se que essa interpretação não é a mais rigorosa. Entretanto, por aproximação, tal interpretação não é equivocada.
} 
Tabela 19: Correlação condicional entre os atributos e a probabilidade de estar matriculado na rede municipal

\begin{tabular}{|c|c|c|c|c|c|c|}
\hline & $\begin{array}{c}(1) \\
\text { Modelo } 9\end{array}$ & $\begin{array}{c}(2) \\
\text { Modelo } 10\end{array}$ & $\begin{array}{c}\text { (3) } \\
\text { Modelo } 11\end{array}$ & $\begin{array}{c}(4) \\
\text { Modelo } 12\end{array}$ & $\begin{array}{c}(5) \\
\text { Modelo } 13\end{array}$ & $\begin{array}{c}(6) \\
d_{y} / d_{x}\end{array}$ \\
\hline 10 anos & $\begin{array}{c}0.0377 \\
(0.0196)\end{array}$ & $\begin{array}{l}0.0451^{*} \\
(0.0207)\end{array}$ & $\begin{array}{l}0.0695^{* *} \\
(0.0269)\end{array}$ & $\begin{array}{l}0.0825^{*} \\
(0.0335)\end{array}$ & $\begin{array}{l}0.0874^{*} \\
(0.0344)\end{array}$ & 0.035 \\
\hline 11anos & $\begin{array}{l}0.133^{* * *} \\
(0.0220)\end{array}$ & $\begin{array}{l}0.117^{* * *} \\
(0.0231)\end{array}$ & $\begin{array}{l}0.145^{* * *} \\
(0.0305)\end{array}$ & $\begin{array}{l}0.152^{* * *} \\
(0.0377)\end{array}$ & $\begin{array}{l}0.154^{* * *} \\
(0.0391)\end{array}$ & 0.061 \\
\hline 12 anos ou + & $\begin{array}{l}0.195^{* * *} \\
(0.0251)\end{array}$ & $\begin{array}{l}0.162^{* * *} \\
(0.0255)\end{array}$ & $\begin{array}{l}0.137^{* * *} \\
(0.0343)\end{array}$ & $\begin{array}{l}0.120^{* *} \\
(0.0422)\end{array}$ & $\begin{array}{l}0.125^{* *} \\
(0.0440)\end{array}$ & 0.049 \\
\hline Homens & $\begin{array}{l}-0.0174^{*} \\
(0.00728)\end{array}$ & $\begin{array}{l}-0.0201^{* *} \\
(0.00771)\end{array}$ & $\begin{array}{l}-0.00634 \\
(0.0101)\end{array}$ & $\begin{array}{l}-0.00499 \\
(0.0131)\end{array}$ & $\begin{array}{l}-0.00634 \\
(0.0137)\end{array}$ & -0.002 \\
\hline Pardo & $\begin{array}{l}0.00899 \\
(0.0123)\end{array}$ & $\begin{array}{l}0.00915 \\
(0.0127)\end{array}$ & $\begin{array}{c}0.0210 \\
(0.0166)\end{array}$ & $\begin{array}{l}0.00765 \\
(0.0217)\end{array}$ & $\begin{array}{l}0.00771 \\
(0.0225)\end{array}$ & 0.003 \\
\hline Negro & $\begin{array}{l}0.0379^{*} \\
(0.0158)\end{array}$ & $\begin{array}{l}0.0329^{*} \\
(0.0164)\end{array}$ & $\begin{array}{l}0.0482^{*} \\
(0.0212)\end{array}$ & $\begin{array}{l}0.0690^{*} \\
(0.0269)\end{array}$ & $\begin{array}{c}0.0623^{*} \\
(0.0277)\end{array}$ & 0.024 \\
\hline Amarelo ou indigena & $\begin{array}{l}0.00697 \\
(0.0192)\end{array}$ & $\begin{array}{c}0.0158 \\
(0.0201)\end{array}$ & $\begin{array}{l}0.0579 * \\
(0.0262)\end{array}$ & $\begin{array}{c}0.0477 \\
(0.0342)\end{array}$ & $\begin{array}{c}0.0544 \\
(0.0360)\end{array}$ & 0.021 \\
\hline Mãe (1-4 EF) & & $\begin{array}{c}0.0483^{* * *} \\
(0.0129)\end{array}$ & $\begin{array}{c}0.0378^{*} \\
(0.0165)\end{array}$ & $\begin{array}{c}0.0181 \\
(0.0203)\end{array}$ & $\begin{array}{c}0.0142 \\
(0.0212)\end{array}$ & 0.005 \\
\hline Mãe (5-8 EF) & & $\begin{array}{c}-0.0800^{* * *} \\
(0.0142)\end{array}$ & $\begin{array}{c}-0.0605^{* * *} \\
(0.0177)\end{array}$ & $\begin{array}{c}-0.0800^{* * *} \\
(0.0225)\end{array}$ & $\begin{array}{c}-0.0948^{* * *} \\
(0.0235)\end{array}$ & -0.049 \\
\hline Mãe (EM) & & $\begin{array}{c}-0.145^{* * *} \\
(0.0174)\end{array}$ & $\begin{array}{c}-0.141^{* * *} \\
(0.0207)\end{array}$ & $\begin{array}{c}-0.121^{* * *} \\
(0.0259)\end{array}$ & $\begin{array}{c}-0.126^{* * *} \\
(0.0274)\end{array}$ & -0.002 \\
\hline Mãe (Superior) & & $\begin{array}{c}-0.163^{* * *} \\
(0.0216)\end{array}$ & $\begin{array}{c}-0.145^{* * *} \\
(0.0243)\end{array}$ & $\begin{array}{c}-0.132^{* * *} \\
(0.0288)\end{array}$ & $\begin{array}{c}-0.125^{* * *} \\
(0.0298)\end{array}$ & -0.049 \\
\hline Mãe (não sabe) & & $\begin{array}{c}-0.0453^{* * *} \\
(0.0117)\end{array}$ & $\begin{array}{l}-0.0171 \\
(0.0140)\end{array}$ & $\begin{array}{l}-0.0103 \\
(0.0175)\end{array}$ & $\begin{array}{r}-0.00650 \\
(0.0183)\end{array}$ & -0.002 \\
\hline Tem computador & & $\begin{array}{c}-0.124^{* * *} \\
(0.0243)\end{array}$ & $\begin{array}{l}-0.132^{* * *} \\
(0.0284)\end{array}$ & $\begin{array}{c}-0.0933^{* *} \\
(0.0354)\end{array}$ & $\begin{array}{l}-0.0873^{*} \\
(0.0369)\end{array}$ & -0.034 \\
\hline Mora c/ o pai e a mãe & & $\begin{array}{c}0.0613^{* * *} \\
(0.0101)\end{array}$ & $\begin{array}{c}0.0432^{* * *} \\
(0.0128)\end{array}$ & $\begin{array}{l}0.0446^{* *} \\
(0.0159)\end{array}$ & $\begin{array}{c}0.0426^{*} \\
(0.0166)\end{array}$ & 0.016 \\
\hline Trabalha fora & & $\begin{array}{l}0.136^{* * *} \\
(0.0161)\end{array}$ & $\begin{array}{l}0.0671^{* *} \\
(0.0209)\end{array}$ & $\begin{array}{l}0.0514^{*} \\
(0.0233)\end{array}$ & $\begin{array}{c}0.0432 \\
(0.0243)\end{array}$ & 0.017 \\
\hline Controles $\mathrm{p} / \mathrm{UF}$ & $\operatorname{sim}$ & $\operatorname{sim}$ & sim & $\operatorname{sim}$ & $\operatorname{sim}$ & \\
\hline $\begin{array}{l}\text { Controles } \mathrm{p} / \text { ano } \\
N\end{array}$ & $\begin{array}{c}\operatorname{sim} \\
118558\end{array}$ & $\begin{array}{c}\operatorname{sim} \\
105192\end{array}$ & $\begin{array}{l}\operatorname{sim} \\
61876\end{array}$ & $\begin{array}{c}\operatorname{sim} \\
38885\end{array}$ & $\begin{array}{c}\operatorname{sim} \\
35527\end{array}$ & \\
\hline
\end{tabular}

Erros padrão ajustados em parênteses

Fonte: Cálculos próprios a partir de dados do SAEB/INEP

${ }^{*} p<0.05,{ }^{* *} p<0.01,{ }^{* * *} p<0.001$ 
Tabela 20: Correlação condicional entre os atributos e a probabilidade de estar matriculado na rede municipal (continuação da tabela 13, características da escola)

\begin{tabular}{|c|c|c|c|c|c|c|}
\hline & $\begin{array}{c}(1) \\
\text { Modelo } 9\end{array}$ & $\begin{array}{c}(2) \\
\text { Modelo } 10\end{array}$ & $\begin{array}{c}(3) \\
\text { Modelo } 11\end{array}$ & $\begin{array}{c}(4) \\
\text { Modelo } 12\end{array}$ & $\begin{array}{c}(5) \\
\text { Modelo } 13\end{array}$ & $\begin{array}{c}(6) \\
d_{y} / d_{x}\end{array}$ \\
\hline Escola Rural & & & $\begin{array}{c}0.133 \\
(0.0732)\end{array}$ & $\begin{array}{l}-0.0390 \\
(0.0985)\end{array}$ & $\begin{array}{r}-0.0946 \\
(0.104)\end{array}$ & 0.038 \\
\hline Quadra de esportes & & & $\begin{array}{c}0.0499 \\
(0.0546)\end{array}$ & $\begin{array}{l}0.194^{* *} \\
(0.0683)\end{array}$ & $\begin{array}{c}0.214^{* *} \\
(0.0711)\end{array}$ & 0.084 \\
\hline Lab. de ciências & & & $\begin{array}{c}-0.383^{* * *} \\
(0.0781)\end{array}$ & $\begin{array}{c}-0.435^{* * *} \\
(0.0949)\end{array}$ & $\begin{array}{c}-0.404^{* * *} \\
(0.0981)\end{array}$ & -0.158 \\
\hline Lab. de informática & & & $\begin{array}{c}0.131 \\
(0.0695)\end{array}$ & $\begin{array}{c}0.120 \\
(0.0823)\end{array}$ & $\begin{array}{c}0.134 \\
(0.0852)\end{array}$ & 0.053 \\
\hline Biblioteca & & & $\begin{array}{l}-0.165^{* *} \\
(0.0544)\end{array}$ & $\begin{array}{l}-0.151^{*} \\
(0.0682)\end{array}$ & $\begin{array}{l}-0.161^{*} \\
(0.0710)\end{array}$ & -0.064 \\
\hline Merenda & & & $\begin{array}{l}0.340^{* * * *} \\
(0.0686)\end{array}$ & $\begin{array}{l}0.286^{* * * *} \\
(0.0822)\end{array}$ & $\begin{array}{l}0.272^{* *} \\
(0.0857)\end{array}$ & 0.107 \\
\hline Transporte & & & $\begin{array}{l}0.175^{* *} \\
(0.0533)\end{array}$ & $\begin{array}{c}0.177^{* *} \\
(0.0629)\end{array}$ & $\begin{array}{l}0.184^{* *} \\
(0.0651)\end{array}$ & 0.073 \\
\hline Curso Superior & & & & $\begin{array}{l}-0.233^{* *} \\
(0.0877)\end{array}$ & $\begin{array}{l}-0.234^{*} \\
(0.0924)\end{array}$ & -0.092 \\
\hline Capacitação & & & & $\begin{array}{l}0.350^{* * *} \\
(0.0941)\end{array}$ & $\begin{array}{l}0.408^{* * *} \\
(0.0981)\end{array}$ & 0.046 \\
\hline Experiência (5-10 anos) & & & & $\begin{array}{c}-0.106 \\
(0.0665)\end{array}$ & $\begin{array}{c}-0.128 \\
(0.0695)\end{array}$ & -0.050 \\
\hline Experiência (+ 10 anos) & & & & $\begin{array}{l}-0.255^{* *} \\
(0.0985)\end{array}$ & $\begin{array}{l}-0.264^{*} \\
(0.103)\end{array}$ & -0.104 \\
\hline Eleição & & & & $\begin{array}{c}-0.385^{* * *} \\
(0.0679)\end{array}$ & $\begin{array}{c}-0.385^{* * *} \\
(0.0706)\end{array}$ & -0.152 \\
\hline Projeto pedagógico (Sec.) & & & & $\begin{array}{l}0.0568 \\
(0.113)\end{array}$ & $\begin{array}{l}0.0665 \\
(0.119)\end{array}$ & 0.026 \\
\hline Projeto pedagógico (Dir e prof) & & & & $\begin{array}{l}-0.237^{* *} \\
(0.0885)\end{array}$ & $\begin{array}{l}-0.212^{*} \\
(0.0923)\end{array}$ & -0.083 \\
\hline Rotatividade & & & & $\begin{array}{c}-0.00193 \\
(0.125)\end{array}$ & $\begin{array}{c}-0.00619 \\
(0.131)\end{array}$ & 0.002 \\
\hline Faltas & & & & $\begin{array}{l}-0.117 \\
(0.126)\end{array}$ & $\begin{array}{l}-0.107 \\
(0.129)\end{array}$ & 0.042 \\
\hline Controles p/ UF & $\operatorname{sim}$ & $\operatorname{sim}$ & $\operatorname{sim}$ & $\operatorname{sim}$ & $\operatorname{sim}$ & \\
\hline Controles $\mathrm{p} /$ ano & $\operatorname{sim}$ & $\operatorname{sim}$ & $\operatorname{sim}$ & $\operatorname{sim}$ & $\operatorname{sim}$ & \\
\hline
\end{tabular}

Erros padrão ajustados em parênteses

Fonte: Cálculos próprios a partir de dados do SAEB/INEP

${ }^{*} p<0.05,{ }^{* *} p<0.01,{ }^{* * *} p<0.001$ 
Tabela 21: Correlação condicional entre os atributos e a probabilidade de estar matriculado na rede municipal, (contuniação da tabela 13, características do professor)

\begin{tabular}{|c|c|c|c|c|c|c|}
\hline & $\begin{array}{c}(1) \\
\text { Modelo } 9\end{array}$ & $\begin{array}{c}(2) \\
\text { Modelo } 10\end{array}$ & $\begin{array}{c}(3) \\
\text { Modelo } 11\end{array}$ & $\begin{array}{c}(4) \\
\text { Modelo } 12\end{array}$ & $\begin{array}{c}(5) \\
\text { Modelo } 13\end{array}$ & $\begin{array}{c}(6) \\
d_{y} / d_{x}\end{array}$ \\
\hline Curso Superior & & & & & $\begin{array}{c}0.169^{* *} \\
(0.0622)\end{array}$ & 0.067 \\
\hline Capacitação & & & & & $\begin{array}{c}0.117 \\
(0.0684)\end{array}$ & 0.047 \\
\hline Concursado & & & & & $\begin{array}{c}0.0551 \\
(0.0576)\end{array}$ & 0.022 \\
\hline Idade (30-40 anos) & & & & & $\begin{array}{c}0.101 \\
(0.0795)\end{array}$ & 0.040 \\
\hline Idade (+ 40 anos) & & & & & $\begin{array}{l}-0.0172 \\
(0.0943)\end{array}$ & -0.006 \\
\hline Experiência (5-10 anos) & & & & & $\begin{array}{l}-0.00541 \\
(0.0712)\end{array}$ & -0.002 \\
\hline Experiência ( +10 anos) & & & & & $\begin{array}{l}-0.217^{*} \\
(0.0992)\end{array}$ & -0.083 \\
\hline de $2-5$ anos na escola & & & & & $\begin{array}{l}-0.0306 \\
(0.0709)\end{array}$ & -0.012 \\
\hline+5 anos na escola & & & & & $\begin{array}{l}-0.212^{* *} \\
(0.0661)\end{array}$ & -0.084 \\
\hline Constante & $\begin{array}{c}-0.737^{* * *} \\
(0.193)\end{array}$ & $\begin{array}{c}-0.783^{* * *} \\
(0.203)\end{array}$ & $\begin{array}{c}-0.883^{* * *} \\
(0.227)\end{array}$ & $\begin{array}{c}0.0905^{* * *} \\
(0.257)\end{array}$ & $\begin{array}{c}-1.405^{* * *} \\
(0.341)\end{array}$ & \\
\hline Controles p/ UF & $\operatorname{sim}$ & $\operatorname{sim}$ & $\operatorname{sim}$ & $\operatorname{sim}$ & $\operatorname{sim}$ & \\
\hline $\begin{array}{l}\text { Controles } \mathrm{p} / \text { ano } \\
N\end{array}$ & $\begin{array}{c}\operatorname{sim} \\
118558\end{array}$ & $\begin{array}{c}\operatorname{sim} \\
105192\end{array}$ & $\begin{array}{c}\operatorname{sim} \\
61876\end{array}$ & $\begin{array}{c}\operatorname{sim} \\
38885\end{array}$ & $\begin{array}{c}\operatorname{sim} \\
35527\end{array}$ & \\
\hline
\end{tabular}

Erros padrão ajustados em parênteses

Fonte: Cálculos próprios a partir de dados do SAEB/INEP

${ }^{*} p<0.05,{ }^{* *} p<0.01,{ }^{* * *} p<0.001$

1 por cento, indicando que, de fato, a probabilidade de que alunos acima da idade escolar recomendada para a série estejam matriculados em escolas das redes publicas municipais é maior, do que as chances de que estejam em escolas das redes públicas estaduais.

Os resultados do modelo 10 , apresentados na coluna (2) da tabela de 19 , reafirmam 
esse indício de que pode estar ocorrendo um processo de seleção do alunato entre as redes públicas estaduais e municipais. Esse modelo inclui, além das características do aluno, o conjunto de variáveis acerca do ambiente familiar dos estudantes.

Quando se examinam os coeficientes estimados para o nível de escolaridade da mãe, nota-se claramente que as chances das escolas municipais recebem alunos cujas mães, em média, têm menor nível de escolaridade são consideravelmente maiores, quando comparadas às escolas estaduais. Ademais, a probabilidade das escolas estaduais recebem alunos cujas mães têm maior nível de escolaridade também é significativamente maior. Haja vista que os coeficientes estimados para as categorias que representam níveis mais elevados de escolaridade, tais como: ensino médio e curso superior, mostram menor prevalência em escolas das redes públicas municipais, resultados que são robustos às diferentes especificações e estatisticamente significantes ao nível de 1 por cento. Já para os níveis mais baixos de escolaridade, tal como, ensino fundamental incompleto (estudou até a 4a. série), essa situação se inverte, sendo mais frequente nas escolas públicas municipais, embora esse resultados não se mostrem tão robustos entre as diferentes especificações. Os coeficientes se mantém sempre positivos, mas, são estatisticamente significantes apenas para os modelos 10 e 11 , aos níveis de 1 e 10 por cento, respectivamente. Enfim, esses achados corroboram a idéia de que famílias com maior nível escolaridade tendem, em média, a matricular seus filhos em escolas das redes públicas estaduais mais frequentemente; e famílias com menores níveis de escolaridade tendem, em média, a matricular seus filhos em escolas das redes públicas municipais.

As demais características do ambiente familiar, para as quais se tem informação, tam- 
bém indicam que pode haver de fato uma espécie de estratificação social entre as redes públicas de ensino. Famílias que possuem computador em casa tem menos probabilidade de matricular seus filhos em escolas das redes públicas municipais. E a prevalência do trabalho fora de casa em idade escolar é um indicador de que as chances do aluno estar matriculado nas escolas das redes municipais é maior. Esses resultados são estatisticamente significantes entre os diferentes modelos apresentados na tabela 19. Por outro lado, alunos que vivem com o pai e com a mãe tendem, em média, estar matriculados com mais frequência em escolas que integram as redes públicas municipais.

Em resumo, os resultados apresentados na tabela 19 acerca das características dos alunos e do ambiente familiar corroboram a hipótese de que parece haver alguma estratificação social entre as redes públicas de ensino. A prevalência de alunos fora da idade recomendada para a série na qual estão matriculados é maior nas escolas municipais. Alunos que se declaram negros apresentam, em média, maiores chances de estarem matriculados em escolas das redes públicas municipais. Outras características do ambiente familiar também apontam para existência desse processo de estratificação entre as redes. Particularmente, quando se examina o comportamento das variáveis que procuram captar o nível de escolaridade da mãe dos alunos, verifica-se que, as categorias que indicam níveis mais elevados de escolaridade (ensino médio e curso superior) diminuem significativamente a chance dos alunos oriundos dessas famílias de estarem matriculados em escolas das redes públicas municipais. Ademais, a presença de computadores em casa aumenta chances de que os alunos estejam matriculados em escolas estaduais. O trabalho fora de casa em idade escolar, por outro lado, tende elevar a probabilidade dos alunos estarem matriculados em escolas das redes públicas 
municipais.

O modelo 11, apresentado na coluna (3) das tabelas 19 e 20, inclui além de características dos alunos e do ambiente familiar, as características de infraestrutura das escolas. Nota-se que que, no geral, não há grandes disparidades na oferta de equipamentos de ensino entre as escolas das redes públicas municipais e públicas estaduais.

Se, por um lado, a presença de quadra de esportes indica que as chances da escola estar vinculada às redes municipais é maior; em se tratando da presença de laboratório de ciências nas escolas a situação se inverte. Os coeficientes estimados para a variável Quadra de esportes são positivos e estatisticamente significantes para duas das três estimações. Quando se analisa os coeficientes estimados para o item Laboratótio de ciências os coeficientes são sempre negativos e significantes em todas as estimações ao nível de 1 por cento, o que pode ser interpretado como um indicador de que as escolas equipadas com laboratórios de ciências têm menor probabilidade de estarem subordinadas às redes municipais.

Não há evidências empíricas de disparidades na oferta de laboratórios de informática entre as redes municipais e estaduais. Com relação a presença de bibliotecas, percebese que a situação das redes públicas estaduais é mais positiva. As escolas que possuem bibliotecas têm mais chances de estarem integradas às redes estaduais do que às municipais. Como demonstra o coeficiente estimado para essa variável que é negativo e significante para todas as especificações estimadas. Quando se examina a oferta de merenda e transporte público, a situação é amplamente favorável às escolas das redes públicas municipais. Percebe-se que para os itens Merenda e Transporte, os coeficientes estimados são positivos e significantes para todas as especificações estimadas. 
O modelo 12, apresentado na coluna (4) das tabelas 19 e 20, traz além de todas as variáveis já comentadas, as características observáveis dos diretores das escolas. No que tange ao conjunto de variáveis dos diretores, as evidências empíricas parecem ratificar a hipótese que há um pequeno, porém consistente, desvio positivo em favor das escolas que integram as redes públicas estaduais.

A prevalência de diretores com curso superior é maior nas escolas das redes estaduais. Os coeficientes estimados para essa variável são negativos e estatisticamente significantes para as estimações apresentadas na tabela 20. Com relação ao item Capacitação, nota-se que a situação é favorável às escolas das redes municipais. Ou seja, os diretores que participaram de cursos de capacitação nos últimos 2 anos têm maiores chances de estarem dirigindo escolas das redes municipais do que escolas das redes estaduais.

Contudo, quando se analisa o conjunto de variáveis que diz respeito a experiência na função de direção, percebe-se que os diretores das escolas estaduais tendem a ter, em média, mais experiência do que os diretores de escolas municipais. Para o item que indica de 5 a 10 anos de experiência na função os coeficientes são negativos, porém não significantes. Para o item que indica mais de 10 anos de experiência na função os coeficientes estimados são também negativos, mas significantes para as duas especificações testadas. No conjunto, então, percebe-se que os diretores com menos experiência no cargo tendem, em média, a dirigir escolas das redes municipais com mais frequência do que escolas das redes estaduais. Com relação ao processo com que foram conduzidos à direção da escola, nota-se que enquanto nas escolas estaduais é prevalente o emprego de eleições ou concursos (representados sob a categoria Eleição), 
nas escolas municipais ainda prevalece a indicação política (categoria omitida). Os estimadores para esta variável são negativos e significantes, ao nível de 1 por cento, para ambas especificações testadas.

Quando se examina como foi elaborado o projeto pedagógico da escola, a disparidade entre as redes públicas municipais e estaduais também se faz presente. Se não há evidências empíricas que indiquem diferenças relevantes para a categoria Projeto pedagógico (Sec.), o qual indica que a escola adotou o projeto pedagógico elaborado pela Secretaria (Municipal ou Estadual) de Educação, sem modificações adcionais. Para a categoria que tem mais impacto sobre o aprendizado dos alunos ${ }^{40}$, Projeto Pedagógico (Dir. e prof.), que é a elaborção de um projeto pedagógico pela direção da escola com a participação dos professores, as chances de que esse projeto pedagógico tenha sido elaborado em uma escola estadual é notavelmente maior do que tenha sido feito dessa maneira em uma escola municipal. Os coeficientes para essa variável são negativos e significantes para ambas as especificações apresentadas na tabela 20. Finalmente, cabe notar que não há evidências empíricas da ocorrência de disparidades relevantes entre as redes públicas municipais e estaduais para as variáveis Faltas e Rotatividade, que indicam problemas com a absenteísmo de professores e problemas com a alta rotatividade de professores, respectivamente.

O modelo 13, apresentado na coluna (4) da tabela 21, traz a especificação mais completa com todas as variáveis dos alunos, do ambiente familiar, da escola, dos diretores e dos professores. Quando se examina o comportamento das variáveis observáveis dos professores, percebe-se que não há praticamente disparidades entre as escolas das re-

\footnotetext{
${ }^{40}$ ver a esse respeito a tabela 16, além dos já citados trabalhos de Franco e Menezes-Filho, 2009, Felício e Fernandes, 2006 e Menezes-Filho, 2007.
} 
des públicas estaduais e municipais para esse conjunto de características. No entanto, cabe destacar que, a prevalência de professores com curso superior é mais frequente em escolas das redes municipais. Como indica o coeficiente estimado para a variável Curso superior, cujo coeficiente é positivo e estatisticamente significante ao nível de 5 por cento. Por outro lado, quando se analisa o conjunto de variáveis que procuram captar a experiência do professor e sua permanência numa mesma escola, nota-se que a disparidade, embora pequena, tende a favorecer as escolas das redes estaduais. Por exemplo, as chances de que um professor com mais de 10 anos de experiência seja docente de uma escola estadual é consideravelmente maior do que de uma escola municipal. Como aponta o coeficiente estimado para a variável Experiência ( + de 10 anos) que é negativo e significante a 10 por cento. Assim como para a variável, + de 5 anos na escola, cujo estimador é negativo e significante, indicando que os professores que permanecem por mais de 5 anos numa mesma escola tendem, em média, a ser mais frequentes nas escolas das redes públicas estaduais. Para as demais variáveis, referentes à forma de contratação de professores e a faixa etária dos docentes não há evidências empíricas de disparidades entre as redes de ensino municipais e estaduais.

Ademais, cabe acrescentar que, a coluna (5) das tabelas 19, 20 e 21 traz os efeitos marginais das variáveis explicativas do modelo 13 , isto é, da especificação que inclui todas as variáveis dos alunos, do ambiente familiar, da escola, do diretor e dos professores. O efeito marginal pode ser entendido como o acréscimo na probabilidade de que o aluno esteja matriculado em uma escola municipal, dada a presença daquela característica específica e mantidas todas as demais variáveis constantes. Assim, por exemplo, o efeito marginal da variável 12 anos é igual a 0.035 . Esse efeito pode ser interpretado como um acréscimo de 0.035 por cento nas chances de que um aluno com 
com 12 anos ou mais esteja matriculado numa escola da rede municipal, tudo o mais constante.

Em suma, os modelos estatísticos apresentados nas tabelas 19, 20, 21, fornecem fortes evidências empíricas que sugerem que a diferença de desempeno acadêmico nos exames do SAEB, verificada anteriormente, parece estar mais associada a um processo de estratificação social do alunato entre as redes públicas de ensino fundamental do que a disparidades nos insumos escolares ou nas condições de oferta de ensino entre as redes municipais e estaduais. Primeiramente, nota-se que as maiores disparidades entre as redes dão-se justamente quanto às características dos alunos e do ambiente familiar. Mais especificamente, as disparidades estão mormente relacionadas à idade dos alunos e à educação da mãe. Alunos acima da idade recomendada para a série têm maiores chances de estar matriculados em escolas municipais. Como também, alunos cujas mães têm o ensino médio ou o curso superior completo têm, em média, mais chances de estar matriculados em escolas das redes públicas estaduais. Outras características socioeconômicas, como, a presença de computador em casa e a prevalência de trabaIho fora de casa em idade escolar, também corroboram a hipótese da estratificação social. Uma vez que, enquanto a primeira característica pode ser interpretada como um indicador de maiores probabilidades de frequentar escolas das redes estaduais; a o trabalho fora de casa aumenta as chances do aluno de frequentar escolas das redes municipais.

Em segundo lugar, pode-se observar que há também algumas disparidades nos insumos escolares: escolas equipadas com bibliotecas e laboratórios de ciências tendem, em média, a integrar as redes estaduais com mais frequência; os diretores com curso 
superior, mais experiência na função ou que assumiram o cargo de direção da escola por meio de processos meritocráticos, tais como: seleção ou eleições, têm maior probabilidade de estarem dirigindo escolas estaduais do que municipais. Há, por outro lado, alguns itens nos quais as escolas municipais são melhor servidas; tais como: merenda e transporte escolar, professores com curso superior e escolas equipadas com quadras de esportes. Esses itens têm, em média, maiores chances de estarem presentes em escolas municipais do que em escolas dirigidas pelos estados.

A estratificação social do alunato e as discrepâncias nos insumos escolares, provavelmente, se complementam e interagem na prática cotidiana das escolas públicas de ensino fundamental. Entretanto, do ponto de vista estritamente analítico, quando se examina as disparidades mencionadas nos paragrafos precedentes à luz dos trabalhos que investigaram os aspectos condicionantes do aprendizado nas escolas brasileiras ${ }^{41}$, pode-se concluir que a diferença nas proficiências médias entre os alunos das redes estaduais e municipais está mais associada ao processo de estratificação social do alunato entre as redes de ensino público; pois, a literatura tem demonstrado que o fator único mais relevante para se explicar o rendimento acadêmico dos estudantes é o nível educacional dos pais, particularmente a escolaridade da mãe (Glewwe \& Kremer 2006). Ademais, como se pode verificar nas tabelas 16 e 18 acima o atraso escolar têm um acentuado efeito negativo sobre a proficiência média dos alunos.

No entanto, é de fundamental importância observar que, não obstante se possa estabelecer, à luz das evidências empíricas, que a diferença na proficiência média nos exames do SAEB entre as redes municipais e estaduais está mais associada a estratifi-

\footnotetext{
${ }^{41}$ ver a esse respeito, entre outros, os já citados: Franco e Menezes-Filho, 2009, Felício e Fernandes, 2006 e Menezes-Filho, 2007; além da tabela 16 acima.
} 
cação social do alunato nas redes do que a disparidades nos insumos escolares; não se pode afirmar com a mesma certeza a direção do processo de causalidade entre esses dois fenômenos sociais. Pois, se por um lado, é razoável supor que a diferença no desempenho acadêmico entre as redes é decorrente da estratificaçao do alunato. Por outra lado, é lógico afirmar que a estratificação social do alunato é causada pelo diferencial de desempenho escolar entre as redes públicas municipais e estaduais. Assim, por exemplo, é verossímel supor que pais mais educados procurem escolas com melhor reputação para seus filhos. Como seria, igualmente, coerente especular que pais mais educados troquem seus filhos de escola em decorrência de más avaliações em exames padronizados do MEC, tais como: o ENEN, o SAEB ou o IDEB.

A título de conclusão, vale destacar os principais achados da presente seção: $(i)$ há, de fato, uma diferença estatisticamente significante de desempenho, tanto em português como em matemática, entre estudantes de escolas públicas municipais e estaduais. Os estudantes da 4a. série do ensino fundamental das escolas estaduais têm um rendimento médio, aproximadamente, 3 pontos percentuais acima do que seu pares de escolas públicas municipais. (ii) Quando se controlam as características dos alunos, do ambiente familiar e das escolas, a diferença de desempenho acadêmico torna-se praticamente nula e estatisticamente não significante. (iii) As evidências empíricas sugerem que a diferença de desempenho acadêmico nos exames do SAEB entre as redes públicas estaduais e municipais está mais associada ao processo de estratificação social do alunato nas redes do que, especificamente, a disparidades nos insumos escolares ou nas condições de ensino oferecidas pelas redes públicas municipais e estaduais. (iv) Nesse ponto, ainda não é possível estabelecer com segurança a direção em que opera o processo de causalidade entre esses dois fenômenos. Ou seja, não se pode afirmar 
com certeza se é a estratificação do alunato entre as redes que causa a diferença de desempenho acadêmico das escolas estaduais e municipais; ou se, alternativamente, a estratificação do alunato é decorrente da diferença de rendimento escolar entre as duas redes públicas de ensino. 


\subsection{O Efeito da municipalização nas escolas}

Vale recapitular que, nesta seção se objetiva responder, especificamente, à seguinte questão: qual o impacto da municipalização das escolas que foram transferidas do controle dos estados para os municípios na proficiência média dos seus alunos nos exames do SAEB e da Prova Brasil? Tal pergunta envolve, evidentemente, um exercício de comparação com as escolas que não foram transferidas. Portanto, poder-se-ia reformular a pergunta original nos seguintes termos: qual o efeito da municipalização das escolas sobre a proficiência média dos seus alunos, quando comparados aos alunos das escolas que permaneceram sob a gestão dos estados e dos municípios?

Como comentado no capítulo quarto desse estudo, para responder a essa pergunta se lança mão do método de estimação por diferença-em-diferenças (DID). A estimação por diferença-em-diferenças baseia-se na comparação das diferenças no desempenho acadêmico nos exames em matemática e língua portuguesa entre o grupo de escolas que foram municipalizadas - aqui denominado grupo tratamento, ou simplesmente, grupo EM - e os dois grupos de escolas que permaneceram sob a gestão municipal ou estadual - aqui denominados grupos controle, ou simplesmente, grupos EE e MM. Grosso modo, a estimação por diferença-em-diferenças é a comparação das mudanças ao longo do período de 1997 a 2007 na proficiência média das escolas que foram municipalizadas (grupo EM) com as mudanças ao longo do mesmo período na proficiência média das escolas que permaneceram sob controle dos estados (grupo EE) e dos municípios (grupo MM).

O efeito da municipalização que se pretende estimar é exatamente o efeito médio do grupo EM em comparação com os grupos controle EE e MM. Isto é, trata-se da 
diferença nas proficiências médias do grupo de escolas que foi transferido do controle estadual para o controle municipal cotejada à diferença nas proficiências médias dos grupos de escolas que permaneceram sob o controle dos estados e municípios.

Figura 8: Proficiências médias em língua portuguesa por grupo de escolas: SAEB (1997-2005) e Prova Brasil (2007)

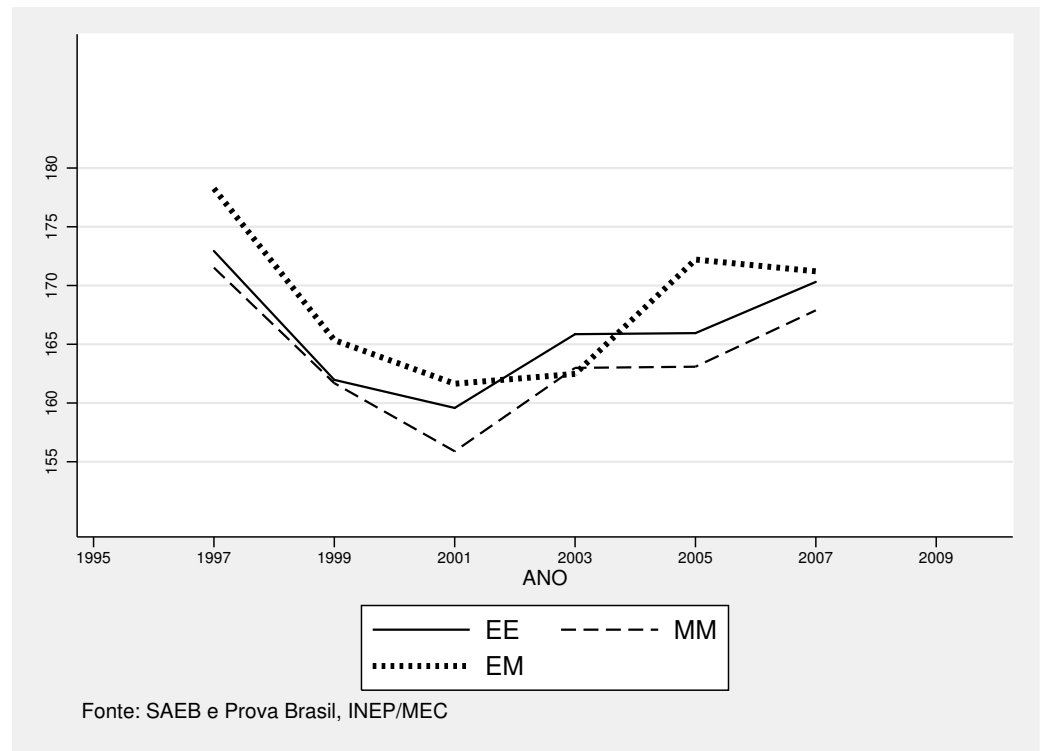

As figuras 8 e 9 apresentam a exposição visual do comportamento das proficiências médias, em português e matemática, segundo o grupo de escolas e o ano, para o período de 1997 à 2007. Como pode ser observado, as diferenças entre os grupos são muito diminutas para quase todos os anos, tanto em português como em matemática. Para alguns anos, em particular, as diferenças entre as proficiências médias parecem aumentar. Como, por exemplo, para o ano de 2001 em matemática ou 2005 em português, quando (em ambos os casos) as escolas do grupo tratamento (EM) tiveram um desempenho notavelmente superior aos grupos controle. Contudo, quando se analisa, o tendência ao longo de todo período, de fato, os grupos tratamento e controle 
Figura 9: Proficiências médias em matemática por grupo de escolas: SAEB (1997-2005) e Prova Brasil (2007)

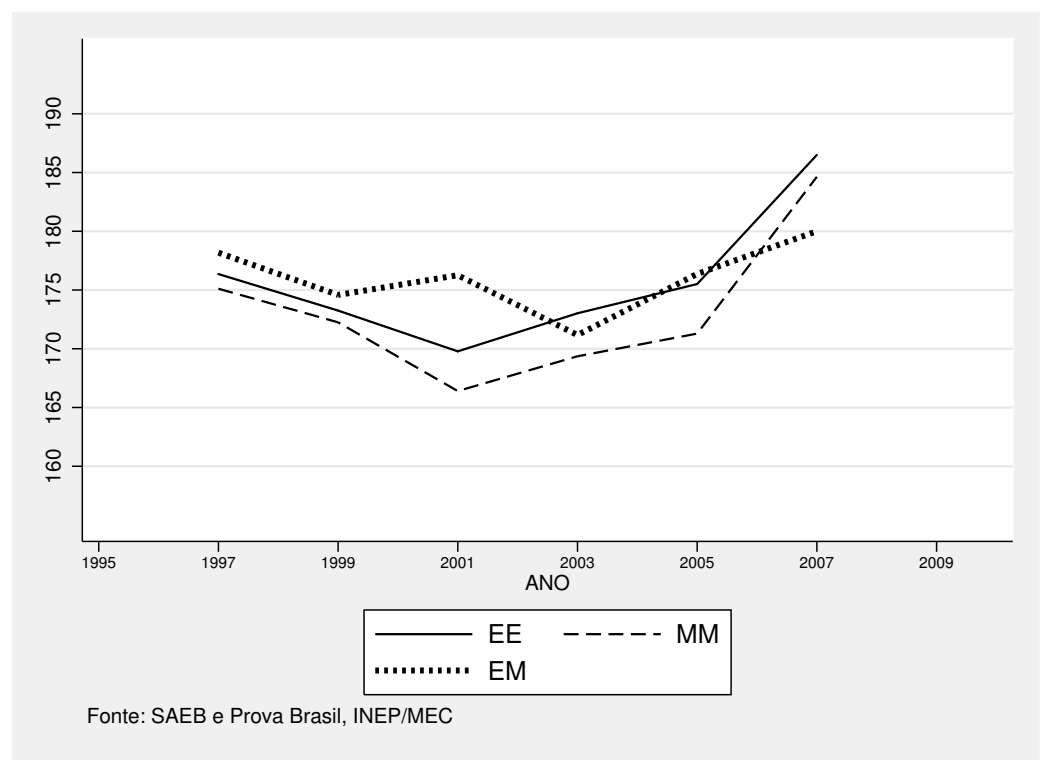

parecem não diferir muito entre si.

Entretanto, antes de proceder a uma análise mais pormenorizada das proficiências médias dos grupos de escolas, faz-se necessário assegurar que não há grandes disparidades nas características dos alunos e do ambiente familiar entre os grupos tratamento e controle. Pois, como visto anteriormente, pode ser que desvios nas características que podem perturbar o aprendizado dos alunos estejam enviesando os resultados acadêmicos dos grupos de escolas. De tal sorte que, inicialmente é levada a efeito uma comparação das características dos alunos e do ambiente familiar, que podem perturbar o desempenho médio dos grupos de escolas.

As tabelas 22 e 23 apresentam os valores médios para as principais características dos alunos e do ambiente familiar, segundo o grupo de escolas e os anos. Nota-se que, 
Tabela 22: Perfil médio dos alunos por grupo de escolas, (1997-2001)

\begin{tabular}{lccccccccc}
\hline & $(1997)$ & $(1997)$ & $(1997)$ & $(1999)$ & $(1999)$ & $(1999)$ & $(2001)$ & $(2001)$ & $(2001)$ \\
& EE & MM & EM & EE & MM & EM & EE & MM & EM \\
\hline Homens & $49,41 \%$ & $48,61 \%$ & $45,35 \%$ & $50,37 \%$ & $50,60 \%$ & $50,25 \%$ & $50,68 \%$ & $50,61 \%$ & $49,41 \%$ \\
11 anos & $22,35 \%$ & $21,85 \%$ & $20,71 \%$ & $20,21 \%$ & $20,18 \%$ & $20,72 \%$ & $23,92 \%$ & $24,50 \%$ & $22,14 \%$ \\
12 anos ou + & $36,81 \%$ & $42,56 \%$ & $28,99 \%$ & $35,95 \%$ & $41,65 \%$ & $34,19 \%$ & $30,51 \%$ & $33,27 \%$ & $25,89 \%$ \\
Branco & $40,73 \%$ & $40,78 \%$ & $31,49 \%$ & $41,94 \%$ & $40,54 \%$ & $38,14 \%$ & $41,14 \%$ & $39,20 \%$ & $41,45 \%$ \\
Negro & $11,43 \%$ & $9,74 \%$ & $8,28 \%$ & $11,23 \%$ & $12,92 \%$ & $12,88 \%$ & $12,78 \%$ & $13,93 \%$ & $15,20 \%$ \\
Mãe (EM) & $14,30 \%$ & $10,51 \%$ & $12,22 \%$ & $7,92 \%$ & $6,45 \%$ & $6,70 \%$ & $14,14 \%$ & $12,59 \%$ & $15,38 \%$ \\
Mãe (sup.) & $5,48 \%$ & $3,93 \%$ & $4,44 \%$ & $7,90 \%$ & $5,69 \%$ & $3,10 \%$ & $5,38 \%$ & $4,35 \%$ & $5,90 \%$ \\
\hline$N$ & 4.898 & 4.898 & 4.898 & 6.320 & 6.320 & 6.320 & 18.578 & 18.578 & 18.578 \\
\hline
\end{tabular}

Fonte: Calculos próprios a partir de dados do SAEB/INEP

Notas: EE: escolas estaduais que permaneceram estaduais

MM: escolas municipais que permaneceram municipais

EM: escolas estaduais que migraram para as redes municipais

Tabela 23: Perfil médio dos alunos por grupo de escolas, (2003-2007)

\begin{tabular}{lccccccccc}
\hline & $\begin{array}{l}(2003) \\
\text { EE }\end{array}$ & $\begin{array}{c}(2003) \\
\text { MM }\end{array}$ & $\begin{array}{c}(2003) \\
\text { EM }\end{array}$ & $\begin{array}{c}(2005) \\
\text { EE }\end{array}$ & $\begin{array}{c}(2005) \\
\text { MM }\end{array}$ & $\begin{array}{c}(2005) \\
\text { EM }\end{array}$ & $\begin{array}{c}(2007) \\
\text { EE }\end{array}$ & $\begin{array}{c}(2007) \\
\text { MM }\end{array}$ & $\begin{array}{c}(2007) \\
\text { EM }\end{array}$ \\
\hline Homens & $50,46 \%$ & $50,30 \%$ & $48,08 \%$ & $49,58 \%$ & $49,50 \%$ & $46,37 \%$ & $50,14 \%$ & $50,67 \%$ & $47,27 \%$ \\
11 anos & $23,64 \%$ & $26,22 \%$ & $25,05 \%$ & $25,85 \%$ & $28,31 \%$ & $28,36 \%$ & $23,45 \%$ & $25,99 \%$ & $26,03 \%$ \\
12 anos ou + & $25,41 \%$ & $27,52 \%$ & $18,96 \%$ & $22,85 \%$ & $23,85 \%$ & $12,10 \%$ & $20,27 \%$ & $20,51 \%$ & $13,23 \%$ \\
Branco & $36,01 \%$ & $35,57 \%$ & $34,68 \%$ & $31,92 \%$ & $29,94 \%$ & $25.96 \%$ & $35,63 \%$ & $32,10 \%$ & $38,07 \%$ \\
Negro & $11,39 \%$ & $12,11 \%$ & $14,18 \%$ & $12,62 \%$ & $14,11 \%$ & $15,97 \%$ & $12,46 \%$ & $13,39 \%$ & $14,11 \%$ \\
Mãe (EM) & $13,86 \%$ & $10,81 \%$ & $15,05 \%$ & $13,58 \%$ & $12,48 \%$ & $12,19 \%$ & $15,29 \%$ & $14,23 \%$ & $15,76 \%$ \\
Mãe (sup.) & $11,96 \%$ & $9,24 \%$ & $6,96 \%$ & $13,32 \%$ & $10,61 \%$ & $11,38 \%$ & $12,59 \%$ & $11,39 \%$ & $10,62 \%$ \\
\hline$N$ & 16.300 & 16.300 & 16.300 & 17.714 & 17.714 & 17.714 & 58.351 & 58.351 & 58.351 \\
\hline Fonte: Calculos próprios a partir de dados do SAEB/INEP & & & & \\
Notas: EE: escolas estaduais que permaneceram estaduais & & & & \\
MM: escolas municipais que permaneceram municipais \\
EM: escolas estaduais que migraram para as redes municipais
\end{tabular}


em geral, os grupos são semelhantes, tanto na composição do alunato com relação a idade, gênero e cor, como também no que se refere à educação da mãe. Contudo, há pequenos, porém consistentes, desvios que merecem ser comentados.

O mais claro desses desvios na composição do alunato entre os grupos tratamento e controle refere-se a prevalência de alunos matriculados fora da série recomendada para sua idade nas escolas do grupo MM e, em menor proporção, nas escolas do grupo EM. Percebe-se que, tanto as escolas que permaneceram sob controle dos municípios, o grupo $\mathrm{MM}$, como as escolas que foram transferidas, o grupo EM, apresentam maior prevalência de alunos em situação de atraso escolar. Essa disparidade dá-se tanto para a categoria 11 anos - que representa um atraso escolar de pelo menos dois anos - e também para a categoria 12 anos ou mais - atraso de pelo menos 3 anos -, nesta última, ainda com mais intensidade. Também é notável que a distorção idade-série perde força nos anos finais da série temporal. Ou seja, percebe-se que a partir de meados dos anos 2000 a prevalência de alunos matriculados fora da série recomendada para sua idade tem um decréscimo significativo para todos os grupos. Assim, por exemplo, os alunos com 12 anos de idade ou mais matriculados na 4a série do ensino fundamental nas escolas do grupo MM, que chegaram a representar mais de 42 por cento do total de alunos matriculados nesse grupo de escolas em 1997; paulatinamente, têm sua proporção reduzida para pouco mais de 20 por cento do total de alunos das escolas do grupo MM.

A composição racial do alunato entre os grupos tratamento e controle merece um breve comentário. Pois, percebe-se que, $(i)$ há um aumento considerável de alunos que se declaram negros nas escolas do grupo tratamento ao longo da série temporal analisada. 
A presença de alunos que se declaram negros nas escolas que foram transferidas dos estados para os municípios somava pouco menos de 8,5 por cento do total de alunos em 1997. Em 2005, a presença desses alunos praticamente dobra, atingindo pouco menos de 16 por cento do total de alunos matriculados nas escolas do grupo EM. Por outro lado, nota-se que, (ii) há um decréscimo na proporção de alunos que se declaram brancos, a partir de 2003, para todos os grupos de escolas. Esse decréscimo é, contudo, mais saliente nas escolas dos grupos MM e EM.

Quando se examina o nível de escolaridade da mãe, observa-se que a porcentagem de mães com ensino médio ou superior é sempre maior nas escolas do grupo $E E$, o grupo que permaneceu sobre o controle dos estados, exceto para 1999, quando se nota uma descontinuidade na série histórica.

Vale destacar que os desvios verificados na composição do corpo discente nos grupos de escolas no período pré-municipalização (1997-2005), em geral, se mantém para o período pós-municipalização (2007). ${ }^{42}$ Salvo pela maior presença de alunos não brancos, que se dá em todos os grupos de escolas (embora com mais intensidade nas escolas do grupo tratamento) e pela diminuição na proporção de alunos matriculados fora da série recomendada para sua idade, que também ocorre para todos os grupos de escolas.

As tabelas 22 e 23, quando vistas como um pano de fundo para as figuras 8 e 9 , que mostram a evolução das proficiências médias dos grupos tratamento e controle,

\footnotetext{
${ }^{42}$ Como já observado no capítulo quarto deste estudo, na seção metodológica, o efeito estimado da municipalização das escolas não leva em conta o tempo em que as escolas do grupo de tratamento (EM) estiveram sob controle dos municípios. Ou seja, a análise ignora o tempo de exposição à gestão municipal. Assim, consideram-se aqui apenas dois períodos: um período inicial, ou período pré-municipalização, que abrange os anos de 1997 a 2005; e um período final, ou pós-municipalização, que abrange dos dados da Prova Brasil de 2007.
} 
oferecem um quadro geral dos alunos e dos grupos de escolas. Esse panorama geral torna evidente, não obstante os desvios mencionados na composição do alunato entre os grupos tratamento e controle, um retrato de alunos e grupos muito semelhantes entre si, tanto em termos de desempenho acadêmico como no perfil socioeconômico.

Finalmente, antes de proceder à comparação das diferenças em desempenho nas proficiências médias dos grupos tratamento e controle, cabe uma última investigação acerca da distribuição geográfica dos grupos de escolas nas regiões do Brasil. Uma vez que, há um diferencial de desempenho entre as regiões, disparidades na distribuição geográfica entre os grupos poderia perturbar a comparação nas diferenças de desempenho entre os grupos controle e tratameto.

Leme, Paredes e Souza (2009), já demonstraram que a transferência de escolas das redes públicas estaduais para as redes públicas municipais foi mais frequente nas regiões nordeste e sudeste do país. Os dados apresentados na tabela 24, confirmam os achados daquele estudo.

Tabela 24: Distribuição dos grupos tratamento e controle segundo as regiões do Brasil

\begin{tabular}{lccc}
\hline $\begin{array}{l}\text { Região } \\
\text { geográfica }\end{array}$ & $\begin{array}{c}\text { Grupo EE } \\
\text { (Controle I) }\end{array}$ & $\begin{array}{c}\text { Grupo MM } \\
\text { (Controle II) }\end{array}$ & $\begin{array}{c}\text { Grupo EM } \\
\text { (Tratamento) }\end{array}$ \\
\hline Norte & $24,38 \%$ & $18,81 \%$ & $09,56 \%$ \\
Nordeste & $31,74 \%$ & $40,61 \%$ & $41,07 \%$ \\
Sudeste & $14,27 \%$ & $15,65 \%$ & $29,52 \%$ \\
Sul & $15,01 \%$ & $15,33 \%$ & $17,15 \%$ \\
Centro Oeste & $14,60 \%$ & $09,61 \%$ & $02,70 \%$ \\
\hline \hline Fonte: Calculos próprios a partir de dados do SAEB/INEP \\
Notas: EE: escolas estaduais que permaneceram estaduais \\
MM: escolas municipais que permaneceram municipais \\
EM: escolas estaduais que migraram para as redes municipais
\end{tabular}

A tabela 24 apresenta a distribuição regional dos grupos tratamento e controle. 0 
exame da tabela 24 torna evidente a maior concentração do grupo tratamento nas regiões nordeste e sudeste, tal como em Leme, Paredes e Souza (2010). O grupo MM, das escolas municipais que permaneceram municipais, também exibe maior concentração no nordeste. Essa distribuição desigual do grupo MM já era esperada e deve-se a maior cobertura das redes municipais, se comparadas às estaduais, na região nordeste do Brasil (MEC, 2010).

Feita a análise da composição socioeconômica e da distribuição geográfica dos grupos tratamento e controle, cujo intuito é simplesmente assegurar que os grupos são, de fato, semelhantes o bastante para que sua comparação faça sentido; pode-se, agora, avançar a um exame mais detido das diferenças em desempenho acadêmico entre os grupos de escolas. Como mencionado anteriormente, a estimação por diferença-emdiferenças funda-se, grosso modo, na comparação das proficiências médias dos grupos tratamento e controle nos períodos pré municipalização e pós municipalização.

Entretanto, é importante esclarecer que a estimação por diferença-em-diferenças não se trata simplesmente de um teste de comparação de proficiências médias não condicionais. Ou seja, não se trata de simplesmente comparar as proficiências médias das escolas sem controlar as demais características dos alunos e do ambiente familiar que podem contribuir para o aprendizado dos estudantes. Mas, pelo contrário, a estimação por diferença-em-diferenças - como outras técnicas de análise de dados em painel garante não apenas que se controle as características observadas dos alunos que variam ao longo do tempo, tais como, cor, gênero, idade, entre outras, como também permite, via o emprego de um termo de efeito específico para as escolas, que se controle as características não observadas das escolas que não variam no tempo. 
Para estimar do efeito da municipalização sobre a proficiência média dos grupos tratamento e controle, se ajustou um modelo estatístico dado pela equação 3. Esse modelo busca captar efeito da municipalização sobre a proficiência média das escolas do grupo tratamento (o grupo EM), quando comparadas às escolas dos grupos controle (grupos EE e MM). Cabe destacar ainda, que a estimação por diferença-em-diferenças é conduzida comparando-se, separadamente, dois grupos de casa vez. Ou seja, inicialmente, compara-se o grupo tratamento com um dos grupos controle, como, por exemplo, com o grupo EE. Então, num segundo momento, compara-se o grupo tratamento com o grupo controle remanescente, o grupo MM.

As tabelas 25, 26, 27 e 28 apresentam os resultados da estimação por diferença-emdiferenças, com efeito fixo da escola, para os exames de português e matemática dos alunos da 4a. série do ensino fundamental. Os resultados da estimação são exibidos separadamente segundo a disciplina, se português ou matemática e segundo o grupo controle utilizado, se grupo EE ou grupo MM.

Pode-se notar, na tabela 25 , que as escolas do grupo EM, no período pré municipalização, tinham uma proficiência média em português, condicional às características observadas dos aluno e ao efeito fixo da escola, de 164, 24 pontos na escala de proficiência do SAEB. As escolas do grupo EE, por sua vez, tinham uma proficiência média condicional de 164,16 . Depois de municipalizadas, as escolas do grupo EM tiveram uma proficiência média condicional de 169,43. Um acréscimo de 5,19 pontos na escala de proficiência em língua portuguesa. Esse incremento na nota média das escolas do grupo tratamento pode ser atribuído à municipalização, como, alternativamente, pode ser atribuído a uma série de outros fatores que contribuem para o aprendizado dos alu- 
Tabela 25: Resultados do estimador de diferença-em-diferenças com efeito fixo da escola para português, 4a. série

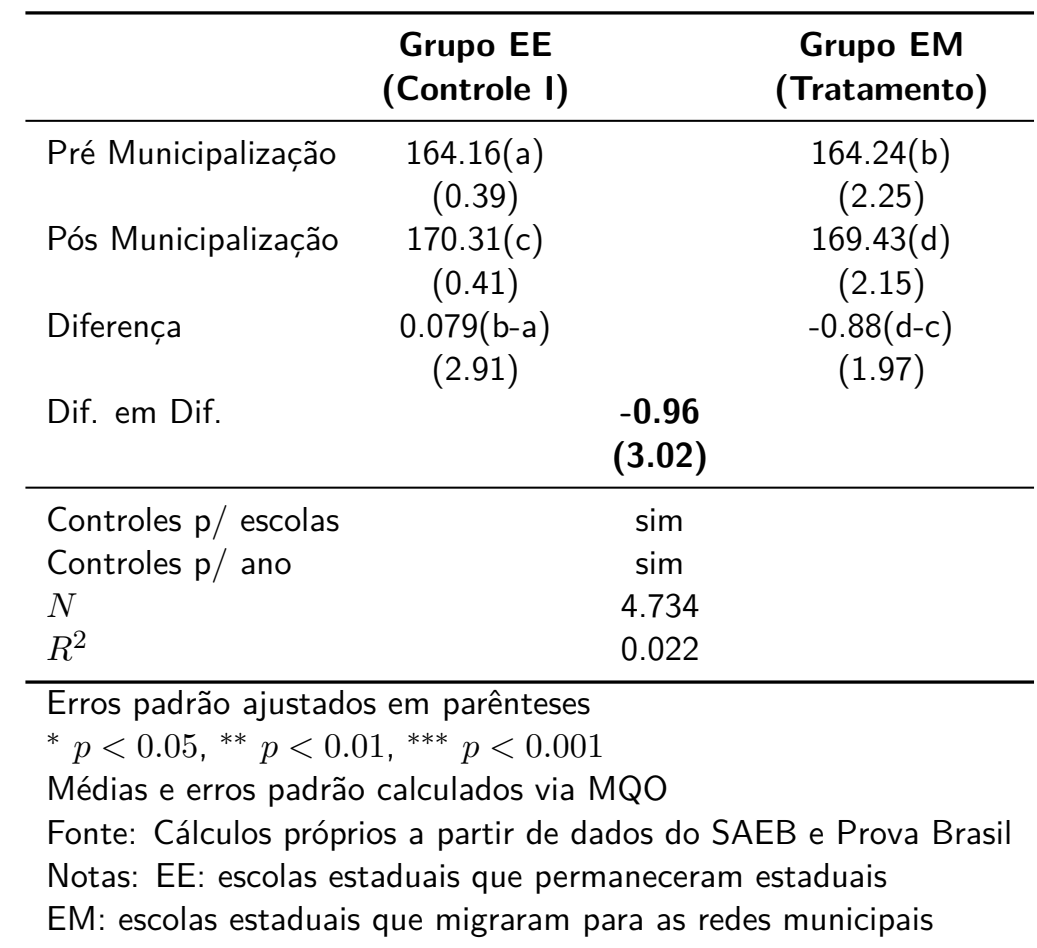

nos. O contrafactual, por conseguinte, seria o que teria acontecido com essas escolas caso tivessem permanecido sob o controle do estado. Isto é, caso não tivessem sido municipalizadas. Nesse caso, esperar-se-ia um incremento na proficiência média das escolas igual aquele experimentado pelas escolas que eram estaduais e que não foram municipalizadas. Isto é, um incremento igual ao apresentado pelo grupo controle, que foi de 6,15, atingindo 170,31 pontos na escala SAEB em 2007.

O estimador de diferença-em-diferenças compara a diferença na proficiência média condicional entre os grupos EM e EE, no período pré municipalização, que é igual a 0.079 ; com a diferença na proficiência média condicional, no período pós municipalização, que é igual a $-0,88$. Calculando-se a diferença das diferenças chega-se ao exato va- 
lor do estimador de diferença-em-diferenças, que é igual a -0.96 ; ou seja, $(-0,88)$ - $(0,079)$. Portanto, o efeito da municipalização é igual ao estimador de diferençaem-diferenças; pois, este representa o exato valor da diferença entre o incremento na proficiência média condicional das escolas estaduais que foram municipalizadas $(5,19)$ e o incremento na proficiência média das escolas estaduais que permaneceram estaduais $(6,15)$; isto é, $5,19-6,15=-0,96$. Nesse sentido, cabe destacar que o efeito da municipalização sobre a proficiência média condicional é quase nulo e não significante estatisticamente.

Tabela 26: Resultados do estimador de diferença-em-diferenças com efeito fixo da escola para português, 4 a. série

\begin{tabular}{|c|c|c|}
\hline & $\begin{array}{l}\text { Grupo MM } \\
\text { (Controle II) }\end{array}$ & $\begin{array}{c}\text { Grupo EM } \\
\text { (Tratamento) }\end{array}$ \\
\hline Pré Municipalização & $\begin{array}{l}161.39(a) \\
(0.36)\end{array}$ & $\begin{array}{l}165.41(b) \\
(1.90)\end{array}$ \\
\hline Pós Municipalização & $\begin{array}{c}167.80(c) \\
(0.35)\end{array}$ & $\begin{array}{l}171.22(\mathrm{~d}) \\
(1.84)\end{array}$ \\
\hline Diferença & $\begin{array}{c}4.01^{* *}(b-a) \\
(0.03)\end{array}$ & $\begin{array}{l}3.41^{*}(\mathrm{~d}-\mathrm{c}) \\
(1.87)\end{array}$ \\
\hline Dif. em Dif. & \multicolumn{2}{|c|}{$\begin{array}{l}-0.60 \\
(2.70)\end{array}$} \\
\hline $\begin{array}{l}\text { Controles } \mathrm{p} / \text { escolas } \\
\text { Controles } \mathrm{p} / \text { ano } \\
N \\
R^{2}\end{array}$ & & \\
\hline \multicolumn{3}{|c|}{$\begin{array}{l}\text { Erros padrão ajustados em parênteses } \\
{ }^{*} p<0.05,{ }^{* *} p<0.01,{ }^{* * *} p<0.001 \\
\text { Médias e erros padrão calculados via MQO } \\
\text { Fonte: Cálculos próprios a partir de dados do SAEB e Prova Brasil } \\
\text { Notas: MM: escolas municipais que permaneceram municipais } \\
\text { EM: escolas estaduais que migraram para as redes municipais }\end{array}$} \\
\hline
\end{tabular}

A tabela 26 apresenta as proficiências médias condicionais dos exames em língua portuguesa dos alunos da 4a. série do ensino fundamental. Agora, se lança mão do grupo de escolas municipais que permaneceram municipais como grupo controle, o grupo 
MM. Admite-se que a comparação entre os grupos MM e EM não é tão informativa do ponto de vista teórico como a comparação prévia, entre os grupos EE e EM; pois, na presente comparação o contrafactual seria não o que teria acontecido com as escolas caso tivessem permanecido sob o controle do estado, mas, pelo contrário, o que teria acontecido com as escolas caso estivessem sob o controle dos municípios. Entretanto, de um ponto de vista estritamente analítico, a comparação é válida; já que informativa acerca das mudanças nas proficiências médias condicionais dos grupos de escolas que permaneceram municipais e que foram municipalizadas. Ou seja, a comparação entre os grupos MM e EM tem a capacidade de informar se houve uma convergência nas proficiências médias condicionais dos dois grupos após a municipalização ou se, pelo contrário, a diferença entre as notas médias condicionais tornou-se mais dilatada no período pós municipalização.

Feita esta ressalva, o exame da tabela 26 demonstra que, no período pré municipalização, as proficiências médias condicionais eram de 161,39 pontos na escala de proficiência do SAEB para as escolas do grupo MM e 165, 41 pontos para as escolas o grupo EM. Ou seja, a diferença pré-municipalização era de 4,01 pontos na escala SAEB. Essa diferença era estatisticamente significante ao nível de 5 por cento. No período pós municipalização, as notas médias condicionais dos grupos $\mathrm{MM}$ e EM atingem 167,80 e 171, 22 pontos, respectivamente. Consequentemente, a diferença nas proficiências médias tem um pequeno decréscimo chegando a 3,41 pontos na escala SAEB. Essa diferença permanece significante, mas ao nível de 10 por cento. Portanto, o efeito da municipalização sobre as escolas transferidas dos estados para os municípios, quando comparadas às escolas que já eram municipais e permaneceram municipais é de -0.60 pontos na escala de proficiência em língua portuguesa. Ou seja, o efeito da 
municipalização é praticamente nulo e não estatisticamente diferente de zero, isto é, não siginificante estatisticamente.

Tabela 27: Resultados do estimador de diferença-em-diferenças com efeito fixo da escola para matemática, 4a. série

\begin{tabular}{|c|c|c|}
\hline & $\begin{array}{l}\text { Grupo EE } \\
\text { (Controle I) }\end{array}$ & $\begin{array}{c}\text { Grupo EM } \\
\text { (Tratamento) }\end{array}$ \\
\hline Pré Municipalização & $\begin{array}{c}173.14(\mathrm{a}) \\
(0.39)\end{array}$ & $\begin{array}{l}174.62(\mathrm{~b}) \\
(2.21)\end{array}$ \\
\hline Pós Municipalização & $\begin{array}{c}186.50(c) \\
(0.43)\end{array}$ & $\begin{array}{c}186.01(\mathrm{~d}) \\
(2.15)\end{array}$ \\
\hline Diferença & $\begin{array}{c}1.48(\mathrm{~b}-\mathrm{a}) \\
(2.25)\end{array}$ & $\begin{array}{c}-0.48(d-c) \\
(2.20)\end{array}$ \\
\hline Dif. em Dif. & \multicolumn{2}{|c|}{$\begin{array}{l}-1.96 \\
(3.15)\end{array}$} \\
\hline $\begin{array}{l}\text { Controles } \mathrm{p} / \text { escolas } \\
\text { Controles } \mathrm{p} / \text { ano } \\
N \\
R^{2}\end{array}$ & & \\
\hline \multicolumn{3}{|c|}{$\begin{array}{l}\text { Erros padrão ajustados em parênteses } \\
{ }^{*} p<0.05,{ }^{* *} p<0.01,{ }^{* * *} p<0.001 \\
\text { Médias e erros padrão calculados via MQO } \\
\text { Fonte: Cálculos próprios a partir de dados do SAEB e Prova Brasil } \\
\text { Notas: EE: escolas estaduais que permaneceram estaduais } \\
\text { EM: escolas estaduais que migraram para as redes municipais }\end{array}$} \\
\hline
\end{tabular}

As tabelas 27 e 28 apresentam os resultados da estimação do efeito da municipalização sobre as proficiências nos exames em matemática para os alunos da 4a. série do ensino fundamental. Primeiramente, deve-se notar que os resutlados para os exames em matemática pouco diferem daqueles apresentados acerca dos exames em língua portuguesa.

A tabela 27 traz a comparação entre os grupos EE e EM, a mais informativa do ponto de vista teórico, pois aquela que tem a capacidade de instruir acerca do efeito da municipalização na proficiência média das escolas municipalizadas (EM), quando 
comparadas às escolas que permaneceram sob o controle dos estados (EE). O exame da dos estimadores reportados na tabela 27 mostram que, no período pré municipalização, a proficiência média condicional do grupo de escolas que foi transferido para os municípios era de 174,62 pontos na escala SAEB. A média condicional do grupo de escolas que permaneceu sob o controle dos estados era de 173,14 pontos. Havia, portanto, uma diferença nas proficiências condicionais, pré municipalização, de exatamente 1,48 pontos. O contrafactual, nesse caso, seria o que teria acontecido com as escolas municipalizadas, caso tivessem permanecido sob o controle dos estados. Sob essa situação hipotética eperar-se-ia que nota média condicional tivesse um incremento de 13.36 pontos no período pós municipalização, tal como se deu com as escolas do grupo controle que tiveram uma proficiência média condicional de 186, 50. Nessa situação, a diferença nas proficiências médias condicionais manter-se-ia em, exatamente, 1, 48 pontos e a nota média condicional das escolas municipalizadas seria de 187, 98 . Contudo, a proficiência média condicional das escolas municipalizadas foi de 186, 01 pontos SAEB, no pós municipalização. Isto é, o incremento na proficiência média do grupo tratamento foi de 11,29 pontos. A diferença pós-municipalização entre os grupos controle e tratamento, por conseguinte, foi de -0.48 pontos. Logo, pode-se concluir que o efeito da municipalização, que é dado pelo exato valor da diferença entre diferenças, pré e pós municipalização, nas proficiências médias condicionais, foi de $(-1.96)$ pontos; ou seja, $(-0.48)-(1,48)$. Mais uma vez, o efeito estimado da municipalização é não apenas pouco expressivo em termos de sua magnitude, como também não se pode assegurar que seja estatisticamente diferente de zero.

Finalmente, a tabela 28 exibe os resultados da estimação na qual são comparadas as proficiências condicionais médias em matemática dos grupos de escolas MM e EM. 
Tabela 28: Resultados do estimador de diferença-em-diferenças com efeito fixo da escola para matemática, 4a. série

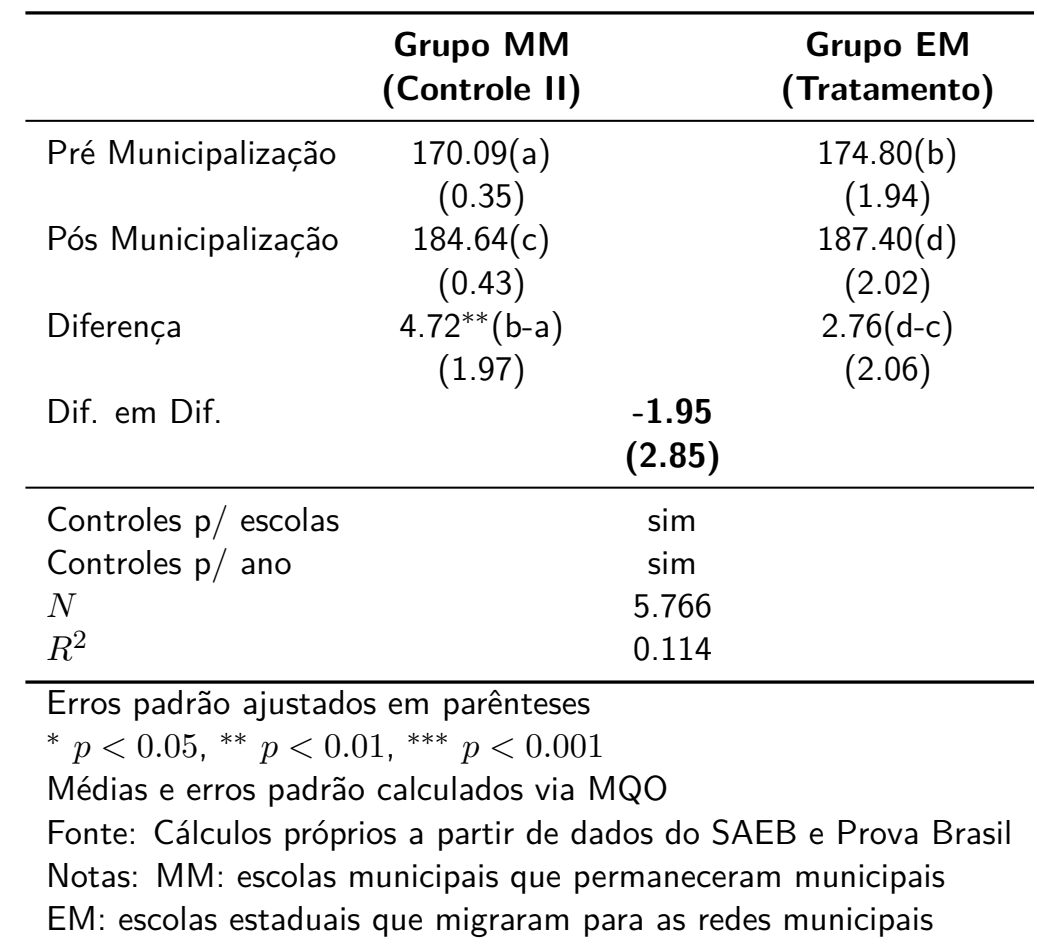

A análise dos estimadores apresentados nesta tabela apontam que a nota condicional média do grupo de escolas municipalizadas era, no período pré municipalização, igual a 174,80 pontos. A proficiência condicional média do grupo de escolas que permaneceram sob controle municipal era de 170,09. A diferença nas proficiências médias, pré municipalização era, portanto, igual a 4,72 pontos na escala de proficiência em matemática. Essa diferença era estatisticamente significante ao nível de 5 por cento. Após a municipalização, verifica-se que a proficiência média das escolas municipalizadas é de 187,40; ou seja, houve um incremento na proficiência média desse grupo de escolas de 12,6 pontos. A proficiência condicional média do grupo de escolas que permaneceu sob a gestão municipal atinge 184,64 pontos. Isto é, houve um incremento de 14,55 pontos na escala SAEB. A diferença na proficiência condicional média entre os grupos 
tratamento e controle, que era de 4,72 pontos no período pré municipalização, cai para 2,76 pontos no período pós municipalização. Ou seja, nota-se um decréscimo de $-1,96$ pontos nas diferenças pré e pós municipalização. Esse decréscimo nas diferenças é o efeito da municipalização sobre as proficiências condicionais média dos exames em matemática para o grupo de escolas municipalizadas, se comparado ao grupo de escolas que permaneceu sob o controle das redes municipais. Ainda, cabe destacar que esse efeito praticamente nulo e estatisticamente não diferente de zero.

Figura 10: Distribuição da variância das proficiências médias condicionais em matemática por grupo de escolas : EM x MM

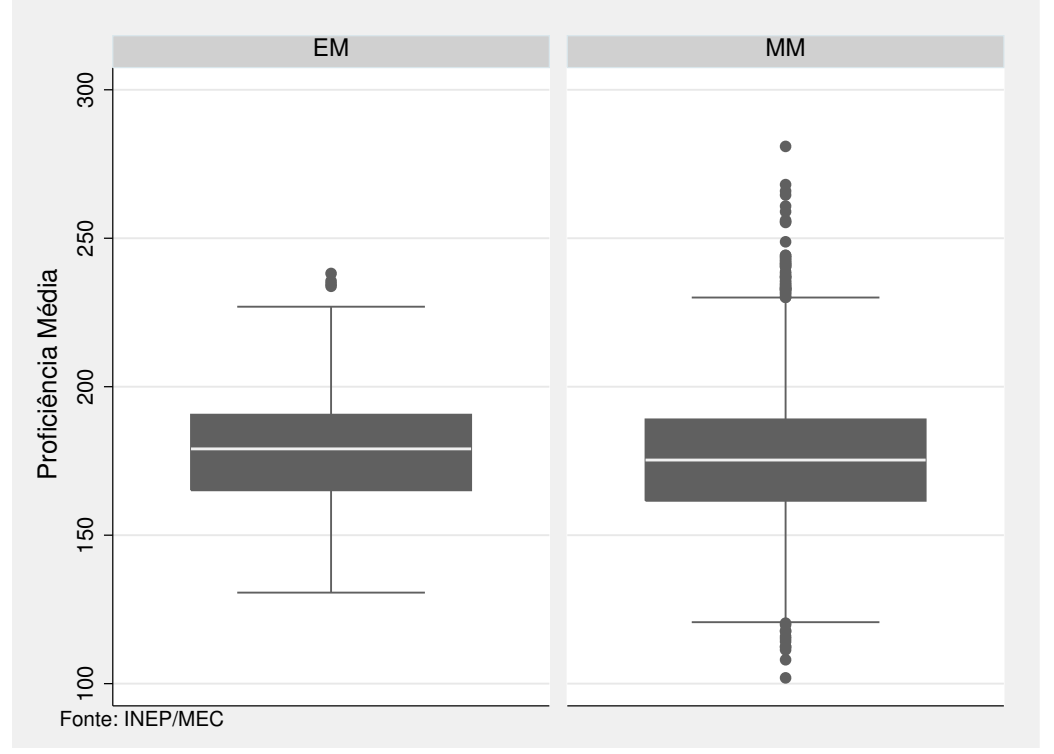

O quadro geral exposto pelo conjunto das tabelas 25, 26, 27 e 28 demonstra que não há efeito perceptível da municipalização sobre o desempenho médio das escolas nos exames de proficiência conduzidos pelo MEC/INEP, seja em matemática, seja em língua portuguesa. Os estimadores de diferença-em-diferenças apontam que, mesmo depois de controlar pelas características observadas dos alunos e pelas características 
Figura 11: Distribuição da variância das proficiências médias condicionais em matemática por grupo de escolas: EM x EE

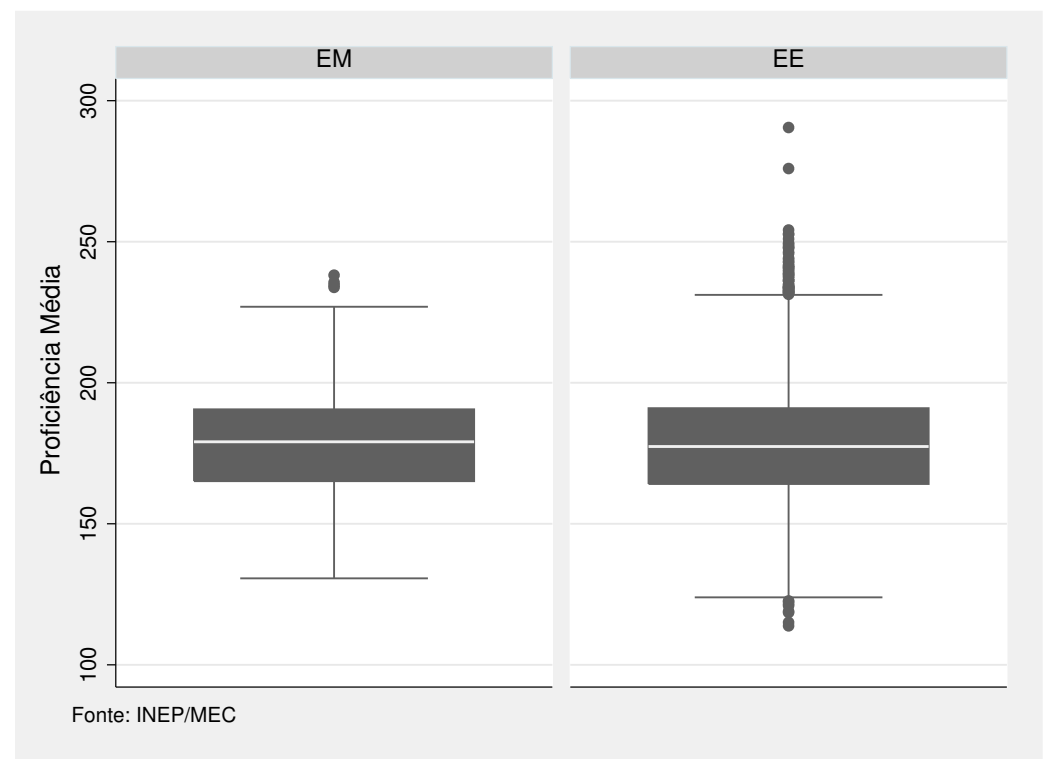

não observadas das escolas, o efeito da municipalização sobre a proficiência média das escolas é praticamente nulo e não se mostrou estatisticamente diferente de zero em nenhum dos grupos ou disciplinas.

Não obstante o efeito estimado da municipalização sobre o desempenho acadêmico das escolas seja sempre negativo, tanto em matemática como em língua portuguesa, pode-se especular que as médias condicionais são tão próximas e as variâncias das proficiências médias entre as escolas dos grupos tratamento e controle são tão grandes que a estimação por diferença-em-diferenças, via MQO ou EF, não é capaz de captar as nuanças de subgrupos de escolas que possivelmente estejam respondendo (positiva ou negativamente, não vem ao caso) à municipalização. As figuras 10 e 11 exibem a distribuição da variância das proficiências médias condicionais em matemática segundo os grupos comparados via estimação por diferença-em-diferenças. Nota-se que tanto 
para o grupo tratamento como para os grupos controle, a variância das proficiências médias é significativamente elevada entre as escolas, tanto em termos de amplitude interquartílica como também pela presença de de valores discrepantes.

A título de conclusão, vale recapitular os principais achados da presente seção. Nesta seção, $(i)$ buscou-se estimar o efeito da municipalização das escolas sobre a proficiência média de seus alunos, quando comparados aos alunos das escolas que permaneceram sob gestão dos estados ou dos municípios. ( $i i$ ) O efeito da municipalização que se buscou estimar é exatamente o efeito médio do grupo de escolas que foram transferidas para o controle dos municípios, quando cotejadas às escolas que permaneceram sob o controle das redes estaduais e municipais. (iii) O estimador de diferença-em-diferenças evidencia que não há efeito relevante da municipalização sobre o desempenho médio das escolas nos exames de proficiência do conduzidos pelo MEC/INEP, seja em matemática, seja em língua portuguesa. (iv) Pode-se especular que o emprego de controles para as características observadas dos alunos e para as características não observadas das escolas ainda não seja suficiente para isolar o impacto da municipalização, dada a proximidade das médias condicionais e a distribuição da variância das proficiências médias. 


\subsection{O Efeito da municipalização sobre as redes escolares}

Tendo estabelecido, nas prévias seções, que $(i)$ uma vez controladas às características dos alunos, e os fatores escolares que podem perturbar o aprendizado dos estudantes, o efeito da rede escolar sobre a proficiência dos alunos torna-se negligenciável. (ii) O impacto da municipalização das escolas sobre o desempenho acadêmico de seus alunos nos exames de proficiência do conduzidos pelo MEC/INEP é praticamente nulo.

Nesta seção, busca-se examinar se houve efeito relevante da municipalização de matrículas sobre a qualidade dos serviços educacionais oferecidos nos municípios brasileiros. Mais especificamente, procura-se estimar o efeito da taxa de municipalização das matrículas sobre alguns indicadores selecionados de insumos escolares e de rendimento do fluxo escolar. Para tanto, utiliza-se uma base de dados em painel na qual as unidades de observação são os municípios brasileiros. Essa base de dados compreende 2.837 municípios e o período de 1999 a 2005.

Como mencionado na seção metodológica do capítulo quarto desta tese, a medida de descentralização utilizada, como variável explicativa, nesta análise é a taxa de municipalização de matrículas nos municípios. Isto é, trata-se da proporção de matrículas no ensino fundamental em escolas da rede pública municipal em função do total de matrículas no ensino fundamental público no município. A taxa de municipalização procura captar o esforço do município em incorporar novas matrículas no ensino fundamental. Esse esforço pode se realizar tanto por meio da criação de novas vagas em escolas da rede pública municipal, como pela municipalização de escolas do ensino fundamental antes mantidas pelos estados. Deve-se destacar que, quando maior a taxa de municipalização no município, mais descentralizada a provisão da educação neste 
município; pois maior a responsabilidade do município na oferta de educação pública vis-à-vis a responsabilidade do estado.

As variáveis respostas desta análise estão subagrupadas em dois conjuntos de indicadores: $(i)$ os insumos escolares e os $(i i)$ as taxas de rendimento de fluxo escolar. O primeiro conjunto compreende: indicadores a respeito da infraestrutura física das escolas, como, por exemplo, se as escolas possuem biblioteca, quadra de esportes, laboratório de ciências, laboratório de informática, a razão computador por aluno, se a escola oferece merenda aos alunos, entre outros; indicadores acerca da composição e formação do corpo docente, como, por exemplo, razão professor por aluno e proporção de professores com curso superior. O segundo conjunto de variáveis, referentes ao rendimento do fluxo escolar, inclui: taxa de reprovação, taxa de abandono e a taxa de distorção idade-série. As tabelas 13 e 14, já apresentadas no capítulo quatro da tese na seção metodológica, traz a relação completa das variáveis respostas, bem como suas médias segundo a rede escolar.

Em suma, nesta seção busca-se examinar a relação entre o esforço do município na provisão do ensino fundamental público e a qualidade da educação ofertada à população pelas redes pública municipal, pública estadual e privada. Como mencionado anteriormente, optou-se pela manutenção dos dados referentes à rede privada na base de dados, diferentemente do que se deu nas duas análises prévias, pois entende-se que as escolas da rede privada podem agora funcionar como um importante grupo controle; já que supostamente a oferta privada de serviços educacionais não foi afetada pela municipalização das matrículas. Ademais, como as informações das escolas foram agregadas para o nível do município segundo o ano e a rede, se municipal, estadual ou 
privada, a base de dados permite acompanhar o impacto da expansão das matrículas municipais sobre as redes escolares separadamente.

A equação 16, apresentada na seção metodológica do capítulo quarto da tese, procura modelar o efeito da taxa de municipalização das matriculas nos municípios sobre os insumos escolares e as taxas de rendimento do fluxo escolar nas redes escolares pública municipal, pública estadual e privada para o painel de 2.837 municípios.

Tabela 29: Efeito da taxa de municipalização sobre os insumos escolares

\begin{tabular}{|c|c|c|c|c|}
\hline & $\begin{array}{c}(1) \\
\text { (Todas) } \\
\text { Modelo } 14\end{array}$ & $\begin{array}{c}(2) \\
\text { (Municipais) } \\
\text { Modelo } 15\end{array}$ & $\begin{array}{c}(3) \\
\text { (Estaduais) } \\
\text { Modelo } 16\end{array}$ & $\begin{array}{c}(3) \\
\text { (Privadas) } \\
\text { Modelo } 17\end{array}$ \\
\hline Bibliotecas & $\begin{array}{l}-0.0006 \\
(0.0003)\end{array}$ & $\begin{array}{l}-0,0016 \\
(0.0022)\end{array}$ & $\begin{array}{c}0.0005 \\
(0.0010)\end{array}$ & $\begin{array}{c}0.0002 \\
(0.0003)\end{array}$ \\
\hline Quadra de esportes & $\begin{array}{l}-0.0002 \\
(0.0042)\end{array}$ & $\begin{array}{l}-0.0027 \\
(0.0051)\end{array}$ & $\begin{array}{c}0.0002 \\
(0.0230)\end{array}$ & $\begin{array}{c}0.0003 \\
(0.0065)\end{array}$ \\
\hline Laboratório de ciências & $\begin{array}{l}-0.0021 \\
(0.0703)\end{array}$ & $\begin{array}{l}-0.0052 \\
(0.0028)\end{array}$ & $\begin{array}{l}-0.0034 \\
(0.0082)\end{array}$ & $\begin{array}{c}0.0001 \\
(0.0024)\end{array}$ \\
\hline Laboratório de informática & $\begin{array}{l}0.0019^{*} \\
(0.0036)\end{array}$ & $\begin{array}{l}0.0051^{* *} \\
(0.0030)\end{array}$ & $\begin{array}{c}0.0016^{*} \\
(0.0013)\end{array}$ & $\begin{array}{c}0.0021 \\
(0.0022)\end{array}$ \\
\hline Aluno/computador & $\begin{array}{c}0.0001 \\
(0.0002)\end{array}$ & $\begin{array}{c}-0.0001 \\
(0.0002)\end{array}$ & $\begin{array}{c}0.0002 \\
(0.0003)\end{array}$ & $\begin{array}{c}0.0001 \\
(0.0015)\end{array}$ \\
\hline Aluno/Professor & $\begin{array}{l}-0.0003 \\
(0.0001)\end{array}$ & $\begin{array}{l}-0.0011 \\
(0.0034)\end{array}$ & $\begin{array}{l}-0.0002 \\
(0.0017)\end{array}$ & $\begin{array}{l}-0.0000 \\
(0.0012)\end{array}$ \\
\hline Curso superior & $\begin{array}{c}0.0003^{*} \\
(0.0003)\end{array}$ & $\begin{array}{l}0.0023^{* *} \\
(0.0015)\end{array}$ & $\begin{array}{c}0.0015^{*} \\
(0.0009)\end{array}$ & $\begin{array}{c}0.0010 \\
(0.0097)\end{array}$ \\
\hline$N$ & 26.086 & 12.698 & 8.051 & 5337 \\
\hline Grupos & 2.837 & 2.837 & 2.837 & 2.837 \\
\hline Controles $p /$ municípios & $\operatorname{sim}$ & $\operatorname{sim}$ & $\operatorname{sim}$ & $\operatorname{sim}$ \\
\hline dummy de ano & $\operatorname{sim}$ & $\operatorname{sim}$ & $\operatorname{sim}$ & $\operatorname{sim}$ \\
\hline Constante & $\operatorname{sim}$ & $\operatorname{sim}$ & $\operatorname{sim}$ & $\operatorname{sim}$ \\
\hline
\end{tabular}

Erros padrão robustos em parênteses

Fonte: Calculos próprios a partir de dados do MEC/INEP

${ }^{*} p<0.05,{ }^{* *} p<0.01,{ }^{* * *} p<0.001$

A tabela 29 mostra os resultados da estimação, pelo método de efeitos fixos, do impacto da taxa de municipalização sobre os insumos escolares nas redes escolares 
públicas municipais e estaduais e na rede privada. Antes de passar à análise dos resultados, vale esclarecer que cada um dos itens apresentados na tabela foram regredidos, um a um, na taxa de municipalização. Primeiro, para todo o conjunto de escolas, cujos resultados são exibidos na coluna (1) da tabela 29. Em seguida, apenas para as escolas públicas municipais, cujos resultados são reportados na coluna (2); e, assim por diante, para as escolas estaduais e privadas, cujos resultados são reportados nas colunas (3) e (4), respectivamente. Em todos os modelos foram incluídas as variáveis de controle dos municípios (listadas na tabela 15, do capítulo quarto), o termo de efeito específico para o município e dummies para os anos, tal como modelado pela equação 16 .

A análise da tabela 29 indica que a taxa de municipalização de matrículas do ensino fundamental nos municípios tem um efeito global muito tênue sobre os insumos escolares das redes públicas de ensino. Tão somente a proporção de escolas equipadas com laboratórios de Informática nos municípios e a proporção de professores do ensino fundamental com curso superior mostram resultados estatisticamente diferentes de zero.

A proporção de escolas do ensino fundamental equipadas com bibliotecas parece não ser afetada pela taxa de municipalização das matrículas de ensino fundamental. Os coeficientes estimados são negativos para o conjunto de escolas dos municípios e para as escolas das redes municipais, embora estatisticamente não diferentes de zero. Para as escolas públicas estaduais e municipais os coeficientes são positivos e não estatisticamente significantes. Para todas as redes a magnitude dos coeficientes estimados é pequena. O coeficiente estimado para a rede municipal, por exemplo, indica que 
para um aumento de 1 ponto percentual na taxa de municipalização das matriculas, esperar-se-ia um decréscimo de 0.0016 pontos percentuais, em média, na proporção de escolas municipais equipadas bom bibliotecas no município. Contundo, mais uma vez, vale lembrar que não se pode assegurar que esse coeficiente não seja estatisticamente diferente de zero, dada a ausência de significância estatística da estimação.

A proporção de escolas equipadas com quadra de esportes não é tampouco impactada pela taxa de municipalização das matrículas no município. Os coeficientes estimados, novamente, são negativos para o conjunto de todas as escolas que oferecem matrículas no ensino fundamental e para as escolas da rede pública municipal. Para as escolas da rede pública estadual e da rede privada, os coeficientes estimados são positivos. Nenhum desses coeficientes, no entanto, exibe significância estatística aos níveis padrão de 1,5 ou 10 por cento.

Tal como se dá com as bibliotecas e quadra de esportes, o coeficiente estimado para o efeito da taxa de municipalização sobre a proporção de escolas equipadas com laboratórios de ciências é negligenciável. Os coeficientes são negativos para o conjunto global de escolas de município e para as escolas municipais e estaduais das redes públicas. Para a rede privada o coeficiente é praticamente nulo. Nenhuma das estimações exibe significância estatística.

O efeito estimado da taxa de municipalização das matrículas do ensino fundamental sobre a proporção de escolas equipadas com laboratórios informática é relevante. Um incremento de 1 ponto percentual na taxa de municipalização das matrículas do ensino fundamental impacta positivamente a proporção de escolas municipais equipadas com laboratórios de informática em média 0.005 pontos percentuais. Esse efeito estimado 
é estatisticamente significante ao nível de 5 por cento. O conjunto de todas as escolas (que têm matriculas no ensino fundamental) do município e as escolas da rede pública estadual também se mostram positivamente afetadas pela taxa de municipalização, embora o efeito estimado seja menor tanto em termos de magnitude do coeficiente estimado - de aproximadamente 0.001 pontos percentuais em ambos os casos - como em relação ao nível de significância estatística do coeficiente, que se mostra não diferente de zero apenas a um nível de 10 por cento.

A razão aluno/professor, como também a razão aluno/computador, não são afetadas pela taxa de municipalização das matrículas. Os coeficientes são todos praticamente nulos para esses itens e não se mostram estatisticamente diferentes de zero. Cabe, entretanto, um pequeno comentário a respeito da ausência de efeito perceptível da taxa de municipalização sobre as razão aluno/professor na rede pública municipal. Sabe-se que houve um considerável aumento no número de alunos matriculados em escolas das redes públicas municipais no ensino fundamental no período investigado (1999-2005), como demonstrado no terceiro capítulo desta tese. Pode-se especular, portanto, que houve um aumento no número de professores mais que proporcional ao aumento no número de alunos matriculados em escolas municipais de ensino fundamental. Esse achado vai ao encontro de outros trabalhos na área, como em Franco e MenezesFilho (2009). O mesmo pode-se argumentar a respeito da razão aluno/computador. Resultado corroborado pelo efeito positivo da taxa de municipalização na proporção de escolas municipais equipadas com laboratórios de informática.

A proporção de professores do ensino fundamental com curso superior é impactada positivamente pela taxa de municipalização das matriculas no ensino fundamental. Em 
escolas das redes públicas municipais, por exemplo, um aumento de 1 ponto percentual na taxa de municipalização tem um impacto positivo médio de 0.0023 na proporção de professores com curso superior. O coeficiente estimado é significante ao nível de 5 por cento. Esse efeito se mostrou também positivo e significante para as escolas estaduais da rede pública e para o conjunto de todas as escolas, não obstante em menor magnitude e com significância estatística apenas ao nível de 10 por cento. É importante observar que não é possível decompor o efeito independente da taxa de municipalização das matrículas sobre a proporção de professores com curso superior do efeito da Lei de Diretrizes e Bases da Educação Nacional (LDB), de 1996, que torna obrigatório o nível de educação superior (em curso de licenciatura realizado em universidades ou institutos superiores de educação) para os professores da educação básica.

A tabela 30 apresenta os resultados estimados, pelo método de efeitos fixos, do efeito da taxa de municipalização de matrículas do ensino fundamental sobre a taxa de reprovação segundo a rede escolar. Inicialmente, foi incluída tão-somente a taxa de municipalização - a variável de interesse - e as variáveis de controle das características dos municípios. Os resultados para essa especificação são reportados nas colunas 1 , 3, 5 e 7. Num segundo momento, foram incluídas também as as características observadas das escolas (agregadas por município em média ou proporção), cujos resultados são reportados nas colunas 2, 4, 6 e 8. Em todos os modelos são também incluídos, além das variáveis de controle das características dos municípios, um termo de efeito específico do município e dummies para os anos.

Como se pode observar, na tabela 30 , nenhum dos modelos exibe resultados estatis- 


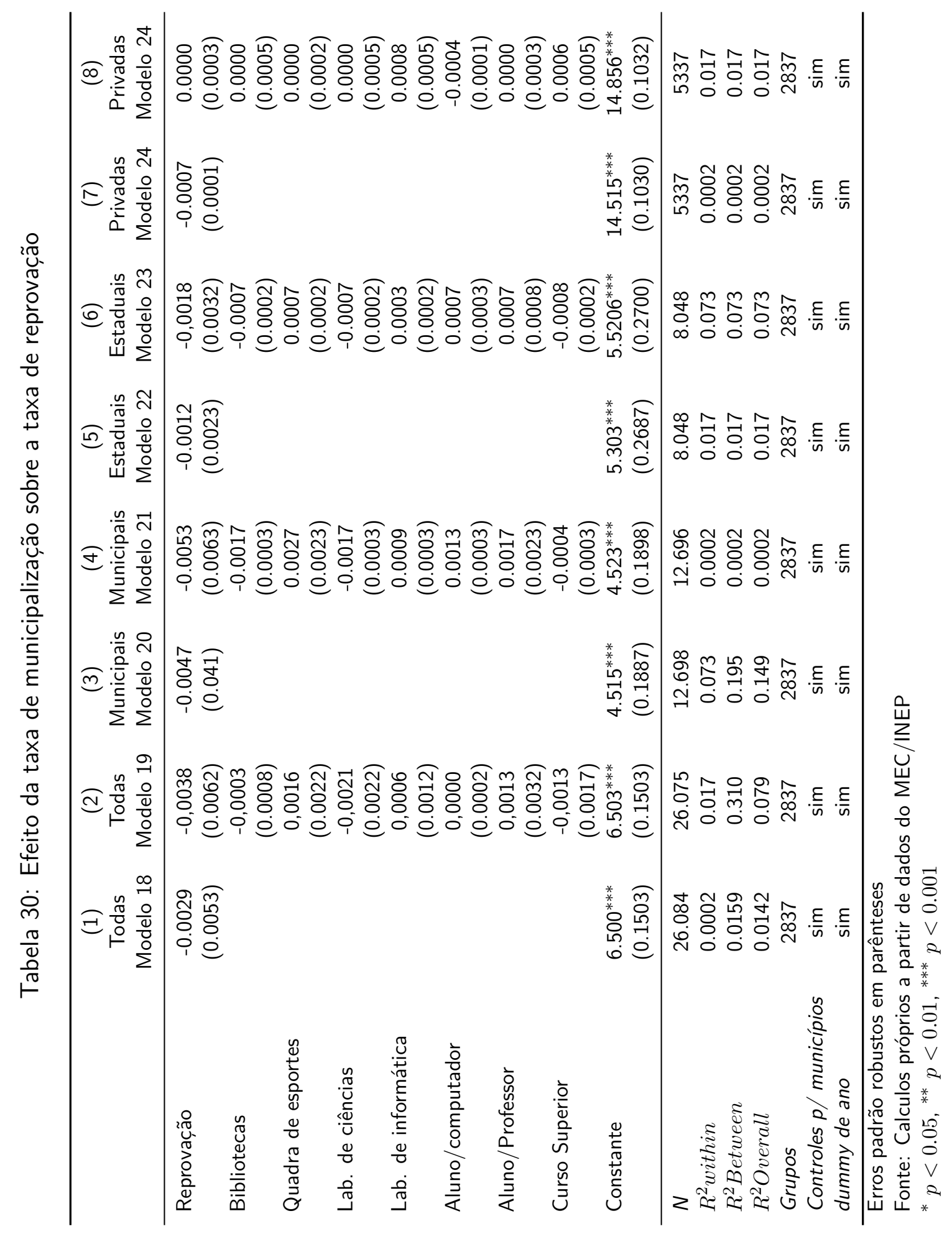


ticamente significantes. Essa ausência de evidências empíricas de qualquer efeito da municipalização das matrículas sobre a taxa de reprovação não chega a ser surpreendente. Já que, como foi destacado na seção de revisão da literatura desta tese, todos os trabalhos anteriores que buscaram mensurar o impacto da descentralização de matrículas e gastos em educação na taxa de reprovação (ou alguma outra variável de rendimento de fluxo escolar) escolar encontram resultados nulos. D'trai (2007), por exemplo, encontra evidências de uma pequena piora nas taxas de matrícula, abandono e distorção idade-série. Orellano e colaboradores (2010) não encontra tampouco nenhum impacto da municipalização sobre a taxa de reprovação.

O exame dos coeficientes estimados para a taxa de reprovação mostra que, embora não exibam significância estatística, todos os coeficientes estimados para as escolas da redes públicas municipais e estaduais e para o conjunto de todas as escolas são negativos. O que apontam para um aumento da taxa de reprovação no ensino fundamental nas escolas da rede pública. O já citado estudo de Franco e Menezes-Filho, acerca dos impactos do FUNDEF sobre as escolas públicas, também chega à mesma conclusão, qual seja, que o FUNDEF teve um impacto negativo sobre as taxas de reprovação no ensino público. Os autores argumentam que o aumento das taxas de matrículas, em decorrência da implementação do FUDEF, em 1998, levou a uma queda do nível dos alunos matriculados, que explicaria maiores taxas de reprovação.

Nas estimações dos modelos 19, 21, 23 e 24, que incluíram as variáveis das características observadas das escolas, pode-se notar que nenhuma dessas características exibe efeitos estatisticamente significantes. 


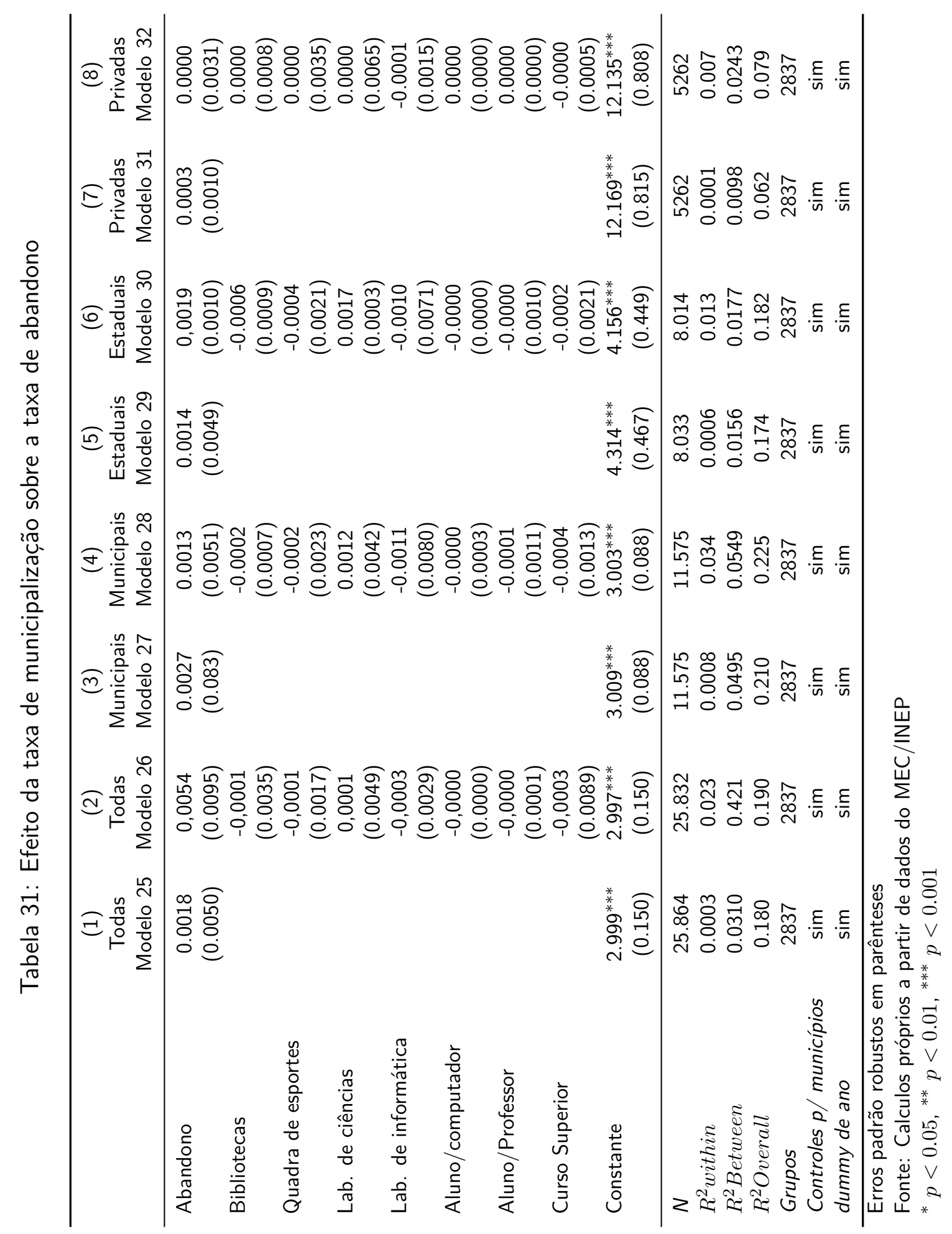


A tabela 31 traz os resultados estimados, pelo método de efeitos fixos, do efeito da taxa de municipalização de matrículas do ensino fundamental sobre a taxa de abandono escolar segundo a rede, se pública municipal, pública estadual ou privada e para o conjunto de todas as escolas. Mais uma vez, inicialmente, foi incluída tão-somente a taxa de municipalização - a variável de interesse - e as variáveis de controle das características dos municípios. Os resultados para essa especificação são reportados nas colunas 1, 3, 5 e 7 . Num segundo momento, foram incluídas também as as características observadas das escolas (agregadas por município em média ou proporção), cujos resultados são reportados nas colunas 2, 4, 6 e 8. Em todos os modelos são também incluídos, além das variáveis de controle das características dos municípios, um termo de efeito específico do município e dummies para os anos.

Tal como se deu na investigação da taxa de reprovação, o exame dos coeficientes estimados do efeito da taxa de municipalização das matriculas sobre o abandono escolar não revela qualquer efeito significativo. Todos os coeficientes estimados para os modelos 25, 27, 29 e 31 não exibem significância estatística. Mais uma vez, vale lembrar que, esses resultados vão ao encontro do que tem sido reportado pela literatura. D'Atri (2007), Madeira (2007) e Orellano (2010) tampouco encontraram qualquer efeito relevante da municipalização sobre indicadores de rendimento de fluxo e da taxa de abandono, em particular.

Nos modelos 26, 28, 30 e 32, nos quais são também incluídas as características observadas das escolas, não se verificam mudanças significativas nos coeficientes estimados. Ainda, esses coeficientes não exibem significância estatística. 


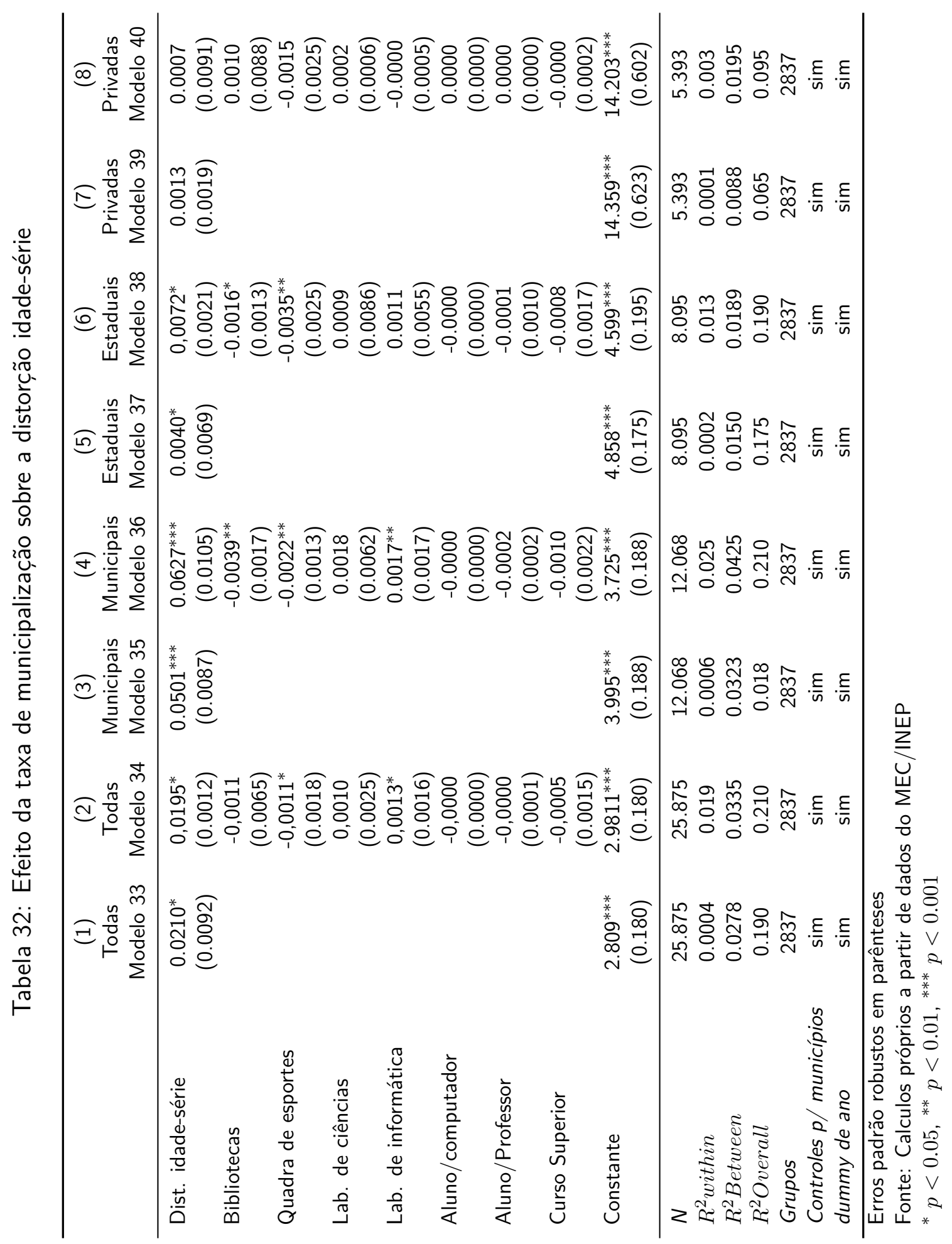


A tabela 32 traz os resultados estimados, pelo método de efeitos fixos, do efeito da taxa de municipalização de matrículas do ensino fundamental sobre a proporção de alunos matriculados fora da série recomendada para sua idade segundo a rede escolar. Mais uma vez, inicialmente, foi incluída tão-somente a taxa de municipalização - a variável de interesse - e as variáveis de controle das características dos municípios. Os resultados para essa especificação são reportados nas colunas 1, 3, 5 e 7 . Num segundo momento, foram incluídas também as as características observadas das escolas (agregadas por município em média ou proporção), cujos resultados são reportados nas colunas 2, 4, 6 e 8. Em todos os modelos são também incluídos, além das variáveis de controle das características dos municípios, um termo de efeito específico do município e dummies para os anos.

Diferentemente do que se verificou para as taxas de reprovação e de abandono escolar, os coeficientes estimados para o efeito da taxa de municipalização sobre a distorção idade-série são positivos estatisticamente significantes.

No modelo 35, apresentado na coluna (3) da tabela 32, nota-se que o coeficiente estimado para o efeito da taxa de municipalização sobre a proporção de alunos do ensino fundamental com pelo menos 2 anos de atraso em relação a idade recomendada para sua série é de aproximadamente 0,050 e estatisticamente significante ao nível de 1 por cento. Ou seja, um incremento de 1 ponto percentual na taxa de municipalização das matrículas do ensino fundamental implica um aumento médio de 0.050 pontos percentuais na proporção de alunos fora da série recomendada para sua idade nas escolas públicas municipais. O modelo 36 , apresentado na coluna (4) da tabela 32 , inclui as variáveis das características observadas das escolas. A inclusão dessas variáveis 
em pouco altera o coeficiente estimado para o efeito da taxa de municipalização, que sofre um pequeno incremento. Algumas características das escolas estão associadas a uma diminuição da defasagem idade-série nas escolas municipais. Um aumento de 1 ponto percentual na proporção de escolas municipais equipadas com bibliotecas no município, por exemplo, está associado a uma diminuição média de 0.004 pontos percentuais na proporção de alunos com 2 ou mais anos de atraso escolar nas escolas municipais.

Outras características associadas a redução na proporção de alunos em situação de atraso escolar são: proporção de escolas equipadas com quadra de esportes, razão aluno/professor e proporção de docentes com curso superior, embora apenas o coeficiente estimado para o item Quadra de esportes seja estatíticamente significante. A proporção de escolas equipadas com laboratórios de informática, por outro lado, apresenta um coeficiente estimado positivo e estatisticamente significante (ao nível de 5 por cento). Um aumento de 1 ponto percentual na proporção de escolas equipadas com laboratórios de informática tem um impacto positivo (isto é, gera um acréscimo) de 0.0017 pontos percentuais na proporção de alunos com 2 anos ou mais de atraso escolar.

O que explica essa associação positiva entre a taxa de municipalização das matrículas e a distorção idade-série? Pode-se especular que se tem aqui, provavelmente, um problema de "efeito composição". Isto é, como visto anteriormente, as escolas municipais incorporaram uma grande quantidade de matrículas, o que pode ter acarretado numa queda do nível socioeconômico do aluno mediano das redes municipais e, por conseguinte, num aumento na proporção de alunos matriculados fora da série reco- 
mendada para sua idade nas escolas das redes públicas municipais. Ademais, é preciso mencionar que esse resultado já era esperado, haja vista o que tem sido reportado pela literatura. Tanto D’Atri (2007) e Madeira (2007), como também Orellano (2010) encontraram um efeito positivo da descentralização do ensino fundamental na proporção de estudantes em situação de defasagem escolar.

Vale observar que, os coeficientes estimados, nos modelos 37 e 38 , para as escolas estaduais são também positivos estatisticamente significantes, embora menos relevantes tanto em termos de magnitude do coeficiente estimado como de significância estatística. Os coeficientes estimados para as características das escolas, acompanham com algumas poucas discrepâncias o comportamento dos coeficientes estimados para as escolas estaduais. O que também se verifica para o conjunto total de escolas. Já para as escolas da rede privada, como era esperado, não se verifica um efeito notável.

Como explicar esse aparente efeito da taxa de municipalização das matriculas na proporção de alunos matriculados fora da série recomendada para sua idade nas escolas estaduais. Por um lado, pode ser que se verifique a ocorrência de um "efeito composição", tal como se deu nas escolas municipais. Nesse caso, a associação verificada entre as duas variáveis seria tão somente uma associação espúria devido a simplesmente a simultaneidade dos dois processos no decurso do período analisado. Mas, por outro lado, pode haver uma possível limitação empírica dos modelos empíricos testados nessa seção decorrentes de um problema de endogeneidade das variáveis empregadas na presente análise. Mais especificamente, admite-se que a taxa de municipalização pode ser endógena, mesmo com o controle do efeito específico das variáveis não observadas dos municípios, aos indicadores de rendimento escolar que se pretende investigar. Seria 
razoável supor, por exemplo, que um governante, comprometido com a educação de seu município, procurasse melhorar os resultados educacionais atraindo os melhores estudantes da rede pública para as escolas municipais com mais gastos em educação, o que possivelmente enviesaria os resultados desta análise.

Por fim, vale recapitular os principais achados da presente seção da tese: $(i)$ a taxa de municipalização de matrículas do ensino fundamental nos municípios tem um efeito global muito tênue sobre os insumos es-colares das redes públicas de ensino. Tão somente a proporção de escolas equipadas com laboratórios de Informática nos municípios e a proporção de professores do ensino fundamental com curso superior mostram resultados posivitos estatisticamente diferentes de zero. (ii) Como reportado pela literatura, a taxa de municipalização das matriculas do ensino fundamental não apresenta qualquer efeito relevante sobre a taxa de reprovação e sobre o abandono escolar. (iii) Por outro lado, a taxa de municipalização tem um impacto positivo - e estatisticamente diferente de zero -sobre a proporção de alunos matriculados fora da série recomendada para sua idade. (iv) Essa associação positiva entre a taxa de municipalização e a defasagem idade-série, possivelmente, é decorrente de um "efeito composição". ( $v)$ Esse resultados, contudo, apresentam algumas limitações empíricas importantes, que tem de ser levadas em conta para se evitar conclusões precipitadas. 


\section{Conclusão}

Primeiramente, vale relembrar a pergunta básica que motivou esta pesquisa: O nível de governo importa para a qualidade da política? Mais especificamente, para o caso da descentralização da educação fundamental no Brasil, que foi tomado como objeto da análise empírica da tese, a pergunta fornulada foi: o nível de governo importa para a qualidade da política de educação oferecida à população?

As evidências empíricas reunidas por esta tese mostram que o nível de governo não importa para o desempenho acadêmico. No entanto, o fato de não se encontrar um efeito positivo da municipalização não implica que a descentralização em si não seja positiva. O que os resultados sugerem é que a expansão das matrículas nas redes municipais, seja por meio da criação de novas vagas em escolas municipais, seja pela transferência de escolas do estados para os municípios, não teve até o presente momento impacto positivo sobre a proficiência dos alunos ou sobre as taxas de rendimento de fluxo das redes.

Os resultados reunidos pela tese mostram que: há uma diferença, de aproximadamente 3 pontos percentuais, no desempenho dos alunos das redes públicas municipais e estaduais. Esse diferencial de desempenho, em favor das redes estaduais, pode ser atribuído principalmente a um processo de estratificação social que se deu entre as redes públicas de ensino. Nota-se que houve um efeito composição que afetou negativamente o desempenho das escolas municipais. Uma vez controladas as diferenças de cor, gênero, idade e do ambiente familiar dos alunos a diferença de desempenho escolar entre as redes municipais e estaduais se mostra estatisticamente negligenciável. 
O efeito da municipalização sobre a proficiência média dos alunos das escolas que migraram dos estados para os municípios é praticamente nulo, tanto em português como em matemática, quando desempenho desse grupo de escolas é comparado ao desempenho médio dos alunos das escolas que permaneceram sob o controle dos estados e municípios.

Finalmente, a expansão da municipalização das matrículas teve um efeito negativo sobre o rendimento do fluxo das coortes das escolas das redes municipais. Verificou-se que existe uma associação positiva (e estatisticamente significante) entre a expansão das matrículas municipais e o aumento na proporção de alunos matriculados fora da série recomendada para sua idade nas escolas municipais. A das matriculas municipais não teve um efeito relevante sobre as taxas de reprovação e de evasão escolar. Mais uma vez, esse efeito da municipalização sobre o aumento dos alunos em situação de atraso escolar pode ser atribuído a um efeito de composição. Isto é, ao ingresso dos alunos provenientes das camadas sociais menos favorecidas socioenconomicamente, que antes encontravam-se fora das escolas.

O efeito da taxa de municipalização das matrículas, que procura captar o esforço dos municípios na educação fundamental, se mostrou praticamente nulo sobre os insumos escolares. Nota-se que houve uma leve melhora na proporção de escolas municipais equipadas com laboratórios de informática, como também na proporção de professores com curso superior. Contudo, esse aumento não pode ser atribuído integralmente à municipalização das matrículas, já que pode estar relacionado ao efeito de outros programas do governo federal, como o pró-info ou ao efeito da LDB, de 1996, que obrigava a contratação de professores com curso superior para a educação básica. 
Enfim, há várias razões para se descentralizar a prestação de políticas públicas, particularmente aquelas de interesse local, como a educação. Mas, a melhoria do desempenho não pode ser uma delas. 


\section{Referências}

Ângela Albernaz, Francisco H. G. Ferreira \& Creso Franco. 2002. "Qualidade e eqüidade no ensino fundamental brasileiro." Pesquisa e Planejamento Econômico 32(3):453 476 .

Arretche, Marta T. S. 1996. "Mitos da Descentralização: mais democracia e eficiência nas políticas públicas?" Revista Brasileira de Ciências Sociais 31(11):44-66.

Arretche, Marta T. S. 2000. Estado federativo e políticas sociais: determinantes da descentralização. Rio de Janeiro, RJ: Editora Revan.

Bennett, Robert John. 1990. Decentralization, local governments, and markets: towards a post-welfare agenda. Gloucestershire: Clarendon Press.

Borja, Jordi. 1987. Descentralización del estado: movimiento social y gestión local. Santiago: Flacso.

Borja, Jordi \& otros. 1989. Estado, descentralización y democracia. Bogotá: Foro Nacional por Colombia.

Bourguignon, Francois, Francisco H. G. Ferreira \& Marta Menendez. 2003. Inequality of Outcomes and Inequality of Opportunities in Brazil. Working Paper No. 630 William Davidson Institute, University of Michigan, Ann Arbor, MI: . Available at SSRN: http://ssrn.com/abstract $=497242$.

Buchanan, James M. 1995. "Federalism As an Ideal Political Order and an Objective for Constitutional Reform." Publius: The Journal of Federalism 25(2):19-28. 
Burki, Shahid Javed, Guillermo Perry \& William R. Dillinger. 1999. Beyond the center: decentralizing the state. Whashington, D.C.: World Bank Publications.

Coleman, James S. et al. 1966. Equality of Educational Opportunity. Technical report United States Department of Education.

URL: http://dx.doi.org/10.3886/ICPSR06389

Crook, Richard C. \& Alan Sturla Sverrisson. 1999. "To what extent can decentralized forms of government enhance the development of pro-poor policies and improve poverty-alleviation outcomes?" Unpublished paper.

D’Atri, Fabiana. 2007. Municipalização do Ensino Fundamental da Rede Pública: Os Impactos sobre o Desempenho Escolar PhD thesis Fundação Getúlio Vargas São Paulo: .

de Araújo, Gilda Cardoso. 2005. Município, Federação e Educação História das Instituições e das Idéias Políticas No Brasil. Tese de doutorado. Universidade de São Paulo, Faculdade de Educação. São Paulo: .

de Barros, Ricardo Paes \& David Lam. 1993. Income Inequality, Inequality in Education, and Children's Schooling Attainment in Brazil. Texto para discussão IPEA No. 294 IPEA. Brasília, DF: .

de Barros, Ricardo Paes \& Roseane S. P. Mendonça. 1995. Os determinantes da desigualdade no Brasil. Texto para discução no. 337 IPEA Brasília, DF: . Unpublished paper.

de Lucena Ruas Riani, Juliana \& Eduardo Luiz Gonçalves Rios-Neto. 2008. “Background familiar versus perfil escolar do município: qual possui maior impacto no 
resultado educacional dos alunos brasileiros?" Revista Brasileira de Estudos de População 25(2):251-269.

de Oliveira, Cleiton. 1999. Municipalização do Ensino Brasileiro. In Municipalizaçã do Ensino no Brasil: algumas leituras, ed. Cleiton de Oliveira, Lisete R. Arelano \& Maria de Fátima Felix Rosar. Belo Horizonte, MG.: Autêntica.

de Rezende Pinto, José Marcelino. 2000. Os recursos para a educação no Brasil no contexto das finanças públicas. Brasília, DF: Editora Plano.

Eaton, Kent. 2000. Decentralization, democratization and liberalization: The history of revenue sharing in Argentina, 1934-1999. In Paper prepared for delivery at the 2000 meeting of the Latin American Studies Association, Miami, USA.

Emerson, Patrick M. \& André Portela Souza. 2003. "Is There a Child Labor Trap? Intergenerational Persistence of Child Labor in Brazil." Economic Development and Cultural Change 51(2):375-398.

Emerson, Patrick M. \& André Portela Souza. 2007. "Child Labor, School Attendance, and Intrahousehold Gender Bias in Brazil." The World Bank Economic Review 21(2):301-316.

Emerson, Patrick M. \& André Portela Souza. 2011. "Is Child Labor Harmful? The Impact of Working Earlier in Life on Adult Earnings." Economic Development and Cultural Change 59(2):345-385.

Faguet, Jean-Paul \& Fabio Sánchez. 2008. “Decentralization's Effects on Educational Outcomes in Bolivia and Colombia." World Development 36(7):1294-1316. 
Falleti, Tulia G. 2005. "A Sequential Theory of Decentralization: Latin American Cases in Comparative Perspective." The American Political Science Review 99(3):327346.

Fernandes, Reynaldo \& Naercio Menezes-Filho. 2000. "A Evolução da Desigualdade no Brasil Metropolitano entre 1983 e 1997." Estudos Econômicos 30(4):549-569.

Ferreira, Sergio G. \& Fernando A. Veloso. 2003. "Mobilidade intergeracional de educação no Brasil." Pesquisa e Planejamento Econômico 33(3):481-514.

Filmer, Deon \& Gunnar A. Eskeland. 2002. "Autonomy, Participation, and Learning in Argentine Schools: Findings and Their Implications for Decentralization." World Bank Policy Research Working Paper No. 2766. Available at SSRN: http://ssrn.com/abstract $=634479$.

Garman, Christopher, Stephan Haggard \& Eliza Willis. 2001. "Fiscal Decentralization: A Political Theory with Latin American Cases." World Politics 53(2):205-236.

Gil, Juca \& Lisete Regina Gomes Arelano. 2004. Contra a municipalização do ensino à brasileira. In Educação municipal: experiências de políticas democráticas. Ubatuba, SP: Estação Palavra pp. 15-46.

Glewwe, Paul \& Michael Kremer. 2006. Chapter 16 Schools, Teachers, and Education Outcomes in Developing Countries. In Handbook of Economics of Education, ed. Eric A. Hanushek \& Finis Welch. Vol. Volume 2 Elsevier pp. 945-1017.

Gomes, Sandra. 2008. Fatores Explicativos das Diferentes Estratégias de Municipalização do Ensino Fundamental nos Governos Subnacionais do Brasil (1997-2000). 
PhD thesis Universidade de São Paulo, Faculdade de Filosofia, Letras e Ciênncias Humanas São Paulo: .

Grindle, Merilee Serrill. 2004. Despite the odds: the contentious politics of education reform. Princeton, NJ: Princeton University Press.

Hanushek, Eric A. 1989. "Expenditures, Efficiency, and Equity in Education: The Federal Government's Role." The American Economic Review 79(2):46-51.

Hanushek, Eric A. 1994. Education Production Functions. In International Encyclopedia of Education,, ed. Torsten Husén \& T. Neville Postlethwaite. 2nd edition ed. Vol. 3 Oxford: Pergamin pp. 1756-1762.

Hanushek, Eric A. 1995. "Interpreting Recent Research on Schooling in Developing Countries." The World Bank Research Observer 10(2):227-246.

Kassouf, Ana Lúcia, Martin McKee \& Elias Mossialos. 2001. "Early entrance to the job market and its effect on adult health: evidence from Brazil." Health Policy and Planning 16(1):21-28.

Kraemer, Moritz. 1997. "Intergovernmental Transfers and Political Representation: Empirical Evidence from Argentina, Brazil and Mexico." Inter American Development Bank. Working Paper 345.

Leme, Maria Carolina, Ricardo Paredes \& André Portela Souza. 2009. A municipalização do ensino fundamental e seu impacto sobre a proficiência no Brasil. In Educação Básica no Brasil, ed. Fernando A. Veloso, Samuel Pessoa, Ricardo Henriques \& Fabio Giambiasi. Rio de Janeiro, RJ: Campus/Elsevier pp. 261-280. 
Madeira, R. 2007. The Effect of Decentralization on Schooling: Evidence from Sa?o Paulo State ?s Education Reform PhD thesis Faculdade de Economia, Administração e Contabilidade da Universidade de São Paulo São Paulo: .

Marteleto, Letícia. 2004. Desigualdade intergeracional de oportunidades educacionais: uma análise da matrícula e escolaridade das crianças brasileiras. Textos para discussão Cedeplar-UFMG Cedeplar, Universidade Federal de Minas Gerais. Unpublished paper.

URL: http://www.cedeplar.ufmg.br/

Menezes-Filho, Naercio. 2001. Educação e desigualdade. In Microeconomia e Sociedade no Brasil., ed. Marcos de Barros Lisboa \& Naercio Menezes-Filho. 1 ed. ed. Rio de Janeiro: Contra Capa pp. 13-50.

Murillo, Maria Victoria. 1999. “Recovering Political Dynamics: Teachers' Unions and the Decentralization of Education in Argentina and Mexico." Journal of Interamerican Studies and World Affairs 41(1):31-57.

Oates, Wallace E. 1972. Fiscal federalism. San Diego, CA: Harcourt Brace Jovanovich.

Olowu, Dele, James Stevenson Wunsch \& Joseph R. A. Ayee. 2004. Local governance in Africa: the challenges of democratic decentralization. Lynne Rienner Publishers.

O'Neill, Kathleen. 2003. "Decentralization as an Electoral Strategy." Comparative Political Studies 36(9):1068-1091.

Orellano, Veronica, Fabiana Rocha, Enlinson Mattos \& Ana Carolina Zoghbi. 2010. Descentralização fiscal e municipalização do Ensino Fundamental: impactos sobre 
os indicadores de desempenho educacional. In 380. Encontro Anual de Economia, ANPEC. Salvador, BA: .

Peterson, Paul E. 1995. The Price of Federalism. Whashington, D.C.: Brookings Institution Press.

Prud'homme, Rémy. 1995. "The Dangers of Decentralization." The World Bank Research Observer 10(2):201-220.

Putnam, Robert D., Robert Leonardi \& Raffaella Nanetti. 1994. Making democracy work: civic traditions in modern Italy. Princeton, NJ: Princeton University Press.

Riker, William H. 1964. Federalism: origin, operation, significance. Boston, MA: Little, Brown and Company.

Samoff, Joel. 1990. "Decentralization: The Politics of Interventionism." Development and Change 21(3):513-530.

Tanzi, Vito. 1996. Fiscal federalism and decentralization: A review of some efficiency and macroeconomic aspects. In Annual Bank Conference on Development Economics. Whashington, D.C.: World Bank Publications pp. 295-315.

Tiebout, Charles M. 1956. "A Pure Theory of Local Expenditures." The Journal of Political Economy 64(5):416-424.

UNPD. 1993. Human Development Reports 1993: People's Participation. Technical report United Nations. New York, NY.: .

URL: http://hdr.undp.org/en/reports/global/hdr1993/ 
Wallis, John Joseph \& Wallace Oates. 1998. The Impact of the New Deal on American Federalism. In The Defining Moment: The Great Depression and the American Economy in the Twentieth Century. Vol. Michael D. Bordo, Claudia Goldin and Eugene N. White, editors University of Chicago Press pp. 155-180.

URL: http://www.nber.org/books/bord98-1

Ward, Peter M. \& Victoria E. Rodriguez. 1999. “New Federalism, Intra-Governmental Relations and Co-Governance in Mexico." Journal of Latin American Studies 31(3):673-710.

Weingast, Barry R. 1995. "The Economic Role of Political Institutions: MarketPreserving Federalism and Economic Development." Journal of Law, Economics, \& Organization 11(1):1-31.

Willis, Eliza, Christopher da C. B. Garman \& Stephan Haggard. 1999. "The Politics of Decentralization in Latin America." Latin American Research Review 34(1):7-56.

World Bank. 1994. World Development Report 1994: Infrastructure for Development. Technical report Oxford University Press. New York, NY.: . 